\title{
The use of Pseudomonas spp. as bacterial biocontrol agents to control plant disease
}

Monica Höfte, Ghent University, Belgium

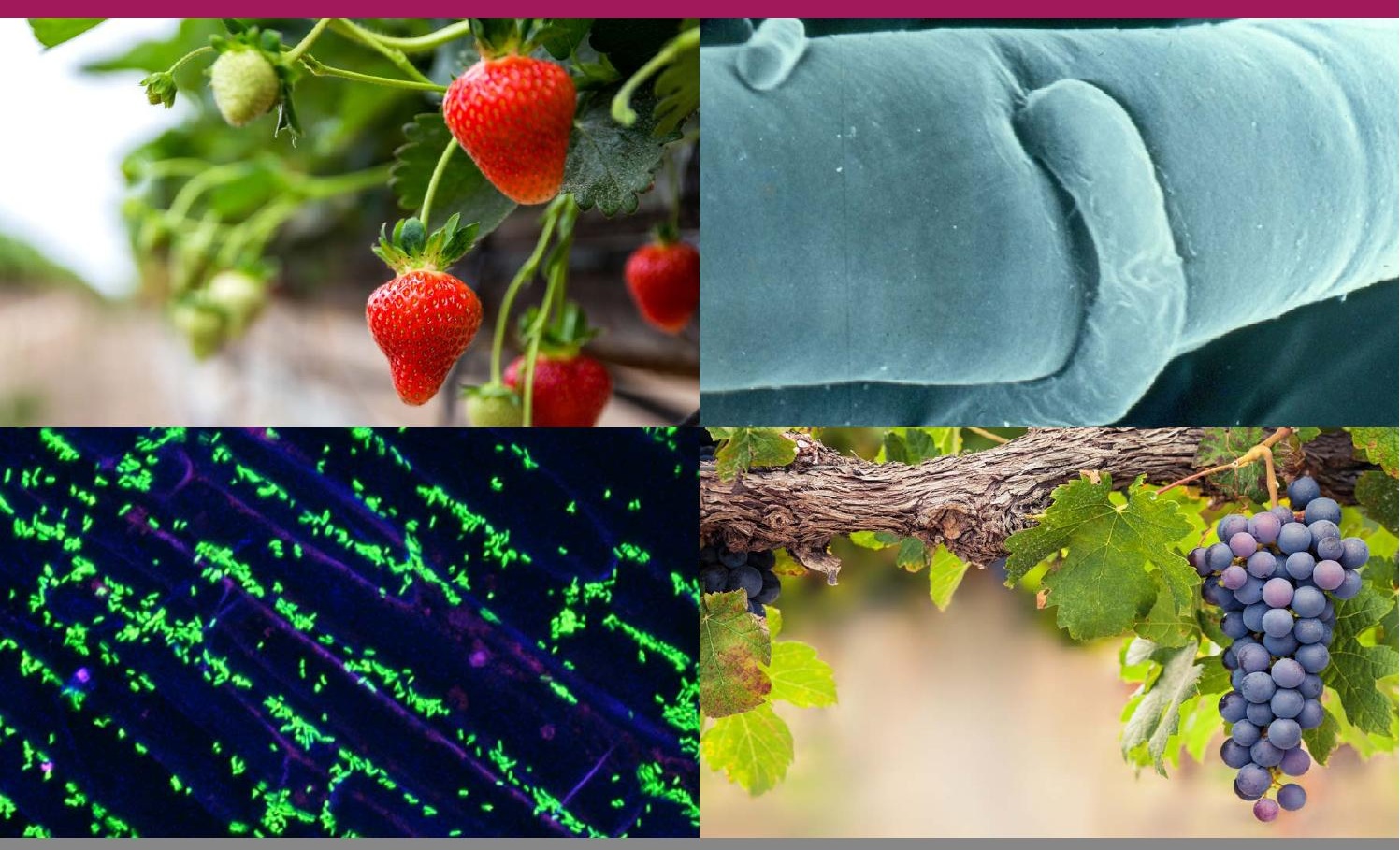




\section{The use of Pseudomonas spp. as bacterial biocontrol agents to control plant disease}

Monica Höfte, Ghent University, Belgium

1 Introduction

2 Pseudomonas taxonomy

3 Plant-beneficial Pseudomonas strains

4 Secondary metabolite production in Pseudomonas biocontrol strains

5 Secretion systems that play a role in biocontrol

6 Pseudomonas biocontrol strains: Pseudomonas protegens subgroup

7 Pseudomonas biocontrol strains: Pseudomonas chlororaphis subgroup

8 Pseudomonas biocontrol strains: Pseudomonas corrugata subgroup

9 Pseudomonas biocontrol strains: Pseudomonas fluorescens subgroup

10 Pseudomonas biocontrol strains: Pseudomonas koreensis subgroup

11 Pseudomonas biocontrol strains: Pseudomonas mandelii subgroup and Pseudomonas gessardii subgroup

12 Pseudomonas biocontrol strains: Pseudomonas putida group

13 Pseudomonas biocontrol strains: Pseudomonas syringae group and Pseudomonas aeruginosa group

14 Commercial Pseudomonas-based bioprotectants

15 Conclusion

16 Where to look for further information

17 Acknowledgements

18 References

\section{Introduction}

Bacteria have their origin in marine environments. They split into a group of land-adapted bacteria, the Terrabacteria, and a group that remained in water, the Hydrobacteria, about 3 billion years ago. The genus Pseudomonas belongs to the Gammaproteobacteria, a class of bacteria that emerged from 
the Hydrobacteria 1.75 billion years ago (Battistuzzi and Hedges, 2009). The Pseudomonas genus diverged well before the colonization of land by plants. The evolutionary history of the Pseudomonas genus is founded on hundreds of millions of years spent mostly in aquatic habitats in the absence of higher plants (Morris et al., 2013). Pseudomonas is now one of the most ubiquitous genera in the world. Pseudomonas bacteria are inhabitants of sea, freshwater and soil-related environments. Many species live in association with plants and animals, mostly as saprophytes, but some are pathogenic for plants or animals. Pseudomonas bacteria have useful applications in biotechnology, plant growth promotion, bioremediation and biocontrol (Peix et al., 2009).

This chapter will focus on beneficial plant-associated Pseudomonas strains with the capacity to control plant diseases. There is an extensive literature on this topic with thousands of papers. Most Pseudomonas biocontrol agents have been isolated from soil, the rhizosphere of plants or from water. They are good root colonizers and well known for their capacity to control soilborne pathogens. Some strains can also protect against leaf pathogens by inducing systemic resistance in plants. They usually do not survive well on above-ground parts of plants, except for a few Pseudomonas biocontrol strains from the $P$. syringae group. This review will start with recent advances in Pseudomonas taxonomy and a summary of its most important biocontrol traits. An overview will then be given of the most important Pseudomonas groups and subgroups harboring biocontrol strains. Examples of well-characterized and representative biocontrol strains will show the links between the phylogeny, ecology and biocontrol traits. The chapter concludes by reviewing commercially available biocontrol strains.

\section{Pseudomonas taxonomy}

The genus Pseudomonas is diverse and complex and is currently divided into various phylogenetic groups with more than 220 described species. New species are being described constantly. A good overview of the historical evolution of Pseudomonas taxonomy and species described up to 2009 is given by Peix et al. (2009). The same authors have published an update of about 70 new species described from 2009 until 2018 (Peix et al., 2018). Species and phylogenetic groups have been delineated based on multi locus sequence analysis (MLSA) using the genes $16 \mathrm{~S}$ rDNA, gyrB, rpoB and rpoD (Gomila et al., 2015; Lalucat et al., 2020; Mulet et al., 2010) and whole-genome sequences (Garrido-Sanz et al., 2016; Hesse et al., 2018). The 16S rRNA gene allows differentiation of the genus Pseudomonas but is not at the species level. Particularly useful for species discrimination are the $r p o D$, gyr $B$ and $r p o B$ genes. The rpoD gene is most discriminative for species delineation, followed by $g y r B$, and by the rpoB which is the least discriminative of these markers (Mulet 
et al., 2010). The taxonomy of Pseudomonas is constantly evolving and major breakthroughs have been made by the availability of rpoD, MLSA and wholegenome sequences of the species type strains (Girard et al., 2020b; Hesse et al., 2018; Lalucat et al., 2020).

The main phylogenetic groups defined by the 4-gene MLSA are to a large extent consistent with the groupings in genomics analyses. This means that new Pseudomonas isolates can easily be taxonomically positioned by sequencing these four genes (Garrido-Sanz et al., 2016) or just the rpoD gene (Girard et al., 2020b). Lalucat et al. (2020) have presented a complete MLSAbased phylogenetic tree using 216 Pseudomonas species. They distinguish three main lineages represented by the species:

- P. aeruginosa;

- P. fluorescens; and

- P. pertucinogena.

The P. fluorescens lineage comprises five phylogenetic groups:

- P. fluorescens;

- P. asplenii;

- P. lutea;

- P. syringae; and

- P. putida.

The $P$. aeruginosa lineage comprises eight phylogenetic groups:

- P. straminea;

- P. anguilliseptica;

- P. oryzihabitans;

- P. stutzeri;

- P. oleovorans;

- P. resinovorans;

- P. aeruginosa;

- P. linyingensis; and

- the genus Azotobacter.

The $P$. fluorescens group is further divided into eight subgroups:

- P. fluorescens;

- P. gessardii;

- P. fragi;

- P. mandelii; 
- P. koreensis;

- P. jessenii;

- P. corrugata; and

- P. chlororaphis.

Hesse et al. (2018) constructed a phylogeny of 166 type strains within the Pseudomonas genus based on protein sequences of 100 single-copy orthologous genes and found 13 groups of Pseudomonas. In their proteinbased phylogeny, the $P$. fluorescens group is composed of 10 subgroups since they distinguish the $P$. protegens subgroup from the $P$. chlororaphis subgroup and, in their phylogeny, $P$. asplenii is clustered within the $P$. fluorescens group. $P$. chlororaphis and $P$. protegens will be considered as two separate subgroups since their biocontrol traits are clearly different.

\section{Plant-beneficial Pseudomonas strains}

Plant-beneficial effects of Pseudomonas bacteria have been extensively studied and the most important findings are summarized in a number of comprehensive reviews. Many Pseudomonas strains can promote plant growth directly in the absence of pathogens by increasing the availability and uptake of mineral nutrients via phosphate solubilization, by enhancing root growth via the production or manipulation of phytohormones, or by enhancing tolerance to abiotic stress. Aspects of plant growth promotion have been reviewed elsewhere and will not be further discussed here (Berg, 2009; Dimkpa et al., 2009; Hayat et al., 2010; Lugtenberg and Kamilova, 2009; Ma et al., 2016; Ngumbi and Kloepper, 2016; Rajkumar et al., 2017).

The most important mechanisms of disease suppression by Pseudomonas biocontrol agents include:

- competition for nutrients or space (Kamilova et al., 2005);

- antibiosis (Haas and Défago, 2005; Raaijmakers et al., 2002; Raaijmakers and Mazzola, 2012); and

- induced systemic resistance (Bakker et al., 2007; De Vleesschauwer and Höfte, 2009; Pieterse et al., 2014).

A hallmark paper on Pseudomonas biocontrol that gives a good introduction to the subject has been published by Haas and Défago (2005). Weller (2007) has given an overview of 30 years of biocontrol research using Pseudomonas to control soilborne pathogens. Many good reviews have also appeared in books. A comprehensive overview of the older literature can be found in Thomashow and Weller (1996). More recent reviews have been published by MercadoBlanco (2015) and Olorunleke et al. (2015b). Reviews about more specific aspects of Pseudomonas biocontrol will be cited later in the chapter. 
The $P$. fluorescens, $P$. putida, $P$. syringae and $P$. aeruginosa groups harbor biocontrol strains. Within the $P$. fluorescens group, $P$. chlororaphis, $P$. protegens and $P$. corrugata subgroups, the so-called CPC cluster are especially rich in biocontrol agents and biocontrol properties (Vacheron et al., 2016). The $P$. fluorescens, P. mandelii, P.jessenii and P. koreensis subgroups, the so-called FMJK cluster, have fewer biocontrol properties but are enriched in phytostimulatory properties such as plant hormone modulation and plant nutrition (Vacheron et al., 2016).

It should be noted that biocontrol agents are not properly taxonomically determined in many published studies. Identification is based only on the $16 \mathrm{~S}$ rDNA gene which does not have enough resolution to discriminate between subgroups or species. Many species that are described in the literature as $P$. fluorescens actually belong to other or undescribed species. Misidentification is a common problem even for publicly available genomes (Tran et al., 2017). In their analysis of 166 genomes of type strains and 1224 additional genomes of Pseudomonas spp. Hesse et al. (2018) identified 350 distinct clusters. They found that 189 clusters potentially represent novel species of Pseudomonas. Many of these clusters are singletons consisting of only one strain of Pseudomonas. These data show the tremendous diversity in Pseudomonas and we can expect the description of many new species in the coming years. Thanks to wholegenome sequencing and major advances made in Pseudomonas taxonomy, mainly in the P. fluorescens group, it is becoming increasingly clear that there is a strong link between phylogeny and biocontrol phenotypes (Garrido-Sanz et al., 2016). Researchers are urged to identify their Pseudomonas biocontrol strains properly by sequencing at least the rpoD gene to determine to which Pseudomonas group or subgroup they belong.

\section{Secondary metabolite production in Pseudomonas biocontrol strains}

Secondary metabolite production in Pseudomonas has been reviewed extensively. A comprehensive overview of the biosynthesis, chemistry and biological significance of Pseudomonas secondary metabolites is provided by Gross and Loper (2009). The literature about secondary metabolites involved in biocontrol is summarized in Haas and Défago (2005), Mishra and Arora (2018), Olorunleke et al. (2015b), and Raaijmakers and Mazzola (2012). It has become evident that only a limited number of bioactive compounds play a clear role in biocontrol of plant diseases:

- hydrogen cyanide (HCN);

- 2,4-diacetylphloroglucinol (DAPG);

- phenazines; 
- pyrrolnitrin;

- pyoluteorin;

- 2-hexyl-5-propyl-alkylresorcinol;

- siderophores; and

- (cyclic) lipopeptides.

These compounds are usually produced by specific phylogenetic groups or subgroups within the Pseudomonas genus (Table 1) and are briefly discussed below.

\subsection{Phenazines}

Phenazines are redox-active nitrogen-containing tricyclic pigments that are produced by Pseudomonas and some other Gram-negative Proteobacteria (Mavrodi et al., 2006). More than 100 different phenazine structures have been described but biocontrol strains produce phenazine-1-carboxylic acid (PCA, lemon yellow), phenazine-1-carboxamide (PCN, green), 2-hydroxyphenazine (2-OH-PHZ, brick-red) or 2-hydroxyphenazine-1-carboxylic acid (2-OH-PCA, orange). Pyocyanin (PYO), a blue phenazine pigment, is only found in $P$. aeruginosa where it contributes to infection in mammalians (Price-Whelan et al., 2006).

The core phenazine biosynthesis genes are clustered and highly conserved. A seven-gene locus, named phzABCDEFG is responsible for the synthesis of PCA, which starts from chorismic acid, a product from the shikimate pathway. Phenazine diversity results from modification of PCA with dedicated enzymes such as PhzO (modifies PCA into 2-OH-PCA), PhzH (modifies PCA into PCN), PhzS (modifies PCA into 1-OH-PCA) and PhzM (modifies PCA into pyocyanin together with PhzS). In all phenazine-producing Pseudomonas strains, phenazine production is regulated by quorum sensing and also requires a functional GacS/GacA two-component signal transduction system. More details about phenazine biosynthesis can be found in Biessy and Filion (2018), Gross and Loper (2009) and Mavrodi et al. (2006).

Phenazines display broad-spectrum activity against fungal, oomycete and bacterial pathogens (Biessy and Filion, 2018), but can also trigger induced systemic resistance (ISR) in various plants (Ma et al., 2016b; De Vleesschauwer and Höfte, 2009). Phenazines have a physiological role in biofilm formation and iron reduction (Mavrodi et al., 2013). Phenazines are typically produced by Pseudomonas strains that belong to $P$. aeruginosa, or the chlororaphis and fluorescens subgroups within the P. fluorescens group (Table 1). Extensive information about microbial phenazines can be found in Chincholkar and Thomashow (2013). 


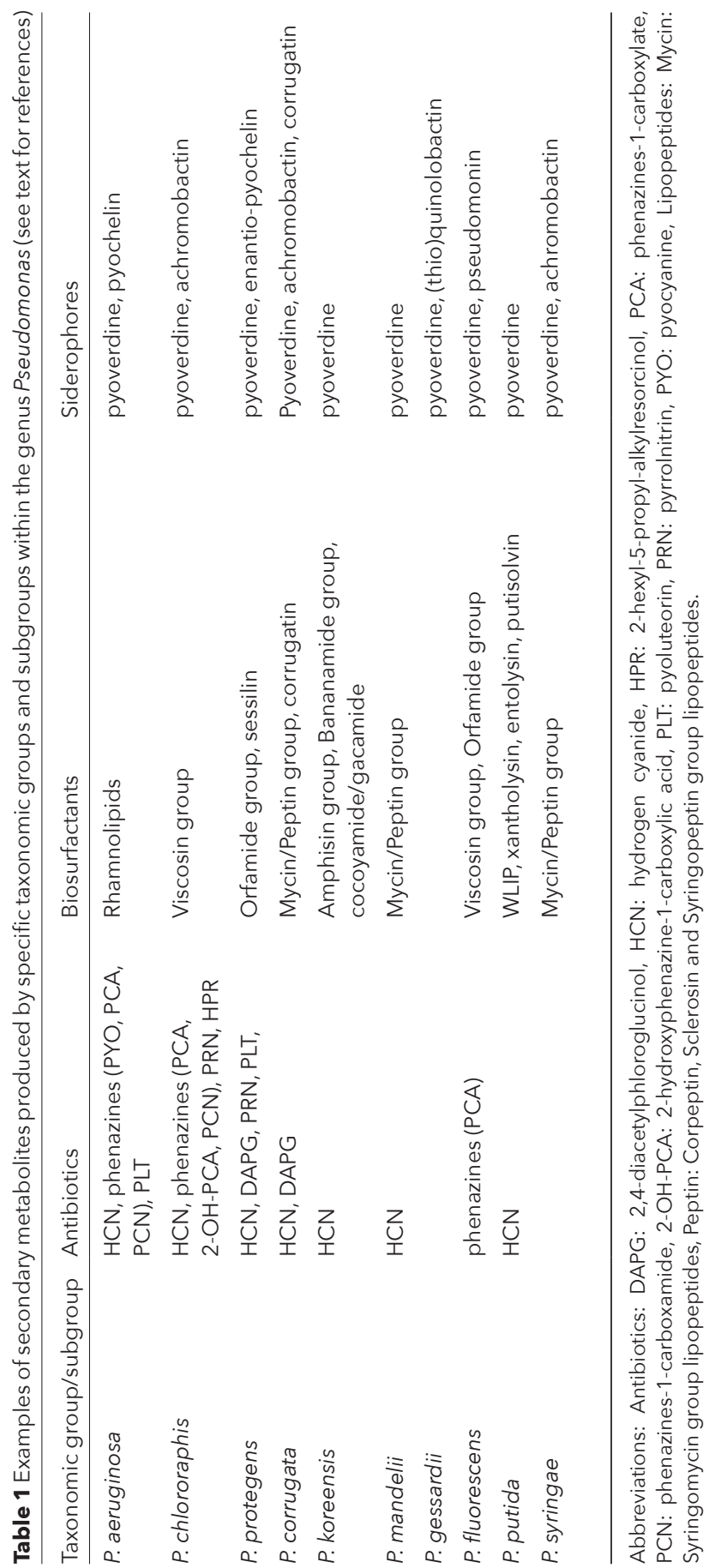




\subsection{2,4-diacetylphloroglucinol (DAPG)}

DAPG is a polyketide antibiotic that is produced by Pseudomonas strains that predominantly belong to the $P$. protegens and $P$. corrugata subgroups (Table 1) and a few isolated strains in other taxonomic groups (Almario et al., 2017). It plays a key role in the biocontrol of root and seedling diseases and is active against fungi, oomycetes, nematodes and bacteria. The compound is phytotoxic at high concentrations. DAPG- producing Pseudomonas strains have typically been isolated from soils suppressive to take-all, an important wheat root disease caused by Gaeumannomyces graminis var. tritici (Weller et al., 2007). The DAPG gene cluster is highly conserved and comprises nine genes involved in biosynthesis (phIACB and phID), efflux (ph/El), degradation $(p h / G)$ and regulation $(p h / H$ and $p h / F)$. The biosynthesis starts from three molecules of malonyl CoA. PhID is a type III polyketide synthase responsible for the biosynthesis of phloroglucinol. Besides its role in direct antibiosis, the compound can induce systemic resistance in Arabidopsis to the downy mildew pathogen Hyaloperonospora parasitica (lavicoli et al., 2003), Pseudomonas syringae pv. tomato (Weller et al., 2012) and Botrytis cinerea (Chae et al., 2020) by triggering jasmonate- and ethylene-mediated defense responses. DAPG can promote amino acid exudation from plant roots by blocking amino acid influx (Phillips et al., 2004) and stimulates root branching in tomato by interacting with the auxin-dependent signaling pathway (Brazelton et al., 2008).

\subsection{Pyoluteorin}

Pyoluteorin is a hybrid non-ribosomal peptide synthetase/polyketide synthase product consisting of a resorcinol ring attached to a dichlorinated pyrrole moiety. Pyoluteorin is produced by Pseudomonas strains belonging to the $P$. protegens subgroup (Ramette et al., 2011) and a few P. aeruginosa isolates (Hu et al., 2005). The antibiotic has not been reported in genera other than Pseudomonas. Pyoluteorin suppresses seedling damping-off diseases caused by the oomycete pathogen Pythium ultimum in cotton and cress (Howell and Stipanovic, 1980; Maurhofer et al., 1994b).

The pyoluteorin biosynthetic gene cluster was first described in $P$. protegens Pf-5. It encompasses 17 genes and contains structural genes ( $p / t A B C D E F G L M$ ) and genes involved in efflux ( $p / t / J K N O P$ ) and regulation ( $p / t Z$ and pltR) (Gross and Loper, 2009). The cluster is only present in Pseudomonas strains that also have phID, either as part of the DAPG operon, as is the case in $P$. protegens or associated with the pyoluteorin gene cluster in $P$. aeruginosa strains. Nanomolar concentrations of phloroglucinol, the precursor of DAPG that is synthesized by PhID are required for pyoluteorin production, while micromolar concentrations of phloroglucinol inhibit pyoluteorin production 
(Kidarsa et al., 2011). Phloroglucinol is transformed by a halogenase encoded in the pyoluteorin gene cluster by pltM into chlorinated derivatives that induce expression of pyoluteorin biosynthetic genes via PltR (Yan et al., 2017).

\subsection{Pyrrolnitrin}

Pyrrolnitrin is a chlorinated phenylpyrrol derived from tryptophan with a broad-spectrum activity against Ascomycete and Basidiomycete fungi (Ligon et al., 2000). Pyrrolnitrin is produced by various bacterial genera, including Pseudomonas, Burkholderia, Serratia and Myxococcus. The four-gene pyrrolnitrin biosynthetic gene cluster prnABCD was first described in $P$. chlororaphis subsp. aurantiaca BL915 (previously identified as P. fluorescens and P. aurantiaca) (Hill et al., 1994; Kirner et al., 1998) and is highly conserved in pyrrolnitrinproducing strains. The cluster is found in Pseudomonas biocontrol strains that belong to the $P$. protegens and $P$. chlororaphis subgroup. Pseudomonas strains may have obtained this cluster by horizontal gene transfer (Costa et al., 2009). The compound has been used as a lead structure in the development of a new class of agricultural fungicides, the phenylpyrroles (Nyfeler and Ackermann, 1992). The phenylpyrrole fungicides, Fenpiclonil and Fludioxonil, are registered against multiple fungal crop diseases for seed or foliar treatment (Kilani and Fillinger, 2016).

\subsection{2-hexyl-5-propyl-alkylresorcinol (HPR)}

2-hexyl-5-propyl-alkylresorcinol (HPR) is structurally related to DAPG but the biosynthesis pathway is completely different. The compound is derived from octanoic acid. The biosynthetic gene cluster for HPR was first elucidated in P. chlororaphis subsp. aurantiaca BL915 and is composed of three biosynthetic genes darABC and two regulatory genes darS and darR (Nowak-Thompson et al., 2003). The biosynthetic gene cluster is present in various biocontrol strains belonging to the P. chlororaphis subgroup (Biessy et al., 2019; Calderón et al., 2013). HPR has antifungal and antibacterial activity.

\subsection{Hydrogen cyanide (HCN)}

Hydrogen cyanide ( $\mathrm{HCN}$ ) is a respiratory poison that inhibits cytochrome c oxidase, the terminal component of the respiratory chain, in many organisms. In prokaryotes, HCN production seems to be restricted to the Proteobacteria and to certain cyanobacteria (Blumer and Haas, 2000a). Within the genus Pseudomonas known $\mathrm{HCN}$ producers can be found in the $P$. aeruginosa group and in various subgroups of the $P$. fluorescens group. Virtually all DAPG producers in the $P$. corrugata and $P$. protegens subgroup also produce HCN and this trait is also common in the P. chlororaphis subgroup (Table 1). 
A cluster of three genes, $h \mathrm{c} A B C$, is responsible for $\mathrm{HCN}$ production from the metabolic precursor glycine (Laville et al., 1998). The hcnABC cluster appears to be ancestral in Pseudomonas strains associated with roots (Frapolli et al., 2012). Cyanogenesis in Pseudomonas is regulated by the GacA/GacS signal transduction system (Sonnleitner et al., 2009) and by the anaerobic regulator ANR and is stimulated by iron (Blumer and Haas, 2000b). HCN production by $P$. protegens $\mathrm{CHAO}$ accounts for the suppression of tobacco black root rot caused by Thielaviopsis basicola and iron sufficiency is important for both HCN production and disease suppression (Voisard et al., 1989). HCN production by Pseudomonas has also been implicated in the suppression of root-knot nematodes (Siddiqui et al., 2006), aphids (Kang et al., 2019), termites (Devi and Kothamasi, 2009) and other insects (Flury et al., 2017). $\mathrm{HCN}$, together with DAPG is also responsible for the biocontrol activity of P. brassicacearum LBUM300 against bacterial canker of tomato caused by Clavibacter michiganensis subsp. michiganensis (Lanteigne et al., 2012; Paulin et al., 2017).

\subsection{Biosurfactants}

Pseudomonas strains produce two types of biosurfactants:

- rhamnolipids; and

- nonribosomal lipopeptides.

Rhamnolipids are glycolipids typically produced by $P$. aeruginosa and their role in biocontrol has been summarized in D'aes et al. (2010), Olorunleke et al. (2015b) and Crouzet et al. (2020). Lipopeptides are produced by strains in various Pseudomonas groups and subgroups (Table 2). They are comprised of an oligopeptide composed of 8-25 amino acids that are N-terminally acylated with a fatty acid. They are produced by nonribosomal peptide synthetases. The vast majority of Pseudomonas lipopeptides is not linear but displays a macrolactone ring that contains 4-9 amino acids.

Pseudomonas CLPs have been classified in at least 15 different groups (Table 2) and their biosynthesis, structures and biological functions have been reviewed recently (Geudens and Martins, 2018; Götze and Stallforth, 2020). A complete overview of all described Pseudomonas lipopeptides to date can be found in Götze and Stallforth (2020). Many new structures have been unraveled in recent years and their identification is greatly facilitated by genome mining (Paterson et al., 2017). They play a role in swarming motility, biofilm formation, environmental adaptation, nutrient availability, root colonization and biocontrol (D'aes et al., 2010; Olorunleke et al., 2015b; Raaijmakers et al., 2010). 


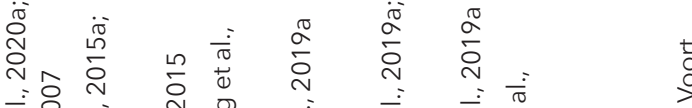

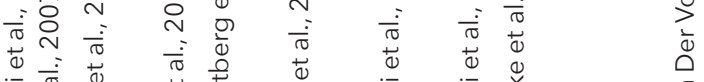

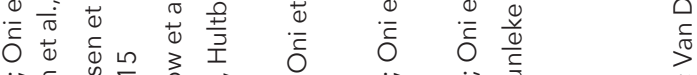

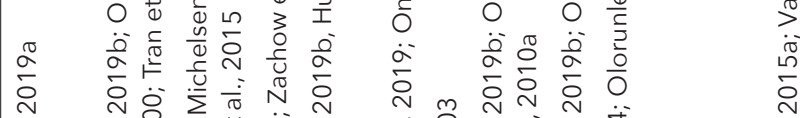

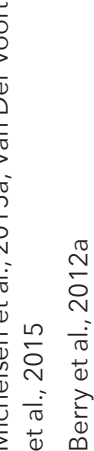

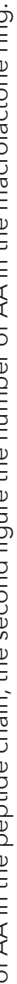

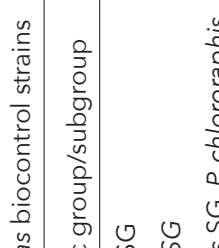

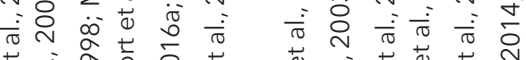

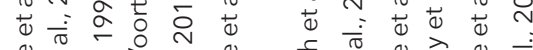

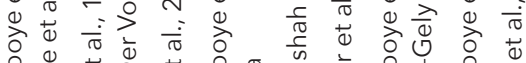

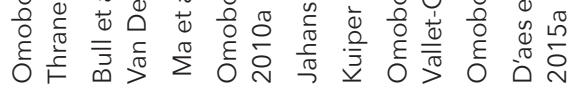

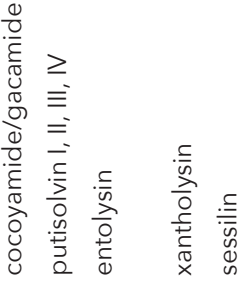

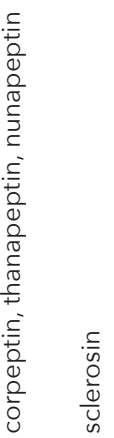

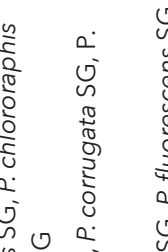

(1)

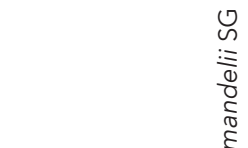

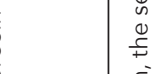

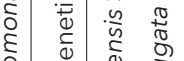

¿

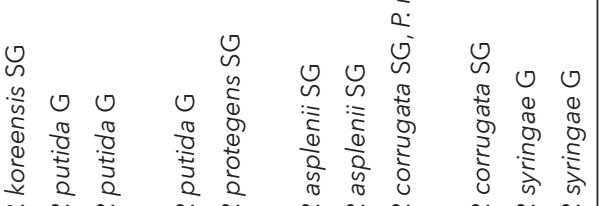

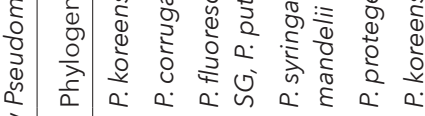

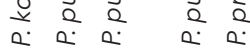

Q. Q. Q.

Q. Q Q

Oे

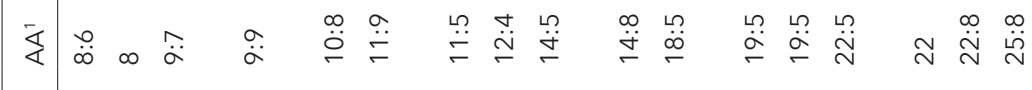

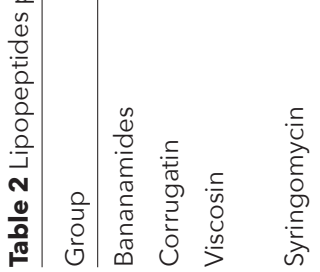

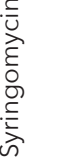

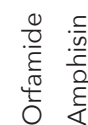

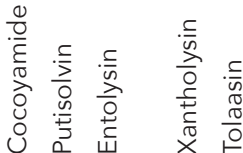

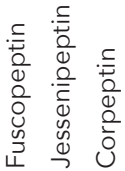

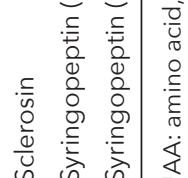

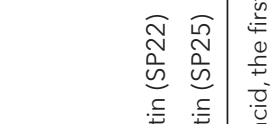

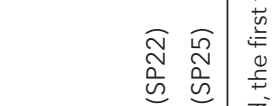




\subsection{Strain-specific bio-active molecules}

In addition, various strain-specific bio-active metabolites are only produced by a limited number of Pseudomonas bacteria. Gene clusters carrying the biosynthetic genes for these metabolites have most likely been obtained by horizontal gene transfer. Examples are:

- rhizoxins;

- promysalin;

- sessilin; and

- L-furanomycin.

Rhizoxins, produced by a few strains from the P. protegens subgroup (Loper et al., 2008; Takeuchi et al., 2015) and P. chlororaphis MA342 (Ligon et al., 2000) have activity against fungi and oomycetes. Sessilin is an antifungal cyclic lipopeptide (CLP) that appears to be unique to the biocontrol strain Pseudomonas sp. CMR12a (D'aes et al., 2014). Promysalin is a salicylic acid-containing antibiotic produced by P. putida RW10S1 (Li et al., 2011) with activity against Grampositive and Gram-negative bacteria (Kaduskar et al., 2017). L-furanomycin is a non-proteinogenic amino acid found in P. fluorescens SBW25 that selectively inhibits Gram-negative plant pathogenic bacteria (Trippe et al., 2013).

\subsection{Siderophores}

Siderophores are implicated in biocontrol activity by competition for iron, direct antagonism or induced systemic resistance. Most Pseudomonas strains produce the fluorescent compound pyoverdine (Meyer, 2000) and about 100 distinct pyoverdines have been identified which are structurally divided into four groups. In addition, many Pseudomonas strains produce other siderophores in addition to pyoverdine with a lower affinity for ferric iron than pyoverdine. Their chemical structures are diverse and include pyochelin and enantio-pyochelin, achromobactin, pseudomonine, corrugatin and (thio)quinolobactin (Cornelis, 2010; Schalk et al., 2020).

\subsection{Insect toxins}

Pseudomonas biocontrol strains that belong to the $P$. protegens and $P$. chlororaphis subgroup interact with insects and produce the insecticidal Fit toxin. This is a large protein toxin related to the insect toxin Mcf of Photorhabdus and Xenorhabdus spp., bacterial symbionts that live in the intestines of entomophagous nematodes. Fit-toxin producers have oral and injectable insecticidal activity against Lepidoptera larvae. The fit locus comprises eight genes, fitABCDEFG and the Fit toxin is the product of fitD. The other gene 
products are involved in transport and regulation (Flury et al., 2017, 2016; Péchy-Tarr et al., 2008; Ruffner et al., 2015, 2012).

\subsection{Regulation of secondary metabolites}

Regulation of secondary metabolites in Pseudomonas is complex and will not be discussed in detail in this review. Excellent overviews of antibiotic regulation are provided by Haas and Keel (2003) and Sonnleitner and Haas (2011). Most antibiotics with a role in biocontrol are produced only when the GacS/GacA two-component system is active. This regulatory system is widely conserved in Gram-negative bacteria and regulates biocontrol traits or pathogenicity factors post-transcriptionally. Mutations in gacS or gacA abolish biocontrol activity in the majority of biocontrol Pseudomonas strains. A good introduction can be found in Haas and Défago (2005). On interaction with bacterial signal molecules, which are presumably intermediates of the Krebs cycle (Takeuchi et al., 2009), GacS is autophosphorylated and a phosphate residue is transferred to GacA. This activates the transcription of small RNA genes. These RNAs bind to small proteins that function as post-transcriptional repressors of biocontrol genes. This relieves the translational repression exerted by these proteins at or near the ribosome-binding sites of the target mRNA (Sonnleitner and Haas, 2011).

Spontaneous mutants in gacA or gacS contribute to the genetic instability of some Pseudomonas strains, which is obviously a problem in biocontrol. Particular strains that produce a large number of secondary metabolites accumulate a high proportion of Gac- mutants in culture (Yan et al., 2018). Colony variants that exhibit a Gac' phenotype are easy to recognize because they have an increased colony size, are more flat and more fluorescent due to overproduction of pyoverdine (Duffy and Defago, 2000).

\section{Secretion systems that play a role in biocontrol}

\subsection{Type III secretion systems}

Many Gram-negative bacteria can interact with diverse eukaryotic hosts via a type III secretion system. This is a protein secretion system that originates from the bacterial flagellar system and spans the two membranes in Gram-negative bacteria. Through this system so-called effector proteins can be secreted directly in the cytoplasm of the host. The type III secretion system plays a role in both parasitic and mutualistic interactions and is found in various Pseudomonas biocontrol strains.

T3SS genes are present in Pseudomonas biocontrol strains belonging to the $P$. fluorescens and $P$. corrugata subgroups and are enriched in the rhizosphere as compared to corresponding bulk soil. T3SS is involved in interactions with phytopathogens, mycorrhizal fungi and predators (Nazir et al., 2017). Most 
Pseudomonas bacteria contain a T3SS that belongs to the Hrp1 family, but some strains also have an additional T3SS that belongs to the SPI-1 family. SPI-1 type T3SS was first identified in P. fluorescens F113, a well-studied biocontrol strain of the $P$. corrugata subgroup and enhances resistance to amoeboid grazing (Barret et al., 2013). The Hrp1-type T3SS of $P$. fluorescens strain KD targets the oomycete pathogen Pythium ultimum, promoting cucumber protection (Rezzonico et al., 2005). The role of the T3SS in other beneficial Pseudomonas bacteria remains elusive, but it was suggested that effectors delivered via this system may suppress host immunity to facilitate root colonization (Yu et al., 2019).

\subsection{Type VI secretion systems}

Another secretion system that is commonly found in commensal, symbiotic and pathogenic plant-associated bacteria is the type VI secretion system. This secretion system is used to inject toxic effectors in eukaryotic and prokaryotic cells and is involved in interbacterial competition. T6SS clusters are widely distributed in the genus Pseudomonas and especially enriched in the P. putida group (Bernal et al., 2018). The biocontrol strain P. putida KT2440 contains three T6SSs and various T6SS effectors and the systems are used to outcompete various phytopathogenic bacteria in vitro and in planta (Bernal et al., 2017).

\section{Pseudomonas biocontrol strains: Pseudomonas protegens subgroup}

Pseudomonas protegens was formally described by Ramette et al. (2011) and comprises isolates that produce the secondary metabolites DAPG and pyoluteorin. Most $P$. protegens strains also produce $\mathrm{HCN}$, pyrrolnitrin, the CLP orfamide and two siderophores: pyoverdine and enantio-pyochelin. The species has insecticidal activity (Flury et al., 2016) and some isolates contain additional gene clusters encoding rhizoxin analogues (Loper et al., 2008) and toxoflavin (Philmus et al., 2015). Isolates belonging to this species have been obtained from the rhizosphere of tobacco, cotton, wheat (Ramette et al., 2011), canola (Zhang et al., 2020b), tomato, cucumber and shepherd's purse (Takeuchi et al., 2014). They have also been found on the phyllosphere of lemon (Michavila et al., 2017) and wheat (Levy et al., 1992), in stored rice grains (Jeong et al., 2018), on lamb's lettuce in hydroponics (Moruzzi et al., 2017), in recycled irrigation water (Yang and Hong, 2020) and on brown macroalga in the Baltic sea (Heiman et al., 2020). Recently it was shown that $P$. protegens can also survive in insects (Flury et al., 2019).

Much of our knowledge about $P$. protegens comes from two of the beststudied biocontrol strains: P. protegens Pf- 5 and P. protegens CHAO. Both strains have become models and many biocontrol traits in Pseudomonas were first 
discovered in these strains. Also our knowledge about the complex regulation of secondary metabolites in Pseudomonas biocontrol strains was largely obtained from these two strains (Haas and Défago, 2005; Haas and Keel, 2003).

P. protegens Pf- 5 was obtained from cotton roots in Texas and suppresses Rhizoctonia solani and Pythium ultimum on cotton (Howell and Stipanovic, $1980,1979)$. It also controls a variety of other diseases such as fungal diseases on wheat (Pfender et al., 1993) and turfgrass (Rodriguez and Pfender, 1997), Fusarium crown and root rot of tomato (Sharifi-Tehrani et al., 1998) and seed piece decay of potato (Xu and Gross, 1986) (see Table 3). P. protegens Pf-5 was the first biocontrol strain of which the whole genome was sequenced (Paulsen et al., 2005). Pf-5 produces the typical P. protegens antibiotics HCN, DAPG, pyrrolnitrin and pyoluteorin (Loper et al., 2007). The CLP orfamide was first discovered in P. protegens Pf-5 by a combination of genome sequence analysis and isotope-guided fractionation (Gross et al., 2007). Further genome mining revealed the capacity to produce two additional antibiotics: rhizoxin (Loper et al., 2008) and toxoflavin (Philmus et al., 2015).

Rhizoxin is a polyketide macrolide with antifungal, phytotoxic and antitumor properties and binds to ß-tubulin. Rhizoxin-producing endosymbionts have been found in the rice-pathogenic fungus Rhizopus microspores. Rhizoxin is the causative agent of rice seedling blight and inhibits mitosis in seedling roots. Rhizoxin biosynthesis genes were first described from the Rhizopus endosymbiont Burkholderia rhizoxina (Partida-Martinez and Hertweck, 2007) and they are orthologous to the biosynthesis genes found in P. protegens Pf-5. The main rhizoxin produced by Pf- 5 inhibits the growth of the plant pathogenic fungus Fusarium oxysporum (Brendel et al., 2007).

Toxoflavin has antibiotic activity against bacteria and fungi and is phytotoxic against a broad range of monocot and dicot plants. The compound is produced by the plant pathogenic bacteria Burkholderia glumae and B. gladioli and is a key virulence factor. The toxoflavin gene cluster in Pf-5 shows substantial differences with the tox genes from Burkholderia. The Pf-5 strain produces trace amounts of toxoflavin with antibiotic activity against various plant pathogenic bacteria (Philmus et al., 2015).

P. protegens CHAO was isolated from the roots of 7-week-old tobacco plants grown in soil from Morens, Switzerland, with natural suppressiveness to black root rot caused by Thielaviopsis basicola (Stutz et al., 1986). Since then, it was shown that strain $\mathrm{CHAO}$ can protect many crop plants including wheat, cucumber, sugar beet, cotton, flax, corn and cress from oomycete and fungal pathogens (Voisard et al., 1994) (Table 3). In addition, P. protegens CHAO can induce systemic resistance to Hyaloperonospora in Arabidopsis (lavicoli et al., 2003), root-knot nematodes in tomato (Siddiqui and Shaukat, 2003), Tobacco Necrosis Virus in tobacco (Maurhofer et al., 1994a) and Banana Bunchy Top Virus in banana (Kavino et al., 2008). Biocontrol traits of $P$. protegens CHAO 


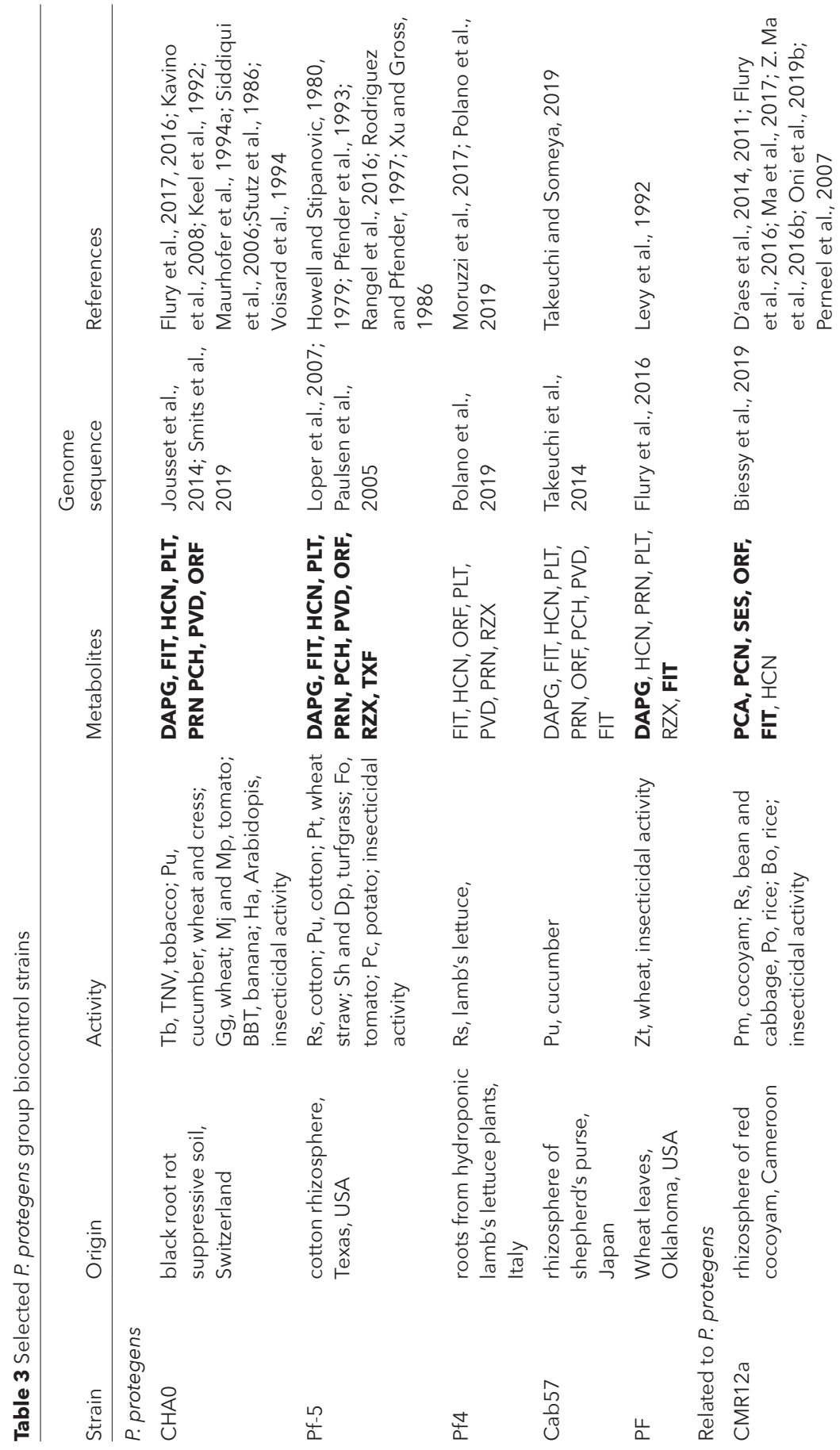




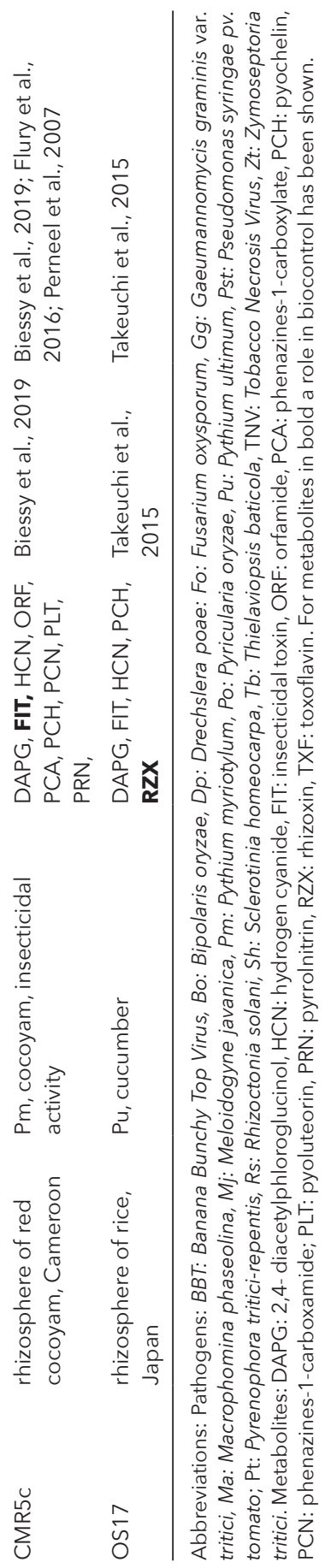


have been investigated in great detail. The strain produces the antibiotics $\mathrm{HCN}$, DAPG, pyrrolnitrin, pyoluteorin (Haas and Défago, 2005), orfamide-type CLPs (Ma et al., 2016a), the siderophores pyoverdine and enantio-pyochelin (Youard et al., 2007), and various traits involved in insect toxicity (Flury et al., 2017, 2016). Mutant analysis has revealed that suppression of the different plant diseases involves different mechanisms. HCN and DAPG are involved in black root rot control, DAPG, but not HCN is needed for take-all control, while pyoluteorin is responsible for Pythium control (Voisard et al., 1994). Determinants that trigger ISR include DAPG and pyoverdine (De Vleesschauwer and Höfte, 2009).

In nutrient-rich cultures both $P$. protegens $\mathrm{Pf}-5$ and $P$. protegens $\mathrm{CHAO}$ readily accumulate $\mathrm{Gac}^{-}$mutations that completely abolish their biocontrol capacities (Bull et al., 2001; Duffy and Defago, 2000; Yan et al., 2018). Cultures of mutants of $P$. protegens Pf-5 unable to produce pyoluteorin or orfamide accumulated a smaller number of Gac- mutants. Pyoluteorin biosynthesis, but not pyoluteorin itself, contributed significantly to accumulation of Gac' mutants. However, few of these mutants accumulated in the presence of the competitor Bacillus subtilis (Yan et al., 2018).

Other P. protegens biocontrol strains have been obtained from North America, Europe and Japan and examples are given in Table 3. P. protegens CAB 57 originates from the rhizosphere of shepherd's purse in Japan and is active against $P$. ultimum in cucumber (Takeuchi et al., 2014). At least in Japan P. protegens strains do not seem to be very common. In a screen of 2800 Pseudomonas isolates from the rhizosphere of various plants in Japan, only 5 isolates belonged to the P. protegens subgroup (Takeuchi and Someya, 2019). P. protegens bacteria were not prevalent either in a collection of 698 Pseudomonas isolates from the maize rhizosphere in France and Switzerland (Vacheron et al., 2016). Their high level of effectiveness in short-term greenhouse trials may be counterbalanced by lower rhizosphere competitiveness and survival under field conditions. This suggests a trade-off between rhizosphere prevalence and the ability to produce a large number of plant-beneficial properties (Vacheron et al., 2016).

The Pseudomonas strain Os17 isolated from the rhizosphere of rice belongs to the $P$. protegens subgroup but is clearly different from the species $P$. protegens. This strain contains the biosynthetic gene clusters for HCN, DAPG, rhizoxin, pyoverdine and enantio-pyochelin, but gene clusters for pyrrolnitrin, pyoluteorin and orfamide are absent. The strain suppresses damping-off and root rot caused by $P$. ultimum on cucumber. Mutant analysis revealed that rhizoxin is important in Pythium biocontrol (Takeuchi et al., 2015).

Pseudomonas sp. CMR12a and CMR5c have been obtained from the rhizosphere of red cocoyam in Cameroon and have antagonistic activity against Pythium myriotylum, the causal agent of the destructive cocoyam root rot disease (Perneel et al., 2007). They belong to the P. protegens group, but 
are clearly different from the core $P$. protegens strains (Biessy et al., 2019; Flury et al., 2016). In terms of biocontrol traits they have characteristics of both $P$. protegens and $P$. chlororaphis. Both strains produce the phenazines PCA and PCN, metabolites that are typically produced by $P$. chlororaphis group strains. CMR5c also has the typical P. protegens biosynthetic gene clusters for DAPG, PLT and PRN (Biessy et al., 2019; Flury et al., 2016; Perneel et al., 2007).

Both strains produce orfamide-type CLPs ( Ma et al., 2016a). In addition, CMR12a produces an unusual CLP, sessilin, which is closely related to tolaasin, a CLP produced by the mushroom pathogen P. tolaasii (D'aes et al., 2014). Analysis of their whole genome has revealed that the phenazine biosynthetic gene cluster in both strains is located on a genomic island. In case of CMR12a, this genomic island also contains the sessilin biosynthetic gene cluster which is absent in CMR5c.

Recently, various isolates closely related to CMR12a were found on the root of tissue-cultured derived cocoyam plantlets that had been grown for 2 or 4 weeks in the cocoyam root rot suppressive soil from Boteva, Cameroon. Some of these isolates did not carry the genomic island and did not produce phenazines or sessilin. Intriguingly, these isolates hardly colonized the roots of 8-week-old cocoyam plantlets, indicating that these strains are associated with young cocoyam plantlets only (Omoboye, 2019).

Biocontrol activity of Pseudomonas sp. CMR12a has been studied in detail. The strain controls damping-off disease on Chinese cabbage caused by $R$. solani AG 2-1 and root rot disease on bean caused by $R$. solani AG 4-HI. In cabbage, phenazines alone were sufficient to suppress Rhizoctonia damping-off, whereas co-production of sessilins and orfamides was required in the absence of phenazines. To suppress $R$. solani on bean, co-production of phenazines, sessilins and orfamides appeared to be important (Olorunleke et al., 2015a). All three metabolites are involved in the suppression of $P$. myriotylum on cocoyam (Oni et al., 2019b). The strain induces resistance to fungal pathogens in rice and bean. Phenazines are solely involved in ISR against the rice blast fungus $P$. oryzae, while phenazines, orfamide and sessilin can trigger ISR in bean against web blight disease caused by $R$. solani AG 2-2 (Ma et al., 2016b). Orfamide at high concentrations is responsible for ISR in rice against the brown spot pathogen Bipolaris oryzae (Teleomorph: Cochliobolus miyabeanus), but is not effective against the rice blast pathogen Pyricularia oryzae (Ma et al., 2017).

The insecticidal activity of $P$. protegens subgroup strains, including P. protegens Pf-5, P. protegens CHA0, Pseudomonas sp. CMR12a and Pseudomonas sp. CMR5c, has intensively been studied but will not be further discussed here. Virulence factors that contribute to insect pathogenicity include the Fit toxin, HCN, cyclic lipopeptides, rhizoxins and secreted lytic enzymes (Flury et al., 2017, 2016; Rangel et al., 2016). In addition the T6SS contributes 
to insect pathogenicity of $P$. protegens in oral infection assays (Vacheron et al., 2019).

\section{Pseudomonas biocontrol strains: Pseudomonas chlororaphis subgroup}

P. chlororaphis isolates have been obtained from soil and the rhizosphere of crops such as tomato, potato, maize, radish, beet, alfalfa, soja and clover (Biessy et al., 2019); the stem of sugarcane (Mehnaz et al., 2009); and roots of avocado (Cazorla et al., 2006). The species is divided in four subspecies: aureofaciens, aurantiaca, chlororaphis (Peix et al., 2007) and piscium. P. chlororaphis subsp. piscium was proposed to accommodate two isolates from the intestines of perch and rainbow trout (Burr et al., 2010), but various rhizosphere isolates also cluster in this subspecies (Biessy et al., 2019). Secondary metabolite production in the P. chlororaphis subgroup has been studied by Biessy et al. (2019).

All P. chlororaphis isolates produce PCA and HCN, but the subspecies differ in the type of phenazines produced and in the production of other secondary metabolites. The subspecies aureofaciens and aurantiaca produce 2-OH-PCA, the piscium subspecies produces $\mathrm{PCN}$, while isolates belonging to the chlororaphis subspecies produce either PCN or 2-OH-PCA. All subspecies, except subsp. piscium also produce pyrrolnitrin and HPR. NRPS clusters for the production of lipopeptides from the Viscosin group are commonly found in the subspecies piscium, aurantiaca and chlororaphis, but not in the subspecies aureofaciens. Many $P$. chlororaphis strains produce two siderophores, pyoverdine and achromobactin. More details can be found in Biessy et al. (2019).

Biocontrol activities of $P$. chlororaphis isolates have been studied extensively and various commercially available biopesticides belong to this species (see Table 6). The biocontrol capacities of $P$. chlororaphis have been reviewed by Anderson and Kim (2020, 2018). P. chlororaphis isolates directly control fungi, nematodes, oomycetes and aphids and can induce resistance to fungal and bacterial leaf pathogens. Metabolites involved in biological control activity include phenazines, HCN, pyrrolnitrin, HPR and 2,3-butanediol (Table 4). Wellstudied strains include $P$. chlororaphis subsp. aureofaciens $O 6, P$. chlororaphis subsp. piscium PCL1391, P. chlororaphis 30-84 and P. chlororaphis PCL1606. These and other strains are listed in Table 4.

The role of phenazines in biocontrol has been studied in various $P$. chlororaphis strains. PCA is involved in the suppression of take-all disease of wheat as was shown for $P$. chlororaphis 30-84 (Pierson and Thomashow, 1992). PCN is clearly more effective than PCA in the biocontrol activity against $F$. oxysporum f. sp. radicis-lycopersici in tomato. P. chlororaphis PCL1391 was active in this pathosystem in contrast to PCA-producing strains such as $P$. chlororaphis 30-84 (Chin-A-Woeng et al., 1998). This has been explained by the fact that PCN is still 


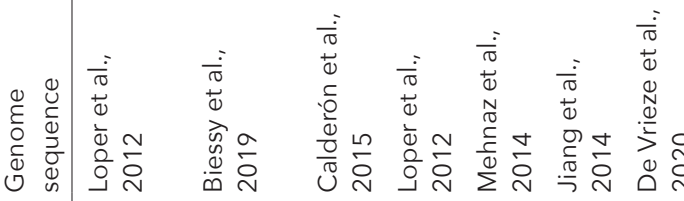

\begin{tabular}{|c|c|c|c|c|c|c|}
\hline 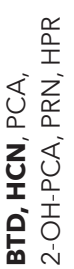 & 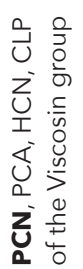 & $\begin{array}{l}Z \\
\cup \\
\text { I } \\
Z \bar{\alpha} \\
\frac{\alpha}{\alpha} \\
\frac{\alpha}{\alpha} \\
\frac{\alpha}{x}\end{array}$ & 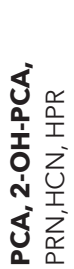 & 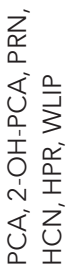 & 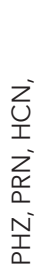 & 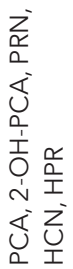 \\
\hline
\end{tabular}

ำ 로

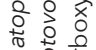

ஓे

$\stackrel{m}{i}$

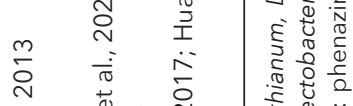

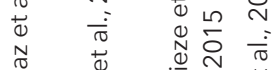

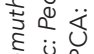

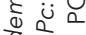

$\leqq$ vo

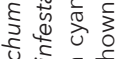

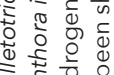

نे

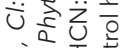

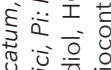

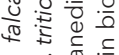

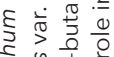

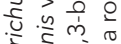

ब

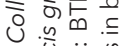

Чٓ है

ic

论 है

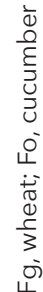

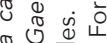

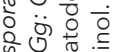

ह हो छ

U 인

U खे

ง

ฮิ

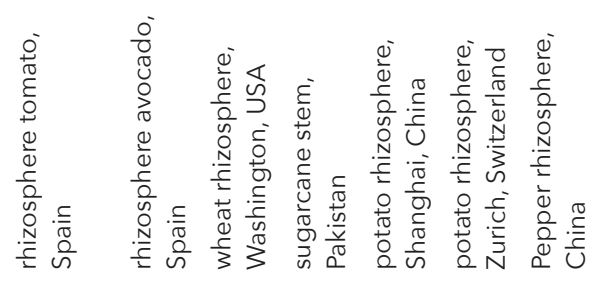

का

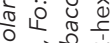

ㄹำ

हं

is है

बे

गे की

is

잉ํㅇ

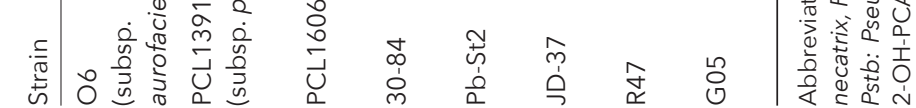


active at a pH of 5.7 and higher, while the antagonistic activity of PCA drastically decreases at this $\mathrm{pH}$ because the anionic form of PCA will predominate. This means that PCA-producing bacteria are most active at acidic $\mathrm{pH}$.

P. chlororaphis Pcho10 was obtained from Fusarium spp.-infested wheat heads in China. This strain strongly reduced $F$. graminearum infections on wheat heads in growth chamber and field conditions and predominantly produces PCN. PCN appeared to be the major compound responsible for activity against F. graminearum (Hu et al., 2014). In case of P. chlororaphis G05 (Table 4), PCA contributed to the ability to suppress $F$. oxysporum on cucumber (Chi et al., 2017), but pyrrolnitrin rather than PCA was essential to control Fusarium head blight on wheat caused by F. graminearum (Huang et al., 2018).

$P$. chlororaphis $\mathrm{O} 6$ is known to induce systemic resistance to bacterial and fungal pathogens and stimulates aerial growth. The strain produces the volatile 2, 3-butanediol, a metabolite also known from Bacillus spp. The compound is responsible for aerial growth stimulation and ISR against $P$. carotovorum (Han et al., 2006). Genes involved in 2,3-butanediol biosynthesis are also present in the genomes of other P. chlororaphis strains (Biessy et al., 2019). In this strain HCN production is involved in nematicidal (Kang et al., 2018; Lee et al., 2011) and aphicidal activity (Kang et al., 2019).

The role of HPR in biocontrol has been investigated in P. chlororaphis PCL1606. This isolate was obtained from a screening of rhizosphere bacteria obtained from healthy avocado roots for in vitro antagonism against Dematophora necatrix (teleomorph: Rosellinia necatrix), the causal agent of white root rot on avocado and various other fruit trees and crops (Cazorla et al., 2006). In contrast to other P. chlororaphis biocontrol strains, PCL1606 does not produce phenazines. The dar genes, responsible for HPR production in PCL1606, are highly homologous to the dar genes present in P. chlororaphis subsp. aurantiaca BL915. Mutants in HPR are impaired in antagonistic activity in an avocado-D. necatrix and a tomato-F. oxysporum f. sp. radicis-lycopersici pathosystem (Calderón et al., 2013). The HPR biosynthetic gene cluster is present in various other $P$. chlororaphis biocontrol strains including $P$. chlororaphis 30-84 and P. chlororaphis O6 (Calderón et al., 2013). Biessy et al. (2019) showed that the HPR biosynthetic cluster is present in the subspecies aureofaciens, aurantiaca and chlororaphis, but not in the subspecies piscium. HPR plays a key role in biofilm production in P. chlororaphis PCL1606 (Calderón et al., 2019).

\section{Pseudomonas biocontrol strains: Pseudomonas corrugata subgroup}

The Pseudomonas corrugata subgroup as defined by Garrido-Sanz et al. (2016) and Hesse et al. (2018) comprises the plant pathogenic species P. corrugata and P. mediterranea and plant beneficial isolates that are classified as $P$. 
brassicacearum, P. kilonenis or P. thivervalensis. This group is called the 'bcm clade' (Melnyk et al., 2019). P. corrugata and P. mediterranea are closely related and both cause stem pith necrosis on tomato and pepper. $P$. corrugata has also been reported on chrysanthemum and geranium (Catara, 2007). The line between plant-pathogenic and beneficial isolates in this subgroup is very thin (Gislason and de Kievit, 2020).

P. corrugata strains have been isolated from soil and from the rhizosphere of non-diseased plants in various countries (see Catara (2007) for an overview). These strains show activity against a wide range of soilborne fungal, bacterial and oomycete pathogens and postharvest fungal pathogens on fruits. Some P. corrugata strains have been patented for biocontrol. P. corrugata produces the antimicrobial and phytotoxic CLPs corpeptin A and corpeptin B with 22 amino acid residues, and cormycin, with 9 AA residues (Emanuele et al., 1998; Strano et al., 2015). Pith necrosis symptoms are strongly reduced in mutants unable to produce these compounds. Biocontrol activity in $P$. corrugata and $P$. mediterranea is mediated by these CLPs and volatiles such as HCN (Strano et al., 2017). P. corrugata and P. mediterranea strains do not produce the fluorescent siderophore, pyoverdine (Gislason and de Kievit, 2020).

Beneficial isolates within the P. corrugata subgroup have been classified as:

\section{- P. brassicacearium}

- P. kilonensis

- P. thivervalensis

P. brassicacearum and P. thivervalensis were first described by Achouak et al. (2000), while the species P. kilonensis was delineated in 2001 (Sikorski et al., 2001). These three species are closely related and it has been suggested that $P$. kilonensis should be considered as a junior synonym of $P$. brassicacearum (Tran et al., 2017). These species generate pyoverdine in contrast to $P$. corrugata and P. mediterranea. P. brassicacearum-like organisms are frequently found in soils that are disease-suppressive against take-all caused by G. graminis var. tritici in wheat. Isolates also have been obtained from agricultural soil or rhizosphere of other crops such as canola, potato, strawberry and tomato. They usually show excellent biocontrol capabilities. Many isolates that belong to these species produce the antibiotic DAPG.

Well-studied DAPG-producing strains in the $P$. corrugata subgroup include Pseudomonas fluorescens F113 (also called P. kilonensis F113), which was originally isolated from the root hairs of a sugar beet plant in Ireland (Shanahan et al., 1992) and Pseudomonas fluorescens Q2-87 (originally called P. aureofaciens Q2-87) obtained from wheat roots in a suppressive soil in Washington (Harrison et al., 1993). The species name of both isolates is in need of revision since they clearly belong to the P. corrugata subgroup (Garrido-Sanz 
et al., 2016). Pseudomonas strain Q2-87 produces DAPG and HCN but only DAPG contributes to its in vitro biocontrol activity against $G$. graminis var. tritici (Vincent et al., 1991).

Pseudomonas strain F113 is an excellent rhizosphere colonizer with biocontrol activity against various bacteria, fungi and nematodes including P. carotovorum (Cronin et al., 1997a), F. oxysporum (Barahona et al., 2011), P. ultimum (Fenton et al., 1992) and Globodera spp. (Cronin et al., 1997b). Biocontrol activity in this strain is strongly linked to the production of DAPG (Redondo-Nieto et al., 2013). The capacity to produce DAPG is lost in the pathogenic species, $P$. corrugata and P. mediterranea, probably because this compound can elicit ISR in plants (Almario et al., 2017).

A subset of $P$. brassicacearum strains does not produce DAPG but contain lipopeptide-encoding NRPS gene clusters located on a genomic island, which has been called the LPQ island by Melnyk et al. (2019). These lipopeptides are very similar to cormycin and corpeptins produced by $P$. corrugata. However, unlike corpeptin, which is a cyclic lipopeptide, sclerosin produced by $P$. brassicacearum DF41 is linear (Berry et al., 2012). P. brassicacearum DF41 isolated from canola root tips in Canada (Savchuk and Fernando, 2004) can protect canola against Sclerotinia sclerotium which is due to the production of sclerosin (Berry et al., 2010).

Pseudomonas sp. SH-C52 produces lipopeptides that have been characterized as thanapeptin and thanamycin. Pseudomonas sp. SH-52 has been found in soils with natural suppressiveness to the fungal pathogen R. solani (Mendes et al., 2011). Thanamycin is implicated in the antagonistic activity of SH-52 against Sclerotium rolfsii on groundnut (Le et al., 2012) and shows activity against various other fungi in vitro. Thanapeptin is active against oomycetes. Besides thanamycin and thanapeptin, this strain produces a 2-amino acid lipopeptide, brabantamide, with activity against Gram-positive bacteria and oomycetes (Van Der Voort et al., 2015).

$\mathrm{SH}-52$ is closely related to $P$. mediterranea and $P$. corrugata and, like these species, lacks the capacity to produce pyoverdine, but has the biosynthetic gene clusters for the siderophores, achromobactin and corrugatin. Various other Pseudomonas strains of the P. corrugata group have biosynthetic gene clusters for thanamycin or thanapeptin-like CLPs. More information about lipopeptide production in the P. corrugata subgroup can be found in Girard et al. (2020a). Gislason and de Kievit (2020) have mined the genomes of 21 P. brassicacearum strains for regions associated with plant beneficial traits and pathogenicity. They found a negative correlation between DAPG and lipopeptide production; strains that produce lipopeptides do not produce DAPG. Selected biocontrol strains belonging to the $P$. corrugata subgroup are listed in Table 5. 


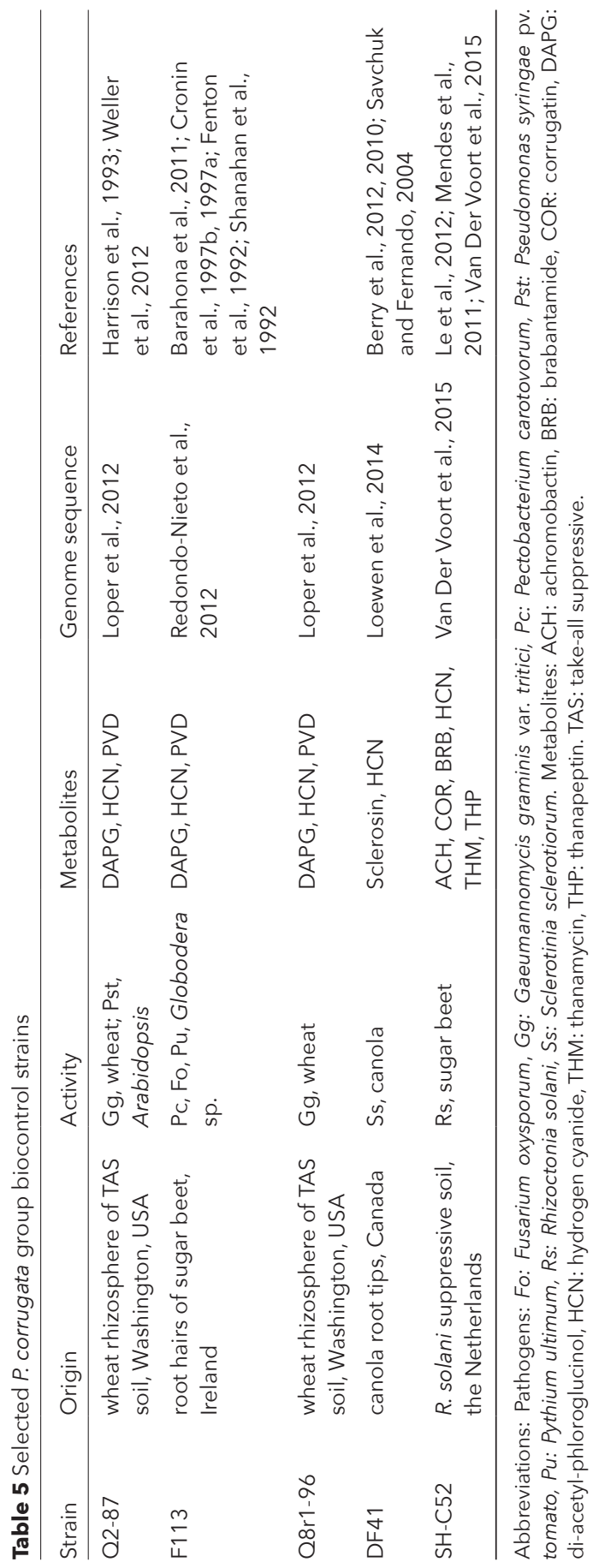




\section{Pseudomonas biocontrol strains: Pseudomonas fluorescens subgroup}

P. fluorescens forms a large subgroup within the P. fluorescens group. At least 20 described type species cluster within this group but many genomes that fall within this subgroup are distinct from the type species. Various well-known and intensively studied biocontrol strains belong to this subgroup. These include two of the so-called Dutch strains that were isolated in the 1980s at the Dutch Phytopathological Laboratory 'Willy Commelin Scholten', WCS374 obtained from the rhizosphere of potato (Geels and Schippers, 1983) and WCS417 from the rhizosphere of wheat grown in a field suppressive to take-all disease (Lamers et al., 1988). These strains have intensively been studied for their plantgrowth-promoting and biocontrol abilities. Whole-genome sequencing has clarified their taxonomic position (Berendsen et al., 2015). WCS417 belongs to the species $P$. simiae. WCS374 is closely related to the biocontrol strains Pseudomonas sp. A506 isolated from the pear phyllosphere in California, USA (Stockwell and Stack, 2007) and Pseudomonas sp. SS101 from the rhizosphere of wheat in the Netherlands (de Souza et al., 2003). It has been proposed to group these strains under the new species name $P$. defensor with WCS374 as the type strain.

P. simiae WCS417 has intensively been studied for its capacity to trigger induced systemic resistance in Arabidopsis, grapevine, radish, banana, bean, carnation and tomato. P. defensor WCS374 does not trigger ISR in Arabidopsis or grapevine, but is able to do so in Eucalypt, radish and rice (reviewed by De Vleesschauwer and Höfte, 2009). Biocontrol activity of these strains is linked to siderophore-mediated competition for iron by pyoverdines. Pyoverdines have also been implicated in the capacity of these strains to elicit ISR, reviewed by Lemanceau et al. (2009). The strains produce bacteriocins, but no antibiotics or CLPs. In addition, the genomes of both strains contain two T6SS loci. Both P. simiae WCS417 and P. defensor WCS374 possess a type III secretion system and putative effectors have been identified by genome mining (Berendsen et al., 2015). Highly similar T3SS clusters to WCS374 have been found in A506 and SS101 (Stringlis et al., 2019). These T3SS gene clusters are quite distinct from T3SS clusters in phytopathogenic Pseudomonas bacteria. Unlike pathogenic bacteria that contain a T3SS cluster, these strains do not trigger a hypersensitive response in tobacco leaves. The presence of T3SS in beneficial rhizosphere bacteria suggests a possible involvement in the suppression of root immune responses, facilitating root colonization.

According to Hesse et al. (2018), another strain that belongs to the same clique group as P. simiae WCS417 is P. fluorescens PICF7, an endophyte of olive roots and an effective biocontrol agent against Verticillium wilt of olive. A cysteine auxotrophic mutant of PICF7 had a reduced root colonization 
capacity and lost full biocontrol efficacy in olive but was not impaired in the inner colonization of olive root tissues. Swimming motility and pyoverdine production were not involved in endophytic colonization and biocontrol (Maldonado-Gonzalez et al., 2015).

Specific strains within the $P$. fluorescens subgroup are known to produce CLPs that belong to the Viscosin group (viscosin, massetolide, WLIP, viscosinamide) (Oni et al., 2020a). Well-studied strains in this aspect include the massetolide producer P. fluorescens (lactis) SS101 and the viscosin-producer $P$. fluorescens SBW25.

P. fluorescens (lactis) SS101 is a plant growth-promoting bacterium and has biocontrol activities against Pythium intermedium root rot of flower bulbs (de Souza et al., 2003), tomato late blight caused by P. infestans (Tran et al., 2007), P. syringae pv. tomato and Spodoptera exigua on Arabidopsis. Massetolide production is involved in the control of Pythium root rot on flower bulbs (de Souza et al., 2003) and P. infestans on tomato. Massetolide mutants of $P$. fluorescens SS101 were significantly less effective in biocontrol against $P$. infestans on tomato and had an impaired capacity to colonize tomato roots (Tran et al., 2007). Key mechanisms that are linked to growth promotion and ISR against $P$. syringae pv. tomato in Arabidopsis include modulation of sulfur assimilation, auxin biosynthesis and transport, steroid biosynthesis and carbohydrate metabolism (Cheng et al., 2017).

P. fluorescens SBW25 was originally isolated from the leaf surface of a sugar beet plant grown at the University farm, Wytham in Oxford, UK. P. fluorescens SBW25 has extensively been used as a model organism to investigate biofilm formation, experimental evolution and adaptation, plant colonization, plant growth promotion and biocontrol. The strain can colonize the roots and leaves of a wide variety of plants and shows biocontrol activity against Rhizoctonia and Pythium (Naseby et al., 2001) and triggers ISR in Arabidopsis thaliana against $P$. syringae pv. tomato (Preston et al., 2003). The strain possesses a rhizosphereinduced type III protein secretion system (Preston et al., 2001). It produces the CLP viscosin which plays a role in swarming motility, biofilm formation and causes lysis of $P$. infestans zoospores (De Bruijn et al., 2007). Another secreted metabolite is L-furanomycin, a non-proteinogenic amino acid with antibacterial activity against several plant pathogens, including Erwinia amylovora, P. syringae and Dickeya dadantii (Trippe et al., 2013).

The endophyte $P$. poae strain RE*1-1-14 was isolated from the internal part of sugar beet roots and is an antagonist of $R$. solani, the causal agent of damping-off and root rot disease of sugar beet. The strain produces the CLP poaeamide, a structurally new member of the Orfamide group. Poaeamide inhibited mycelial growth of $R$. solani and various oomycetes in vitro, and was essential for swarming motility, while a poaemide-deficient mutant colonized the plants at higher densities (Zachow et al., 2015). 
Various strains within the $P$. fluorescens subgroup produce the phenazine PCA. Taxonomically, they are associated with the species $P$. synxantha, $P$. libanensis, $P$. orientalis and $P$. aridus. $P$. aridus is a provisionally named species and has not been formally described (Biessy et al., 2019; Parejko et al., 2013). Most of these strains have been obtained from the rhizosphere of dryland wheat in the USA (Mavrodi et al., 2012a,b). All strains produce a T3SS. These strains do not produce other antibiotics or HCN, but some of them have NRPS gene clusters encoding CLPs that based on predictions belong to the Viscosin or Orfamide group. A well-characterized biocontrol strain that belongs to this subgroup is $P$. fluorescens 2-79. The strain was isolated in 1979 from the roots of wheat plants grown in a take-all suppressive soil in Washington state, USA, and is a strong biocontrol agent suppressing G. graminis var. tritici in vitro and in planta (Nesemann et al., 2015).

\section{Pseudomonas biocontrol strains: Pseudomonas koreensis subgroup}

P. koreensis was first described as a new species by Kwon et al. (2003). The species was obtained from a Korean agricultural soil with low $\mathrm{pH}$ and is able to grow at $4^{\circ} \mathrm{C}$. Mulet et al. (2010) created the P. koreensis subgroup based on partial sequencing of the four housekeeping genes $16 \mathrm{~S} r R N A, g y r B, r p o B$ and $r p o D$. Type strains that belong to this subgroup include $P$. moraviensis, $P$. granadensis, $P$. helmanticensis and P. baetica (Hesse et al., 2018). P. fluorescens Pf0-1, a Gac-deficient model strain of Pseudomonas behavior in soil (Seaton et al., 2013), is also a member of the P. koreensis subgroup.

Many P. koreensis-like organisms are found in tropical regions. Lopes et al. (2018) analyzed the fluorescent Pseudomonas population from a low pH Brazilian soil ( $\mathrm{pH}=5$ ) under sugarcane cultivation. They found that 55 of the 74 isolates belonged to the P. fluorescens group and of these $37(67 \%)$ associated to the $P$. koreensis subgroup. In research on the cocoyam rhizosphere in the disease suppressive soil of Boteva in Cameroon ( $\mathrm{pH}=5.15)$, it was found that $55 \%$ of the Pseudomonas isolates belonged to the P. fluorescens group. Within this group $84 \%$ were members of the $P$. koreensis subgroup (Oni et al., 2020b). Intriguingly, $58 \%$ of these isolates produce CLPs that belong to various families.

A great number of isolates produce the newly described CLP cocoyamide, which contains a peptide tail of 11 amino acids. This CLP appears identical to gacamide, a CLP that was recently described in P.fluorescens PfO-1 complemented for GacA (Jahanshah et al., 2019). Other CLPs produced by these isolates are bananamide, lokisin and rhizoamide (Oni et al., 2020b). Lokisin and rhizoamide belong to the amphisin group of CLPs (Table 2). Pseudomonas spp. COW3 and COW 65 from the cocoyam rhizosphere produces novel variants of bananamide termed bananamide D, E, F and G (Omoboye et al., 2019a). These compounds 
display antagonistic activity against the oomycete pathogen P. myriotylum and inhibit appressoria formation in the blast fungus Pyricularia oryzae. The lokisin producer Pseudomonas sp. COR10 and a crude extract containing lokisin induced systemic resistance to $P$. oryzae in rice (Omoboye et al., 2019b).

CLP production appears to be a very common trait within the $P$. koreensis subgroup (Oni et al., 2020b; Stringlis et al., 2018). Virtually all P. koreensis isolates from the sugarcane rhizosphere in Brazil are predicted to produce CLPs. $P$. granadensis LMG27940, isolated from a soil sample in Granada, Spain produces the CLP MDN-0066, a compound very closely related to bananamides (Cautain et al., 2015). Pseudomonas sp. BW11P2, isolated from the banana rhizoplane in the tropical wetlands of Galgadera, Sri Lanka, produces bananamide A-C (Nguyen et al., 2016). Other putative bananamide producers (predicted by genome mining only) originate from cotton in South Korea and soybean roots in Mississippi, USA (Omoboye et al., 2019a).

P. koreensis 2.74 (CBS 125413) was isolated from the filter skin of a slow filter used in a closed hydroponic system in which tomato was cultivated in Sweden. This strain produces the CLP lokisin and a crude extract of this CLP has a protective effect against $P$. ultimum on tomato (Hultberg et al., 2010a). These authors also showed that P. koreensis 2.74 and the CLP could significantly reduce potato late blight caused by Phytophthora infestans in a detached-leaf assay (Hultberg et al., 2010b).

P. koreensis RU47 obtained from a take-all suppressive soil in the UK, shows biocontrol effects against $R$. solani AG1-1B in lettuce and R. solani AG3 in potato under growth chamber and field conditions (Adesina et al., 2009; Schreiter et al., 2018). The in vitro antagonistic activity of RU47 against $R$. solani AG1-1B is weak, but the strain consistently suppressed the pathogen on lettuce in four independent greenhouse experiments. OtherPseudomonas strains with strong in vitro antagonism were inconsistent in the four experiments (Adesina et al., 2009). This example shows that many interesting Pseudomonas biocontrol strains are missed if initial screening is based on in vitro antagonism. This is especially true for CLP producers, since they usually do not show clear inhibition zones in vitro. Genome mining revealed that RU47 produces HCN, extracellular enzymes and an amphisin-type CLP that is yet to be characterized (Kuzmanović et al., 2018).

\section{Pseudomonas biocontrol strains: Pseudomonas mandelii subgroup and Pseudomonas gessardii subgroup}

\subsection{Pseudomonas mandelii subgroup}

P. mandelii originates from mineral water and was first described by Verhille et al. (1999). Other species that belong to this subgroup include 
P. frederiksbergensis, P. lini, P. migulae, P. proseki and P. arsenicoxydans. These species are typically found in extreme or polluted environments. P. prosekii is a recently described species comprising psychrotolerant strains isolated from James Ross Island close to the Antarctic Peninsula (Kosina et al., 2013; Snopkova et al., 2020). P. migulae strains have been found in mineral water, oil-contaminated rhizosphere of Galega orientalis in Finland (Jussila et al., 2006) and in soil samples in a selenium mining area in southwest China (Li et al., 2015). The type strain of $P$. arsenicoxydans is an arsenite-oxidizing bacterium isolated from sediment samples from the Camarones Valley in the Atacama Desert in Chile (Campos et al., 2010). P. lini has been isolated from the rhizosphere of jujube, a drought-tolerant plant perennial fruit tree that is cultivated in arid and semiarid regions (Zhang et al., 2020a). Tellurite-resistant and tellurite-reducing P. lini strains were found in Antarctica (Arenas et al., 2014).

Biocontrol strains in the mandelii subgroup include Pseudomonas sp. PICF141 obtained from the rhizosphere of olive in a commercial nursery in Cordoba, Spain (Gomez-Lama Cabanas et al., 2018) and Pseudomonas sp. In5 originating from a potato soil in Greenland suppressive to R. solani AG3 (Michelsen et al., 2015b; Michelsen and Stougaard, 2011).

Pseudomonas sp. In5 is closely related to P. frederiksbergensis (Girard et al., 2020a) and produces the CLPs nunamycin and nunapeptin (Michelsen et al., 2015b). P. frederiksbergensis 39A2 and P. frederiksbergensis 38F7, both obtained from Wyoming soil in the USA in 2008 (South et al., 2020) are predicted to also produce the same CLPs (Girard et al., 2020a), reinforcing the close relatedness of these strains. Nunapeptin contains a 22 amino acid peptide similar to corpeptin produced by $P$. corrugata, sclerosin produced by $P$. brassicacearum DF41 and thanapeptin produced by Pseudomonas sp. SH-52. All these strains co-produce a second CLP with 9 amino acid peptide, which is nunamycin in case of Pseudomonas sp. In5. The presence of nunamycin has also been predicted in the two $P$. frederiksbergensis strains. A crude extract which contains both nunamycin and nunapeptin possessed strong antimicrobial activity against the basidiomycete $R$. solani AG3 and the oomycete P. aphanidermatum (Michelsen et al., 2015a). Recently it was shown that fungalassociated molecules, rather than plant signal molecules, positively regulate nunamycin and nunapeptin synthesis in Pseudomonas sp. In5 (Christiansen et al., 2020).

Pseudomonas sp. PICF141 is most closely related to P. lini in the P. mandelii subgroup and shows biocontrol activity against defoliating pathotypes of Verticillium dahlia on 5-month-old olive plants. Gene clusters for the production of $\mathrm{HCN}, 2$,3-butanediol, fusaricidin, amphisin and the insecticidal Fit toxin were detected in the genome of PICF141 (Gomez-Lama Cabanas et al., 2018). Fusaricidin is a potent depsipeptide antibiotic produced by Paenibacillus 
polymyxa. It remains to be proven that these compounds are actually produced by Pseudomonas sp. PICF141.

\subsection{Pseudomonas gessardii subgroup}

The unusual siderophore, thioquinolobactin, was first described by Matthijs et al. (2007) and Mossialos et al. (2000) in P. fluorescens ATCC 17400, a psychrophilic organism isolated from hen's egg (Stanier et al., 1966). This strain shows a strong in vitro antagonism against the oomycete Pythium debaryanum. The antagonism is repressed by iron and lost in a mutant impaired in thioquinolobactin production (Matthijs et al., 2007). More recently, the gene cluster encoding this siderophore was found in Pseudomonas sp. DTU12.1, a strain obtained from leaf-covered soil in Denmark with bioactivity against Xanthomonas campestris and $P$. carotovorum.

Genome mining revealed that the cluster is also present in three other Pseudomonas strains, Pseudomonas sp. O6C 162, P. brenneri BIGb2073 and P. fluorescens PS834 (Sazinas et al., 2019). In Pseudomonas sp. 06C 126, a strain from Lake Erie (central basin), the quinolobactin gene cluster contributes to the growth inhibition of oomycete plant pathogens (Wagner et al., 2018) and P. aeruginosa isolates from cystic fibrosis patients (Chatterjee et al., 2017). Based on rpoD sequencing and ANIb values, all these strains clustered closely together and belong to the same species (Sazinas et al., 2019). They are most related to the type strain of $P$. proteolytica (LMG 22170) in the P. gessardi subgroup (Hesse et al., 2018). The type strain of $P$. proteolytica was isolated from cyanobacterial mat samples from a pond in Antarctica (Reddy et al., 2004).

\section{Pseudomonas biocontrol strains: Pseudomonas putida group}

P. putida is ubiquitous and abundant in temperate soils and waters. Microorganisms belonging to this group are commonly found in polluted soil. P. putida is characterized by its physiological robustness, metabolic versatility and high tolerance to stress (Volke et al., 2020). P. putida isolates can use natural and man-made toxic organic compounds as a source of carbon and energy and have been studied intensively for their role in the biodegradation of environmental pollutants. P. putida is also routinely used as a host in industrial biocatalysis. Readers are referred to the recent review of Kivisaar (2020) for more information about these aspects. The P. putida group includes also clinical isolates. They have been detected in human secretions and tissues in hospitals and $P$. putida infections can be fatal in severely ill or immune-compromised patients (Ogura et al., 2019). 
The $P$. putida group includes a variety of species and is taxonomically and phylogenetically poorly described. Unlike the $P$. fluorescens group, no subgroups have formally been described and the group is clearly in need of taxonomic revision. Yonezuka et al. (2017) subjected 59 clinical and nonclinical strains of the P. putida group to phylogenetic analysis based on ANI analysis. Based on a 95\% threshold, they were classified into 26 species and included nine strain clusters and 17 singletons. A MLSA analysis based on nine housekeeping genes agreed with the ANI analysis. Their results indicate a mixed distribution of clinical and non-clinical isolates suggesting that some limited genes are responsible for pathogenicity.

Many P. putida strains are excellent colonizers of plant roots and promote their growth. Plant growth promotion is due to their ability to secrete phytohormones such as indole acetic acid that promote root elongation. Many isolates can solubilize phosphates and have the ability to induce systemic resistance or stress tolerance in plants. Inhibition of fungal growth is mainly through the production of siderophores. Isolates of the P. putida group do not usually produce the archetypical Pseudomonas biocontrol antibiotics such as phenazines, DAPG, pyoluteorin or pyrrolnitrin. But their genomes contain orphan gene clusters with uncharacterized NPRS or hybrid NRPS/PKS orthologs.

Production of CLPs is a common feature and include WLIP (Oni et al., 2020a, 2019b; Rokni-Zadeh et al., 2013), xantholysin (Li et al., 2013a,b; Oni et al., 2019b), entolysin (Oni et al., 2020b; Vallet-Gely et al., 2010) and putisolvin (Kuiper et al., 2003; Oni et al., 2020b, 2019b). WLIP and entolysin can induce systemic resistance to Pyricularia oryzae in rice (Omoboye et al., $2019 b$ ). Putisolvin-producing P. putida strains were enriched in the cocoyam rhizosphere from soils in Nigeria and Cameroon conducive to the cocoyam root rot disease caused by P. myriotylum (Oni et al., 2020b) and in the rhizosphere of black pepper in Vietnam (Le et al., 2012). They appear to abound in harsh or contaminated environments where CLP diversity is low, but their role in biocontrol is marginal. Xantholysin can inhibit appressoria formation in $P$. oryzae (Omoboye et al., 2019b) and shows strong insecticidal activity against aphids (Lim et al., 2017).

Various $P$. putida biocontrol strains have been reported in the literature, but often their taxonomic position has only been determined by sequencing the $16 \mathrm{~S}$ rDNA which is not reliable in differentiating Pseudomonas groups, subgroups or species. As an example, Pseudomonas CMR12a and CMR5c were initially classified as $P$. putida strains based on their $16 \mathrm{~S}$ rDNA sequence (Perneel et al., 2007), but turned out to belong to the $P$. protegens group based on MLSA and whole-genome sequencing (Biessy et al., 2019; Flury et al., 2016).

The best-characterized strain in the P. putida group is $P$. putida KT2440, a metabolically versatile strain with a remarkable ability to survive in marginal and polluted soil and a workhorse for Pseudomonas research and 
biotechnological applications (Timmis, 2002). The strain is used as a model organism in biodegradation studies. It was the first Pseudomonas strain for which the genome was sequenced in 2002 (Belda et al., 2016; Nelson et al., 2002). P. putida KT2440 is also an efficient colonizer of the spermosphere and rhizosphere of plants (Molina et al., 2000). The strain induces systemic resistance to $P$. syringae pv. tomato in Arabidopsis and an extracellular haemperoxidase was found to be important for both root colonization and induction of ISR (Matilla et al., 2010). P. putida KT2240 has three T6SS gene clusters and 10 potential T6SS effectors. P. putida KT2440 outcompetes various Gram-negative phytopathogenic bacteria including $P$. syringae, $X$. campestris, $P$. carotovorum and $A$. tumefaciens. This destruction appears to be dependent on the K1-T6SS (Bernal et al., 2017).

Another well-studied plant-growth-promoting and biocontrol strain is $P$. putida WCS358, one of the Dutch strains from the 'Willie Commelin Scholten' collection. WCS358 produces a pyoverdine-type siderophore PVD358 that can be used by very few other Pseudomonas strains, while the strain has a large number of pyoverdine receptors. As such it is able to utilize pyoverdines by a wide range of other Pseudomonas strains. WCS358 was originally isolated from the rhizosphere of potato (Geels and Schippers, 1983) and can suppress soilborne plant diseases by siderophore-mediated competition for iron (reviewed by Lemanceau et al. (2009)). WCS358 can induce systemic resistance in Arabidopsis against $P$. syringae pv. tomato and F. oxysporum f. sp. raphani (Van Wees et al., 1997); in bean against Colletotrichum lindemuthianum and $B$. cinerea; and in tomato against B. cinerea. Multiple microbe-associated molecular patterns of WCS358 including PVD358, LPS-containing cell walls and flagella induced resistance in Arabidopsis, while in bean and tomato, flagella were not effective, whereas PVD358 and LPS-containing cell walls did induce resistance (Meziane et al., 2005). The taxonomic position of this strain within the P. putida group has been elucidated (Berendsen et al., 2015) and the species name $P$. capeferrum was proposed because the plant protective effects of this strain are linked to siderophore production.

Recently, a new bioactive metabolite has been discovered in P. donguensis SVBP6, an isolate from an agricultural plot in Argentina with broad-spectrum antifungal activity (Agaras et al., 2018; Muzio et al., 2020). The compound was identified as 7-hydroxytropolone, a compound with a seven-membered nonbenzenoid aromatic ring. The biosynthetic gene cluster was identified by Tn5 mutagenesis and harbors 15 genes encoding metabolic enzyme functions, a putative efflux transport system and transcriptional regulators. Genome mining revealed that 15 strains among all Pseudomonas genomes available at the Pseudomonas Genome Database harbor this gene cluster (Muzio et al., 2020). They are representatives of $P$. donghuensis ( 8 strains), $P$. qingdaonensis ( 7 strains) and $P$. wadenswilerensis (1 strain). These species were recently described 
(Frasson et al., 2017; Gao et al., 2015; Wang et al., 2019), are closely related and belong to the $P$. putida group. The 7-hydroxytropolone genomic region is associated with antibacterial activity against the black leg and soft rot pathogens Dickeya solani and P. carotovorum subsp. brasiliense in P. donghuensis P482 (Krzyzanowska et al., 2016).P. donguensis P482 is a tomato rhizosphere isolate from Poland with antibacterial and antifungal activity (Krzyzanowska et al., 2014, 2012). P. donguensis HYS, the type strain of the newly established donguensis species, was isolated from water of East Lake in Wuhan, China. In this strain 7-hydroxytropolone is used as an iron scavenger (Jiang et al., 2016).

\section{Pseudomonas biocontrol strains: Pseudomonas syringae group and Pseudomonas aeruginosa group}

\subsection{Pseudomonas syringae group}

The P. syringae group is a phylogenetic complex of strains from agricultural and environmental habitats. They are commonly isolated from diseased plants and many organisms that belong to this group are plant pathogens. They can also be found as saprophytes in environments linked to the water cycle such as freshwater, epilithic biofilms, snowpacks, precipitation and wild alpine plants (Morris et al., 2013). The P. syringae group contains 15 validly described species, 62 pathovars defined by pathogenic characters, 9 genomospecies defined by DNA-DNA hybridization (Gardan et al., 1999), and 13 phylogroups defined by MLSA (Berge et al., 2014). Based on a combination of methods (3-gene MLSA, amino acid sequences of 139 monocopy genes and average nucleotide identities based on BLAST (ANIb) calculated for 139 genomes), Gomila et al. (2017) distinguished 19 phylogenomic species distributed within 6 phylogenomic branches within the $P$. syringae group.

A few $P$. syringae biocontrol stains have been described. They probably all belong to Genomospecies 1 as defined by Gardan et al. (1999), phylogroup 2 as described by Berge et al. (2014) or phylogenomic branch I as defined by Gomila et al. (2017). The best-studied P. syringae biocontrol strains are ESC-10 and ESC-11 (also known as strain L-59-66), isolated from apple fruits (Stockwell and Stack, 2007) and leaves (Janisiewicz and Marchi, 1992), respectively. Both strains have been developed in commercial products Bio-Save 10 and BioSave 11 which have been registered in 1995 and are commercially available in the USA (Table 6). The strains are effective biocontrol agents against various postharvest diseases on apple, pear and citrus. Strain ESC-10 produces a hypersensitive response on tobacco and is a weakly virulent pathogen of citrus. Strain ESC-11 is not a pathogen and does not produce a hypersensitive response (Smilanick et al., 1996). Strain ESC-10 is superior for the protection of citrus from green and blue molds, while strain ESC-11 is superior to control postharvest pathogens on apples and pears (Bull et al., 1997). In vitro, both 
strains produce the CLP syringomycin. Purified syringomycin E inhibited $P$. digitatum spore germination at about $5 \mu \mathrm{g} / \mathrm{mL}$ but about $100 \mu \mathrm{g}$ syringomycin $E$ per wound was needed to control green mold on lemon to an extent equal to that provided by the biocontrol strains ESC-10 and ESC-11 (Bull et al., 1998). Strain ESC-10 reduced Rhizopus rot on peach caused by Rhizopus stolonifera to levels comparable with that of dichloran and iprodione (Northover and Zhou, 2002).

The P. syringae strains MA-4 and NSA-6, obtained from the phyllosphere of apple in Canada, also effectively controlled Rhizopus rot on peach. These strains were also effective against brown rot on peach caused by Monilinia fructicola and the activity was significantly improved by adding $0.5 \% \mathrm{CaCl}_{2}$ to the soak solution (Zhou et al., 1999). According to Zhou et al. (1999) MA-4 and NSA-6 can also control apple scab, caused by Venturia inaequalis on apple.

P. syringae pv. syringae $22 \mathrm{~d} / 93$ isolated from the phyllosphere of soybean in Jena, Germany (Völksch et al., 1996), is a strong antagonist of $P$. syringae pv. glycinea, the causal agent of bacterial blight of soybean. Antagonism has been demonstrated in vitro and in planta under greenhouse and field conditions (May et al., 1997; Völksch and May, 2001). The cyclic lipopeptides, syringomycin and syringopeptin, are produced but have no activity against $P$. syringae pv. glycinea (Braun et al., 2010). The rare amino acid 3-methylarginine selectively inhibits P. syringae pv. glycinea in vitro and the toxin probably acts as an inhibitor of the arginine biosynthesis pathway or an arginine-dependent pathway (Braun et al., 2010). Purified 3-methylarginine suppressed the growth of the pathogen in planta. Mutant analysis revealed that none of these compounds is required for antagonistic activity in planta when the pathogen was applied to artificial wounds (Braun et al., 2010). The strain produces two siderophores, pyoverdine and achromobactin, that play an essential role in leaf colonization but are not directly implicated in biocontrol (Wensing et al., 2010).

\subsection{Pseudomonas aeruginosa group}

Pseudomonas aeruginosa is an ubiquitous organism with minimal requirements for survival that is commonly found in water, soil, animal hosts and associated with plants (Botzenhart and Döring, 1993; Hardalo and Edberg, 1997). P. aeruginosa is best known as an opportunistic pathogen of humans. It can cause severe problems in patients hospitalized with cancer, AIDS, cystic fibrosis and severe burns. The bacterium can invade any tissue in which the immune system is compromised (Moradali et al., 2017). P. aeruginosa has also been found in association with various other organisms such as nematodes, insects (MahajanMiklos et al., 2000) and amoebae (Pukatzki et al., 2002). P. aeruginosa has many secondary metabolites in common with biocontrol Pseudomonas strains and produces phenazine antibiotics, $\mathrm{HCN}$, the siderophores pyoverdine and 


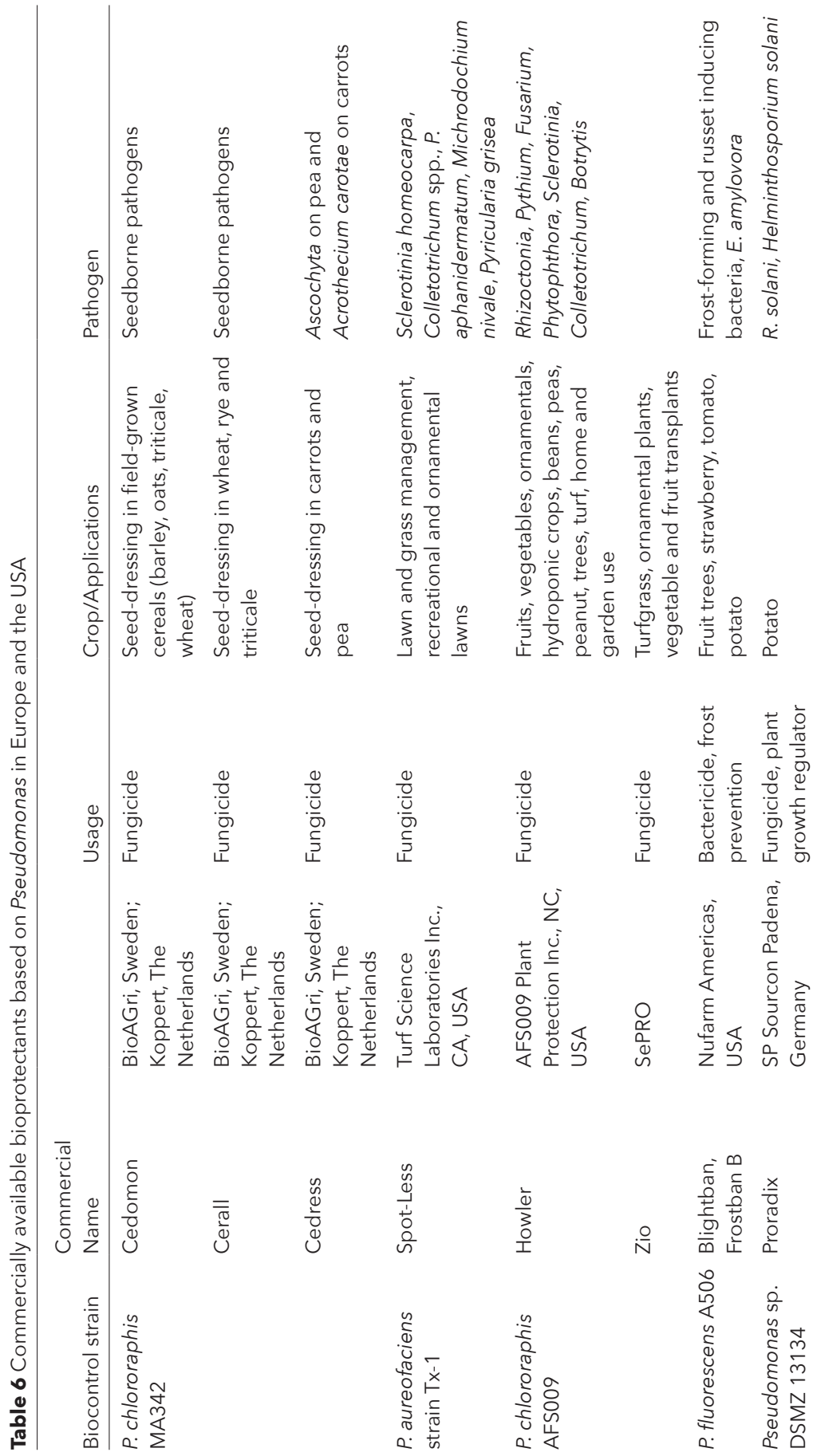




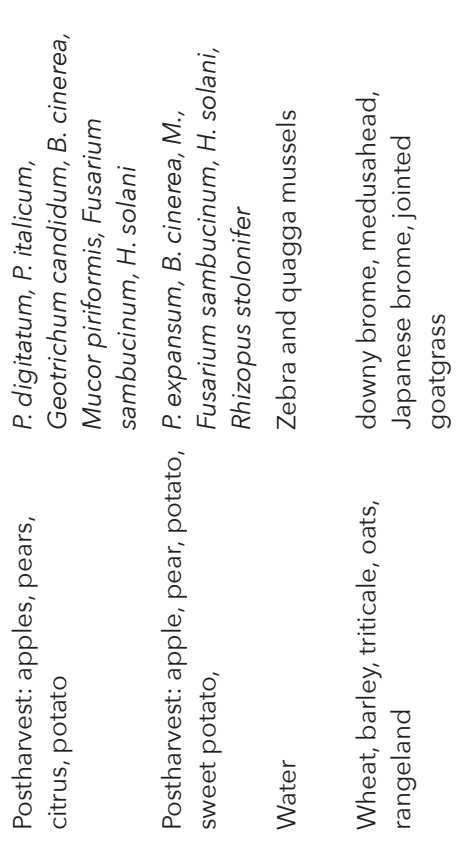

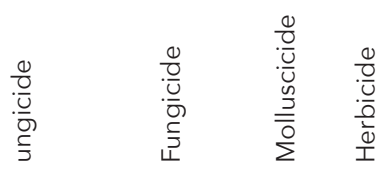

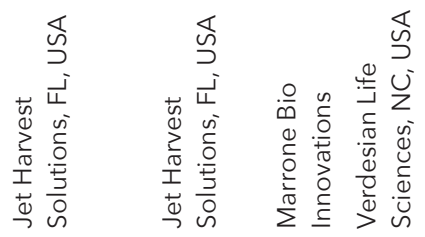

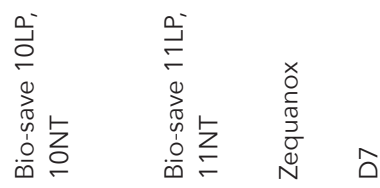

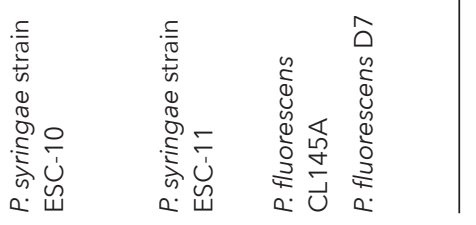


pyochelin, and rhamnolipid-type biosurfactants. Phenazines produced by $P$. aeruginosa are pyocyanin, a blue pigment, but some strains can also produce 1-OH-PHZ, PCA and PCN (Mavrodi et al., 2006). Hence, it is not a surprise that they are able to inhibit a wide range of plant pathogens by the secretion of antimicrobial compounds or by inducing systemic resistance. $P$. aeruginosa is commonly found in the rhizosphere or as an endophyte of plants, especially in tropical regions. Antagonistic plant-associated $P$. aeruginosa strains have, for instance, been isolated from chickpea (Anjaiah et al., 1998), chilli pepper (Paul et al., 2013), black pepper (Kumar et al., 2013), rice (Yasmin et al., 2017), cotton (Yasmin et al., 2014), ginger (Jasim et al., 2014), tomato (Kumar et al., 2009) and cocoyam (Oni et al., 2020b).

Well-studied $P$. aeruginosa biocontrol strains include PNA1, isolated from chickpea roots in India (Anjaiah et al., 1998), 7NSK2, isolated from the rhizosphere of barley in Belgium (Iswandi et al., 1987) and M18 from the rhizosphere of sweet melon in Shanghai, China (Hu et al., 2005).

$P$. aeruginosa 7NSK2 produces pyocanin and the siderophores, pyoverdine and pyochelin. Pyoverdine and pyochelin are involved in suppression of Pythium-damping-off of tomato (Buysens et al., 1996). ISR against B. cinerea in tomato is mediated by pyocyanin and pyochelin (Audenaert et al., 2002), while pyocyanin triggers ISR against $P$. oryzae in rice, but enhances susceptibility to $R$. solani (De Vleesschauwer et al., 2006). P. aeruginosa PNA1 produces rhamnolipids, PCA and PCN. Phenazines contributed to the suppression of Fusarium wilt caused by F. oxysporum f. sp. ciceris in chickpea (Anjaiah et al., 1998) and Fusarium udum in pigeonpea (Anjaiah et al., 2003). Phenazines and rhamnolipids acted synergistically in the control of Pythium splendens on bean and P. myriotylum on cocoyam (Perneel et al., 2008). Ginger is also susceptible to $P$. myriotylum and an endophytic PCA-producing P. aeruginosa isolate obtained from the ginger rhizome gave protection against the pathogen (Jasim et al., 2014).

P. aeruginosa M18 can effectively control Mycosphaerella melonis on sweat melon plants (Wu et al., 2011) and has strong activity against various fungal, oomycete and bacterial pathogens (Xu and Liu, 2013). The strain predominantly produces PCA rather than pyocyanin especially at $28^{\circ} \mathrm{C}$ (Huang et al., 2009). In addition it produces pyoluteorin, an antibiotic that is commonly found in $P$. protegens isolates but not in $P$. aeruginosa (Huang et al., 2004). Interestingly, PCA is negatively regulated and pyoluteorin is positively regulated by the global regular GacA (Ge et al., 2004). Expression and regulation of PCA in this strain has been studied in great detail and a high-yielding engineered strain has been constructed (Du et al., 2013) and the fermentation was optimized using surface response methodology ( $\mathrm{Li}$ et al., 2008). PCA produced by the engineered $P$. aeruginosa M18 strain has been developed in a biopesticide called Shenqinmeisu that was approved in China in 2011 for the control of 
various fungal and microbial diseases of fruits, vegetables, rice, wheat, potatoes and other crops (Xu and Liu, 2013).

\section{Commercial Pseudomonas-based bioprotectants}

Despite the overwhelming literature on Pseudomonas biocontrol, few Pseudomonas-based products are commercialized as bioprotectants (Table 6). In Europe, only P. chlororaphis MA342 and Pseudomonas sp. DSMZ 13134 are registered and sold in various European countries under the commercial names Cedomon, Cerall, Cedress and Proradix.

P. chlororaphis MA342 was isolated from roots of wild crowberry (Empetrum nigrum L.) in Sweden (Hökeberg et al., 1997) and included in the EU list of approved active substances in 2004. It is used as a seed treatment on cereals (wheat, rye, triticale), carrot and pea to protect against seedborne pathogens and against foliar and ear pathogens in cereals (EFSA, 2017; Johnsson et al., 1998). It is a good spermosphere, but poor rhizosphere and phyllosphere colonizer. The strain is known to produce 2,3-deepoxy-2,3-didehydro-rhizoxin (DDR). Cerall is a ready-to-use water-based formulation for seed treatment. Cedomon is an oil-based formulation used in barley and oat. Cedress is a flowable suspension for seed treatment of carrots and peas.

It should be noted that the taxonomic identification of MA342 as P. chlororaphis is questionable. The strain has not properly been identified and based on 16S rRNA sequence analysis, the strain most probably does not belong to the species $P$. chlororaphis. The production of the metabolite DDR has become an issue for the renewal of the approval of $P$. chlororaphis MA342 as an active substance because of potential genotoxic effects (HernandezJerez et al., 2020).

Field trials in Sweden (Johnsson et al., 1998), Finland (Lötjönen and Torniainen, 2005) and Lithuania (Liatukas et al., 2019) have revealed that $P$. chlororaphis MA 342 can effectively control seedborne cereal pathogens that are present on the seed or near the seed coat such as Pyrenophora spp., but does not control seedborne pathogens like the loose smut Ustilago nuda that are located in the seed embryo. There is no effect either against soilborne diseases or leaf diseases. Average yield increases in spring barley range between $2 \%$ and $5 \%$, but there are strong differences between cultivars. In field trials in Lithuania, seeds of the cultivar 'Alisa DS' were effectively sanitized by the use of Cedomon, leading to yield increases of 5-15\%, while this was not observed on the cultivar 'Luoke' (Liatukas et al., 2019). Field experiments in Finland have revealed that Cedomon could control net blotch (Pyrenophora tera) in barley nearly as well as chemical products and increased yield with 200 $300 \mathrm{~kg}$. Barley life stripe (Pyrenophora graminae) was decreased with 40-80\%. There was no effect against loose smut (Ustilago nuda) of barley or Fusarium. 
Seed dressing treatments with Cedomon did not increase the yield of oat compared to untreated controls (Lötjönen and Torniainen, 2005).

Pseudomonas sp. DSMZ 13134 was isolated from the roots of lettuce (EFSA, 2012) in a search for biocontrol agents against $P$. ultimum. The taxonomic position of this strain is uncertain and it is not clear which metabolites it can produce. Its modes of action include competition for space, induced systemic resistance and stimulation of root growth. The strain was included in the EU list of approved active substances in 2013 (EU, 2013). The Proradix product is a wettable powder that is approved for tuber treatment of potato prior to planting against black scurf ( $R$. solani) and silver scurf (Helminthosporium solani). The product controls black scurf on potato with an efficacy of 28-40\% and silver scurf with an average efficacy of 46\% (Moszczynska et al., 2015; CTGB, 2014). In field trials with barley in Germany seed inoculation with Proradix increased yields with 4-19\% (Fröhlich et al., 2012).

P. chlororaphis-based products commercially sold in the USA are Spot-Less, Howler and Zio. Howler and Zio are biofungicides containing P. chlororaphis strain AFS009 (PC code 006800, registered 2017) to control various oomycete and fungal pathogens on many different crops (EPA, 2017a,b). AgBiome selected the strain after screening a library of more than 60000 microorganisms. Both products are wettable powders that should be mixed with water and can be applied as a foliar spray, soil drench, in furrow spray, transplant spray or dip, cuttings or bare root dip, or in hydroponic or chemigation application. The products can also be mixed with potting mix or applied dry in furrow. Zio is marketed to the turf and ornamental sector by SePRO. Howler is marketed for use on specialty crops. According to AgBiome, modes of action of $P$. chlororaphis strain AFS009 include production of antibiotics and cell wall degrading enzymes, competition and induced resistance, but further details could not be found.

Spot-less is based on P. chlororaphis subsp. aureofaciens Tx-1 (PC code 006473, registered 1999) (Hardebeck et al., 2004; Powell et al., 2000) and is registered for use in turf grass against dollar spot (Sclerotinia homoeocarpa), anthracnose (Colletotrichum spp.), Pythium, pink snow mold (Microdochium nivale) and grey leaf spot (Pyricularia grisea) (EPA, 2006). The product is a fermented culture of $P$. aureofaciens Tx-1 following 12-14 h of culture in the BioJect ${ }^{\circledR}$ Fermentation and Injection System. The culture is diluted with water and injected into a sprinkler irrigation system. The strain is known to produce PCA. In field trials it was shown that PCA provided significantly better management of dollar spot on creeping bentgrass than untreated plots. Results were comparable to management provided by chlorothalonil (Powell et al., 2000). Field studies carried out at West Lafayette, Indiana in 1998 and 1999 revealed that Tx-1 marginally controls dollar spot, only when disease pressure is low. In combination with fungicides and under low disease pressure, Tx-1 
could increase the dollar spot control of fungicides by $37 \%$ and increased the duration of control by 2.6 days (Hardebeck et al., 2004). Repeated inoculation with TX-1 resulted in the establishment of the strain in the rhizosphere of turfgrass with a minimal impact on the indigenous bacterial community. The strain also was capable of overwintering. Low activity of TX-1 in the field may be explained by limited PCA production in situ (Sigler et al., 2001).

$P$. syringae-derived products sold in the USA are the Bio-Save products based on P. syringae ESC-10 (PC code 006441, registered 1994) and ESC-11 (PC code 006451, registered 1996) that are used for the control of postharvest pathogens on fruits, potato and sweet potato that have been discussed above. The active ingredients were registered in 1990 and 1996, respectively. Their history has extensively been reviewed by Stockwell and Stack (2007). ESC10 reduces green and blue mold on lemon with $80-99 \%$ effectiveness and on orange with 40-59\% effectiveness. ECS-11 gives excellent control of blue mold and grey mold on apple and pear, but host-specific effects are observed for control of postharvest diseases on pear. Both products can be used in combination with fungicides and are very useful to control fungicide-resistant pathogen populations. Their use in the USA is widely adopted (Stockwell and Stack, 2007).

P. fluorescens A506 (PC code 006438, registered 1992) is the active ingredient in Frostban B (Blightban) (EPA, 2017c). The product is used to suppress frost damage on various crops and to suppress fire blight caused by $E$. amylovora. The primary mechanism in fire blight control is competitive exclusion. The commercial product is composed of lyophilized cells of the bacterium that need to be diluted in water. A506 is reviewed by Stockwell and Stack (2007). In non-inoculated orchards in California, P. fluorescens A506 could reduce the incidence of fire blight by $50-80 \%$, fruit russet by $30-50 \%$ and frost injury by 40-50\% (Lindow et al., 1996; Lindow and Suslow, 2003). The strain did not provide significant control in inoculated experimental orchards in Oregon (Stockwell et al., 2010).

Other Pseudomonas strains have been registered in the USA ( $P$. syringae 724RS, P. fluorescens 1629RS, P. chlororaphis 63-28) but they are not, or no longer, commercially available. Anderson and Kim (2018) list various bioprotectants based on $P$. chlororaphis $\mathrm{O} 6$ that are registered by HyunNong Inc. in South Korea. These include NematoKill against root-knot nematodes, ItaEpi against aphids and three products that are used as microbial fertilizer. However, additional information about these products could not be found.

Bioprotectants or biofertilizers based on various strains of $P$. chlororaphis are commercially available in Russia and listed by Maksimov et al. (2011) with the trade names Pseudobacterin-2, Agat-25K, Helen and Binoram. AGAT-25 is used to control roots rots, mildew, septoriose, brown rust, ear fusariosis, cercosporiosis and pseudoperonosporosis, while Pseudobacterin-2 is used to 
control root rots (Kabaluk et al., 2010). The active ingredient in Pseudobacterin-2 is $P$. aureofaciens BS1393, a strain obtained from the rhizosphere of barley. Trials in cereals, vegetables and oilseed crops have indicated that Pseudobacterin-2 can reduce disease severity by $65-88 \%$, resulting in a $20-25 \%$ yield increase (Thomashow, 2013).

Various Pseudomonas-based bioprotectants are registered for commercial use in India. They are all called P. fluorescens and have different formulations and accession numbers. A strain with accession number MTCC 5176 is registered to control loose smut on wheat. Strain IPL/PS-01 (accession number MTCC 5727) is available in different formulations to control bacterial leaf blight on rice, and soilborne diseases on tomato. Strain IIHR-PF-2 (accession number ITCCB0034) is approved to control root rot and wilt diseases on to mato, brinjal, carrot and okra. A strain with accession number MTCC 2539 is approved for late leaf spot control on groundnut. Strain TNAU (accession number ITCC BE 0005 ) is used on groundnut, rice, chili seedlings, tomato and cotton. Strain BIL331 (accession number MTCC 5866) is approved to control various diseases on rice (Government of India, 2020). The taxonomic status, origin and mode of action of these strains are unclear.

Table 6 lists two other applications of Pseudomonas biocontrol. P. fluorescens D7 (PC code 16418, registered 2014) is the active ingredient in D7, a product approved in 2014 for use as a herbicide in cereals. D7 is a freezedried powder that is dissolved in water and applied as a spray solution to the soil surface. It is used for preemergence applications. Zequanox contains killed cells of $P$. fluorescens CL145A and is registered for control of quagga and zebra mussels in limited open-water environments and in cooling and service water systems for industrial facilities. It was shown that dead P. fluorescens CL145A cells achieved the same percentage mussel mortality as live cells and that the mode of action is intoxication (Molloy et al., 2013).

It is not entirely clear why so few Pseudomonas strains are commercialized. Possible bottlenecks are inconsistency in field performance, genetic instability, poor shelf life in comparison with spore-forming biocontrol agents, and costs and difficulty of registration (Berg, 2009; Mark et al., 2006; Tabassum et al., 2017). A lot of progress has been made in recent years in the formulation of non-sporulating bacteria (Berninger et al., 2018) and poor shelf life should probably no longer be a major issue. Inconsistency in field performance is, however, a key problem. Good performance in specific trials is often not translated in consistent and effective control in diverse field situations. This can be due to external factors such as soil or climatic conditions, but is also driven by intrinsic traits of the biocontrol agent, such as variable production of secondary metabolites or poor host colonization (Mark et al., 2006). Host-specific responses to bioprotectants are observed, which could in part be driven by quantitative and qualitative differences in plant exudates. 
Microbiome studies have revealed that plant species, cultivars and soil type are key drivers of rhizosphere microbiome composition and functioning. A series of elegant studies by the Raaijmakers' group using bean as a model have shown that plant domestication and resistance breeding caused changes in root architecture and altered root exudates. This in turn changed rhizosphere microbiome composition and functioning (Mendes et al., 2019, 2017; Mendes and Mendes, 2018; Pérez- Jaramillo et al., 2016). Specific root exudates may be needed to stimulate Pseudomonas colonization and the in situ production of bio-active molecules. The regulation of secondary metabolites in Pseudomonas spp. is complex and may require specific nutrients and environmental stimuli or the presence of other microorganisms as was recently shown for Pseudomonas sp. In5 (Christiansen et al., 2020). A second major hurdle in the commercialization of microbial biopesticides is the slow, difficult and costly registration process, especially in Europe. These aspects have recently been reviewed (Frederiks and Wesseler, 2018; Scheepmaker et al., 2019).

\section{Conclusion}

Recently an ever-increasing number of high-quality Pseudomonas wholegenome sequences has become available, and insights in the taxonomy of Pseudomonas have greatly advanced. Genome mining and the division of the vastly heterogeneous genus Pseudomonas in phylogenomic groups and subgroups have clarified the relationship between phenotypic characteristics and phylogeny. Well-known Pseudomonas biocontrol strains that have been studied for many years can now be positioned in their correct phylogenetic (sub)group.

Based on their activity, three types of Pseudomonas biocontrol strains can be distinguished. The first type comprises the CPC (chlororaphis, protegens, corrugata subgroups) cluster defined by Vacheron et al. (2016) and $P$. aeruginosa. CPC isolates produce an arsenal of secondary metabolites, including antibiotics with antagonistic properties such as pyrrolnitrin, DAPG, phenazines and HCN. They have broad-spectrum activity against soilborne pathogens and many strains can induce systemic resistance to foliar pathogens. This cluster has received considerable attention in the past.

CPC strains are readily picked up in in vitro screens for biocontrol strains because of their clear antagonism on plate and broad-spectrum antimicrobial activity. However, several disadvantages come with the production of multiple bioactive compounds, as evidenced in the $P$. protegens group. $P$. protegens strains are prone to gac mutations, some of their metabolites are phytotoxic, and they are outcompeted by other bacteria in the rhizosphere of field-grown plants. This may explain why they have not been commercialized. 
P. chlororaphis strains are genetically more stable (Yan et al., 2018), and most strains do not produce potential phytotoxic compounds. They are preferred by biopesticide companies. It is striking that a $P$. chlororaphis strain was selected in the 60000 strain-screen by Agbiome. To my knowledge, there are no commercial biopesticides containing Pseudomonas strains from the $P$. corrugata group although Salavida, a product from Sourcon Padena, based on P. brassicacearum 3Re-27, is commercialized as a biostimulant in Germany (Berg, 2009). P. aeruginosa strains with biocontrol properties also belong to this division. Their spectrum of metabolites is rather similar to $P$. chlororaphis subgroup isolates. The fact that they are opportunistic human pathogens precludes their commercialization, but they are a source of bioactive compounds such as phenazines and rhamnolipids.

A second type is found in the $P$. putida group and the $P$. fluorescens, $P$. koreensis, $P$. mandelii and $P$. gessardii subgroups in the $P$. fluorescens group. Vacheron et al. (2016) has termed P. fluorescens, P. koreensis, P. mandelii and $P$. jessenii the FMJK cluster. It was found that FMJK and P. putida are predominantly present in the maize rhizosphere and have fewer biocontrol traits, but more phytostimulatory properties than CPC strains (Vacheron et al., 2016). These (sub)groups harbor many plant growth-promoting Pseudomonas strains. An example is P. jessenii UW4, an ACC deaminase-producing strain that promotes plant growth in the presence of different environmental stresses, such as flooding, heavy metals, cold, high concentrations of salt and the phytopathogenic bacterium Agrobacterium (Duan et al., 2013).

Biocontrol strains from the second type do not produce the archetypical Pseudomonas antibiotics. Their biocontrol capacities predominantly depend on siderophores or a diverse arsenal of CLPs. CLPs have interesting antimicrobial and resistance-inducing properties. It has been hypothesized that their large diversity is driven by microbial competition in the rhizosphere (Oni et al., 2020a). An enrichment in CLP production is also seen in a subset of isolates closely related to the plant pathogenic $P$. corrugata and $P$. mediterranea in the $P$. corrugata subgroup. Other traits remain to be investigated such as the targets and roles of the effector proteins secreted by the T3SS and T6SS machinery and the function of strain-specific orphan gene clusters. This second type has significant potential because these strains are often competitive root colonizers and adapted to harsh conditions. The fact that they usually do not produce antibiotics will also facilitate the registration process in case of commercialization.

The third type encompasses biocontrol strains adapted to above-ground plant parts. They predominantly belong to the $P$. syringae group and have antagonistic activities against aerial pathogens. P. fluorescens A506 also belongs to this type. Their main mode of action is probably competition. Commercial biofungicides based on P. syringae and P. fluorescens A506 
are already on the market for 30 years to control postharvest and bacterial pathogens.

Despite the overwhelming literature on Pseudomonas biocontrol, only few Pseudomonas strains are commercialized. This is mainly due to inconsistent field performance, which can be explained by poor adaptation to environmental conditions, suboptimal formulation, and host-specific responses to microorganisms. In addition, the expensive, tedious and time-consuming registration procedure, especially in Europe, hampers the introduction of new microbial bioprotectants.

\section{Where to look for further information}

\subsection{Pseudomonas biocontrol}

Haas and Défago, 2005; Mercado-Blanco, 2015; Olorunleke et al., 2015b; Müller and Behrendt, 2021

\subsection{Pseudomonas taxonomy}

Garrido-Sanz et al., 2017; Girard et al., 2020b; Gomila et al., 2015; Hesse et al., 2018; Lalucat et al., 2020; Mulet et al., 2010

\subsection{Secondary metabolites in Pseudomonas}

Gross and Loper, 2009

\subsection{Phenazines}

Biessy and Filion, 2018; Mavrodi et al., 2013, 2006; Chincholkar and Thomashow, 2013

\subsection{Lipopeptides}

Geudens and Martins, 2018; Götze and Stallforth, 2020; Raaijmakers et al., 2010

\subsection{Whole genomes of Pseudomonas}

Pseudomonas genome DB https://www.pseudomonas.com/

\subsection{Whole genome comparisons of Pseudomonas biocontrol strains}

Biessy et al., 2019; Garrido-Sanz et al., 2016; Loper et al., 2012 


\subsection{Formulation}

Berninger et al., 2018

\section{Acknowledgements}

Pseudomonas biocontrol and cyclic lipopeptide research in the laboratory of $\mathrm{M}$. Höfte is supported by grants from the INTERREG France-WallonieVlaanderen Program SmartBiocontrol, Fonds Wetenschappelijk Onderzoek Vlaanderen (FWO) under Excellence of Science grant RhizoCLiP (EOS Project No. 30650620) and the Concerted Research Action MEMCLiP supported by the Special Research Fund of Ghent University (GOA-028-19).

\section{References}

Achouak, W., Sutra, L., Heulin, T., Meyer, J. M., Fromin, N., Degraeve, S., Christen, R. and Gardan, L. 2000. Pseudomonas brassicacearum sp. nov. and Pseudomonas thivervalensis sp. nov., two root-associated bacteria isolated from Brassica napus and Arabidopsis thaliana. Int. J. Syst. Evol. Microbiol. 50(1), 9-18. https://doi.org/10 .1099/00207713-50-1-9.

Adesina, M. F., Grosch, R., Lembke, A., Vatchev, T. D. and Smalla, K. 2009. In vitro antagonists of Rhizoctonia solani tested on lettuce: rhizosphere competence, biocontrol efficiency and rhizosphere microbial community response. FEMS Microbiol. Ecol. 69(1), 62-74. https://doi.org/10.1111/j.1574-6941.2009.00685.x.

Agaras, B. C., Iriarte, A. and Valverde, C. F. 2018. Genomic insights into the broad antifungal activity, plant-probiotic properties, and their regulation, in Pseudomonas donghuensis strain SVBP6. PLoS ONE 13(3), e0194088. https://doi.org/10.1371/ journal.pone.0194088.

Almario, J., Bruto, M., Vacheron, J., Prigent-Combaret, C., Moënne-Loccoz, Y. and Muller, D. 2017. Distribution of 2,4-diacetylphloroglucinol biosynthetic genes among the Pseudomonas spp. reveals unexpected polyphyletism. Front. Microbiol. 8, 1218. https://doi.org/10.3389/fmicb.2017.01218.

Anderson, A. J. and Kim, Y. C. 2020. Insights into plant-beneficial traits of probiotic Pseudomonas chlororaphis isolates. J. Med. Microbiol. 69(3), 361-371. https://doi .org/10.1099/jmm.0.001157.

Anderson, A. J. and Kim, Y. C. 2018. Biopesticides produced by plant-probiotic Pseudomonas chlororaphis isolates. Crop Prot. 105, 62-69. https://doi.org/10.1016 /j.cropro.2017.11.009.

Anjaiah, V., Cornelis, P. and Koedam, N. 2003. Effect of genotype and root colonization in biological control of fusarium wilts in pigeonpea and chickpea by Pseudomonas aeruginosa PNA1. Can. J. Microbiol. 49(2), 85-91. https://doi.org/10.1139/w03-011.

Anjaiah, V., Koedam, N., Nowak-Thompson, B., Loper, J. E., Höfte, M., Tambong, J. T. and Cornelis, P. 1998. Involvement of phenazines and anthranilate in the antagonism of Pseudomonas aeruginosa PNA1 and Tn5 derivatives toward Fusarium spp. and Pythium spp. Mol. Plant Microbe Interact. 11(9), 847-854. https://doi.org/10.1094/ MPMI.1998.11.9.847. 
Arenas, F. A., Pugin, B., Henriquez, N. A., Arenas-Salinas, M. A., Dias-Vasquez, W. A., Pozo, M., Munoz, C. M., Chasteen, T. G., Perez-Donoso, J. M. and Vasquez, C. C. 2014. Isolation, identification and characterization of highly tellurite-resistant, telluritereducing bacteria from Antarctica. Polar Sci. 8, 40-52. https://doi.org/10.1016/j.pola r.2014.01.001.

Arrebola, E., Tienda, S., Vida, C., De Vicente, A. and Cazorla, F. M. 2019. Fitness features involved in the biocontrol interaction of Pseudomonas chlororaphis with host plants: the case study of PCPCL1606. Front. Microbiol. 10, 719. https://doi.org/10.3389/ fmicb.2019.00719.

Audenaert, K., Pattery, T., Cornelis, P. and Höfte, M. 2002. Induction of systemic resistance to Botrytis cinerea in tomato by Pseudomonas aeruginosa 7NSK2: role of salicylic acid, pyochelin, and pyocyanin. Mol. Plant Microbe Interact. 15(11), 1147-1156.

Bakker, P. A. H. M., Pieterse, C. M. J. and Loon, L. C. Van 2007. Induced systemic resistance by fluorescent Pseudomonas spp. Phytopathology 97(2), 239-243.

Barahona, E., Navazo, A., Martínez-Granero, F., Zea-Bonilla, T., Pérez-Jiménez, R. M., Martín, M. and Rivilla, R. 2011. Pseudomonas fluorescens F113 mutant with enhanced competitive colonization ability and improved biocontrol activity against fungal root pathogens. Appl. Environ. Microbiol. 77(15), 5412-5419. https://doi.org/10.1128/ AEM.00320-11.

Bardas, G. A., Lagopodi, A. L., Kadoglidou, K. and Tzavella-Klonari, K. 2009. Biological control of three Colletotrichum lindemuthianum races using Pseudomonas chlororaphis PCL1391 and Pseudomonas fluorescens WCS365. Biol. Control 49(2), 139-145. https://doi.org/10.1016/j.biocontrol.2009.01.012.

Barret, M., Egan, F., Moynihan, J., Morrissey, J. P., Lesouhaitier, O. and O'Gara, F. 2013. Characterization of the SPI-1 and Rsp type three secretion systems in Pseudomonas fluorescens F113. Environ. Microbiol. Rep. 5(3), 377-386. https://doi.org/10.1111 /1758-2229.12039.

Battistuzzi, F. U. and Hedges, S. B. 2009. A major clade of prokaryotes with ancient adaptations to life on land. Mol. Biol. Evol. 26(2), 335-343. https://doi.org/10.1093/ molbev/msn247.

Belda, E., van Heck, R. G. A., José Lopez-Sanchez, M., Cruveiller, S., Barbe, V., Fraser, C., Klenk, H. P., Petersen, J., Morgat, A., Nikel, P. I., Vallenet, D., Rouy, Z., Sekowska, A., Martins dos Santos, V. A. P., de Lorenzo, V., Danchin, A. and Médigue, C. 2016. The revisited genome of Pseudomonas putida KT2440 enlightens its value as a robust metabolic chassis. Environ. Microbiol. 18(10), 3403-3424. https://doi.org/10.1111 /1462-2920.13230.

Berendsen, R. L., van Verk, M. C., Stringlis, I. A., Zamioudis, C., Tommassen, J., Pieterse, C. M. J. and Bakker, P. A. H. M. 2015. Unearthing the genomes of plant-beneficial Pseudomonas model strains WCS358, WCS374 and WCS417. BMC Genomics 16, 539. https://doi.org/10.1186/s12864-015-1632-z.

Berg, G. 2009. Plant-microbe interactions promoting plant growth and health: perspectives for controlled use of microorganisms in agriculture. Appl. Microbiol. Biotechnol. 84(1), 11-18. https://doi.org/10.1007/s00253-009-2092-7.

Berge, O., Monteil, C. L., Bartoli, C., Chandeysson, C., Guilbaud, C., Sands, D. C. and Morris, C. E. 2014. A user's guide to a data base of the diversity of Pseudomonas syringae and its application to classifying strains in this phylogenetic complex. PLoS ONE 9(9), e105547. https://doi.org/10.1371/journal.pone.0105547. 
Bernal, P., Allsopp, L. P., Filloux, A. and Llamas, M. A. 2017. The Pseudomonas putida T6SS is a plant warden against phytopathogens. ISME J. 11(4), 972-987. https://doi.org /10.1038/ismej.2016.169.

Bernal, P., Llamas, M. A. and Filloux, A. 2018. Type VI secretion systems in plantassociated bacteria. Environ. Microbiol. 20(1), 1-15. https://doi.org/10.1111/1462 $-2920.13956$.

Berninger, T., González López, Ó, Bejarano, A., Preininger, C. and Sessitsch, A. 2018. Maintenance and assessment of cell viability in formulation of non-sporulating bacterial inoculants. Microb. Biotechnol. 11(2), 277-301. https://doi.org/10.1111 /1751-7915.12880.

Berry, C., Fernando, W. G. D., Loewen, P. C. and de Kievit, T. R. 2010. Lipopeptides are essential for Pseudomonas sp DF41 biocontrol of Sclerotinia sclerotiorum. Biol. Control 55(3), 211-218. https://doi.org/10.1016/j.biocontrol.2010.09.011.

Berry, C. L., Brassinga, A. K. C., Donald, L. J., Fernando, W. G. D., Loewen, P. C. and de Kievit, T. R. 2012. Chemical and biological characterization of sclerosin, an antifungal lipopeptide. Can. J. Microbiol. 58(8), 1027-1034. https://doi.org/10.1139/w2012 $-079$.

Biessy, A. and Filion, M. 2018. Phenazines in plant-beneficial Pseudomonas spp.: biosynthesis, regulation, function and genomics. Environ. Microbiol. 20(11), 39053917. https://doi.org/10.1111/1462-2920.14395.

Biessy, A., Novinscak, A., Blom, J., Léger, G., Thomashow, L. S., Cazorla, F. M., Josic, D. and Filion, M. 2019. Diversity of phytobeneficial traits revealed by whole-genome analysis of worldwide-isolated phenazine-producing Pseudomonas spp. Environ. Microbiol. 21(1), 437-455. https://doi.org/10.1111/1462-2920.14476.

Blumer, C. and Haas, D. 2000a. Mechanism, regulation, and ecological role of bacterial cyanide biosynthesis. Arch. Microbiol. 173(3), 170-177. https://doi.org/10.1007/ s002039900127.

Blumer, C. and Haas, D. 2000b. Iron regulation of the hcnABC genes encoding hydrogen cyanide synthase depends on the anaerobic regulator ANR rather than on the global activator GacA in Pseudomonas fluorescens CHA0. Microbiology (Reading) 146(10), 2417-2424. https://doi.org/10.1099/00221287-146-10-2417.

Botzenhart, K. and Döring, G. 1993. Ecology and epidemiology of Pseudomonas aeruginosa. In: Campa, M. (Ed), Pseudomonas Aeruginosa as an Opportunistic Pathogen. Plenum Press, New York, pp. 1-18. https://doi.org/10.1007/978-1-46153036-7_1.

Braun, S. D., Hofmann, J., Wensing, A., Weingart, H., Ullrich, M. S., Spiteller, D. and Völksch, B. 2010. In vitro antibiosis by Pseudomonas syringae Pss22d, acting against the bacterial blight pathogen of soybean plants, does not influence in planta biocontrol. J. Phytopathol. 158(4), 288-295. https://doi.org/10.1111/j.1439-0434.2009.01612.x.

Brazelton, J. N., Pfeufer, E. E., Sweat, T. A., Gardener, B. B. M. and Coenen, C. 2008. 2,4-Diacetylphloroglucinol alters plant root development. Mol. Plant Microbe Interact. 21(10), 1349-1358. https://doi.org/10.1094/MPMI-21-10-1349.

Brendel, N., Partida-Martinez, L. P., Scherlach, K. and Hertweck, C. 2007. A cryptic PKSNRPS gene locus in the plant commensal Pseudomonas fluorescens Pf-5 codes for the biosynthesis of an antimitotic rhizoxin complex. Org. Biomol. Chem. 5(14), 2211 2213. https://doi.org/10.1039/b707762a.

Bull, C. T., Duffy, B., Voisard, C., Défago, G., Keel, C. and Haas, D. 2001. Characterization of spontaneous gacS and gacA regulatory mutants of Pseudomonas fluorescens 
biocontrol strain C H A0. Antonie van Leeuwenhoek. Int. J. Gen. Mol. Microbiol. 79, 327-336. https://doi.org/10.1023/A:1012061014717.

Bull, C. T., Stack, J. P. and Smilanick, J. L. 1997. Pseudomonas syringae strains ESC-10 and ESC-11 survive in wounds on citrus and control green and blue molds of citrus. Biol. Control 8(1), 81-88. https://doi.org/10.1006/bcon.1996.0476.

Bull, C. T., Wadsworth, M. L., Sorensen, K. N., Takemoto, J. Y., Austin, R. K. and Smilanick, J. L. 1998. Syringomycin E produced by biological control agents controls green mold on lemons. Biol. Control 12(2), 89-95. https://doi.org/10.1006/bcon.1998 .0622 .

Burr, S. E., Gobeli, S., Kuhnert, P., Goldschmidt-Clermont, E. and Frey, J. 2010. Pseudomonas chlororaphis subsp. piscium subsp. nov., isolated from freshwater fish. Int. J. Syst. Evol. Microbiol. 60(12), 2753-2757. https://doi.org/10.1099/ijs.0.011692-0.

Buysens, S., Heungens, K., Poppe, J. and Hofte, M. 1996. Involvement of pyochelin and pyoverdin in suppression of Pythium-induced damping-off of tomato by Pseudomonas aeruginosa 7NSK2. Appl. Environ. Microbiol. 62(3), 865-871.

Calderón, C. E., Pérez-García, A., De Vicente, A. and Cazorla, F. M. 2013. The dar genes of Pseudomonas chlororaphis PCL1606 are crucial for biocontrol activity via production of the antifungal compound 2-hexyl, 5-propyl resorcinol. Mol. Plant Microbe Interact. 26(5), 554-565. https://doi.org/10.1094/MPMI-01-13-0012-R.

Calderón, C. E., Ramos, C., De Vicente, A. and Cazorla, F. M. 2015. Comparative genomic analysis of Pseudomonas chlororaphis PCL1606 reveals new insight into antifungal compounds involved in biocontrol. Mol. Plant Microbe Interact. 28(3), 249-260. https ://doi.org/10.1094/MPMI-10-14-0326-FI.

Calderón, C. E., Tienda, S., Heredia-Ponce, Z., Arrebola, E., Cárcamo-Oyarce, G., Eberl, L. and Cazorla, F. M. 2019. The compound 2-hexyl, 5-propyl resorcinol has a key role in biofilm formation by the biocontrol rhizobacterium Pseudomonas chlororaphis PCL1606. Front. Microbiol. 10, 396. https://doi.org/10.3389/fmicb.2019.00396.

Campos, V. L., Valenzuela, C., Yarza, P., Kämpfer, P., Vidal, R., Zaror, C., Mondaca, M. A., Lopez-Lopez, A. and Rosselló-Móra, R. 2010. Pseudomonas arsenicoxydans sp nov., an arsenite-oxidizing strain isolated from the Atacama Desert. Syst. Appl. Microbiol. 33(4), 193-197. https://doi.org/10.1016/j.syapm.2010.02.007.

Catara, V. 2007. Pseudomonas corrugata: plant pathogen and/or biological resource?: pathogen. Mol. Plant Pathol. 8(3), 233-244. https://doi.org/10.1111/j.1364-3703 .2007.00391.x.

Cautain, B., De Pedro, N., Schulz, C., Pascual, J., Sousa, T. D. S., Martin, J., Pérez-Victoria, I., Asensio, F., González, I., Bills, G. F., Reyes, F., Genilloud, O. and Vicente, F. 2015. Identification of the lipodepsipeptide MDN-0066, a novel inhibitor of VHL/HIF pathway produced by a new Pseudomonas species. PLoS ONE 10, 1-17. https://doi .org/10.1371/journal.pone.0125221.

Cazorla, F. M., Duckett, S. B., Bergström, E. T., Noreen, S., Odijk, R., Lugtenberg, B. J. J., Thomas-Oates, J. E. and Bloemberg, G. V. 2006. Biocontrol of avocado Dematophora root rot by antagonistic Pseudomonas fluorescens PCL1606 correlates with the production of 2-hexyl 5-propyl resorcinol. Mol. Plant Microbe Interact. 19(4), 418428. https://doi.org/10.1094/MPMI-19-0418.

Chae, D. H., Kim, D. R., Cheong, M. S., Lee, Y. B. and Kwak, Y. S. 2020. Investigating the induced systemic resistance mechanism of 2,4-diacetylphloroglucinol (DAPG) using DAPG hydrolase-transgenic Arabidopsis. Plant Pathol. J. 36(3), 255-266. https://doi .org/10.5423/PPJ.OA.02.2020.0031. 
Chatterjee, P., Davis, E., Yu, F., James, S., Wildschutte, J. H., Wiegmann, D. D., Sherman, D. H., Mckay, R. M., Lipuma, J. J. and Wildschutte, H. 2017. Environmental pseudomonads inhibit cystic fibrosis patient-derived pseudomonas aeruginosa. Appl. Environ. Microbiol. 83(2), 1-13. https://doi.org/https://aem.asm.org/content /83/2/e02701-16.

Cheng, X., Etalo, D. W., van de Mortel, J. E., Dekkers, E., Nguyen, L., Medema, M. H. and Raaijmakers, J. M. 2017. Genome-wide analysis of bacterial determinants of plant growth promotion and induced systemic resistance by Pseudomonas fluorescens. Environ. Microbiol. 19(11), 4638-4656. https://doi.org/10.1111/1462-2920.13927.

Chi, X., Wang, Y., Miao, J., Feng, Z., Zhang, H., Zhai, J., Zhang, H., Tian, L., Xue, W., Yang, T., Huang, R., Hu, X. and Ge, Y. 2017. Development and characterization of a fusion mutant with the truncated lac $Z$ to screen regulatory genes for phenazine biosynthesis in Pseudomonas chlororaphis G05. Biol. Control 108, 70-76. https://doi.org/10.1016 /j.biocontrol.2017.02.012.

Chin-A-Woeng, T. F. C., Bloemberg, G. V., Van Der Bij, A. J., Van Der Drift, K. M. G. M., Schripsema, J., Kroon, B., Scheffer, R. J., Keel, C., Bakker, P. A. H. M., Tichy, H. V., De Bruijn, F. J., Thomas-Oates, J. E., Lugtenberg, B. J. J. 1998. Biocontrol by phenazine1-carboxamide-producing Pseudomonas chlororaphis PCL1391 of tomato root rot caused by Fusarium oxysporum f. sp. radicis-lycopersici. Mol. Plant-Microbe Interact. 11, 1069-1077. https://doi.org/10.1094/MPMI.1998.11.11.1069.

Chincholkar, S. and Thomashow, L. S. 2013. Microbial Phenazines: Biosynthesis, Agriculture and Health. Springer, Berlin, Heidelberg. https://doi.org/10.1007/978 -3-642-40573-0.

Christiansen, L., Alanin, K. S., Phippen, C. B. W., Olsson, S., Stougaard, P. and Hennessy, R. C. 2020. Fungal-associated molecules induce key genes involved in the biosynthesis of the antifungal secondary metabolites nunamycin and nunapeptin in the biocontrol strain Pseudomonas fluorescens In5. Appl. Environ. Microbiol. 86(21), 1-14. https:// doi.org/10.1128/AEM.01284-20.

Cornelis, P. 2010. Iron uptake and metabolism in pseudomonads. Appl. Microbiol. Biotechnol. 86(6), 1637-1645. https://doi.org/10.1007/s00253-010-2550-2.

Costa, R., Van Aarle, I. M., Mendes, R. and Van Elsas, J. D. 2009. Genomics of pyrrolnitrin biosynthetic loci: evidence for conservation and whole-operon mobility within Gram-negative bacteria. Environ. Microbiol. 11(1), 159-175. https://doi.org/10.1111 /j.1462-2920.2008.01750.x.

Cronin, D., Moënne-Loccoz, Y., Fenton, A., Dunne, C., Dowling, D. N. and O'Gara, F. 1997 a. Ecological interaction of a biocontrol Pseudomonas fluorescens strain producing 2,4-diacetylphloroglucinol with the soft rot potato pathogen Erwinia carotovora subsp. atroseptica. FEMS Microbiol. Ecol. 23(2), 95-106.

Cronin, D., Moënne-Loccoz, Y., Fenton, A., Dunne, C., Dowling, D. N. and O'Gara, F. 1997b. Role of 2,4-diacetylphloroglucinol in the interactions of the biocontrol pseudomonad strain F113 with the potato cyst nematode Globodera rostochiensis. Appl. Environ. Microbiol. 63(4), 1357-1361. https://doi.org/10.1128/AEM.63.4.1357 $-1361.1997$.

Crouzet, J., Arguelles-arias, A., Dhondt-Cordelier, S., Cordelier, S., Pršic, J., Hoff, G., Mazeyrat-Gourbeyre, F., Baillieul, F., Clément, C., Ongena, M. and Dorey, S. 2020. Biosurfactants in plant protection against diseases: rhamnolipids and lipopeptides case study. Front. Bioeng. Biotechnol. 8, 1014. https://doi.org/10.3389/fbioe.2020 .01014 . 
CTGB 2014. Proradix Agro. Registration report-Central Zone.

D'aes, J., De Maeyer, K., Pauwelyn, E. and Höfte, M. 2010. Biosurfactants in plantPseudomonas interactions and their importance to biocontrol. Environ. Microbiol. Rep. 2(3), 359-372. https://doi.org/10.1111/j.1758-2229.2009.00104.x.

D'aes, J., Hua, G. K. H., De Maeyer, K., Pannecoucque, J., Forrez, I., Ongena, M., Dietrich, L. E. P., Thomashow, L. S., Mavrodi, D. V. and Höfte, M. 2011. Biological control of Rhizoctonia root rot on bean by phenazineand cyclic lipopeptide-producing Pseudomonas CMR12a. Phytopathology 101(8), 996-1004. https://doi.org/10.1094 /PHYTO-11-10-0315.

D’aes, J., Kieu, N. P., Léclère, V., Tokarski, C., Olorunleke, F. E., De Maeyer, K., Jacques, P., Höfte, M. and Ongena, M. 2014. To settle or to move? The interplay between two classes of cyclic lipopeptides in the biocontrol strain Pseudomonas CMR12a. Environ. Microbiol. 16(7), 2282-2300. https://doi.org/10.1111/1462-2920.12462.

De Bruijn, I., De Kock, M. J. D., Yang, M., De Waard, P., Van Beek, T. A. and Raaijmakers, J. M. 2007. Genome-based discovery, structure prediction and functional analysis of cyclic lipopeptide antibiotics in Pseudomonas species. Mol. Microbiol. 63(2), 417428. https://doi.org/10.1111/j.1365-2958.2006.05525.x.

de Souza, J. T., de Boer, M., de Waard, P., van Beek, T. A. and Raaijmakers, J. M. 2003. Biochemical, genetic, and zoosporicidal properties of cyclic lipopeptide surfactants produced by Pseudomonas fluorescens. Appl. Environ. Microbiol. 69(12), $7161-$ 7172. https://doi.org/10.1128/aem.69.12.7161-7172.2003.

De Vleesschauwer, D., Cornelis, P. and Höfte, M. 2006. Redox-active pyocyanin secreted by Pseudomonas aeruginosa 7NSK2 triggers systemic resistance to Magnaporthe grisea but enhances Rhizoctonia solani susceptibility in rice. Mol. Plant Microbe Interact. 19(12), 1406-1419. https://doi.org/10.1094/MPMI-19-1406.

De Vleesschauwer, D. and Höfte, M. 2009. Chapter 6 Rhizobacteria-induced systemic resistance. Adv. Bot. Res. 51, 223-281. https://doi.org/10.1016/S0065-2296(09)51 006-3.

De Vrieze, M., Varadarajan, A. R., Schneeberger, K., Bailly, A., Rohr, R. P., Ahrens, C. H. and Weisskopf, L. 2020. Linking comparative genomics of nine potato-associated pseudomonas isolates with their differing biocontrol potential against late blight. Front. Microbiol. 11, 857. https://doi.org/10.3389/fmicb.2020.00857.

Devi, K. K. and Kothamasi, D. 2009. Pseudomonas fluorescens CHAO can kill subterranean termite Odontotermes obesus by inhibiting cytochrome c oxidase of the termite respiratory chain. FEMS Microbiol. Lett. 300(2), 195-200. https://doi.org/10.1111/j .1574-6968.2009.01782.x.

Dimkpa, C., Weinand, T. and Asch, F. 2009. Plant-rhizobacteria interactions alleviate abiotic stress conditions. Plant Cell Environ. 32(12), 1682-1694. https://doi.org/10.1 111/j.1365-3040.2009.02028.x.

Du, X., Li, Y., Zhou, W., Zhou, Q., Liu, H. and Xu, Y. 2013. Phenazine-1-carboxylic acid production in a chromosomally non-scar triple-deleted mutant pseudomonas aeruginosa using statistical experimental designs to optimize yield. Appl. Microbiol. Biotechnol. 97(17), 7767-7778. https://doi.org/10.1007/s00253-013-4921-y.

Duan, J., Jiang, W., Cheng, Z., Heikkila, J. J. and Glick, B. R. 2013. The complete genome sequence of the plant growth-promoting bacterium pseudomonas sp. UW4. PLoS ONE 8(3), e58640. https://doi.org/10.1371/journal.pone.0058640.

Duffy, B. K. and Defago, G. 2000. Controlling instability in gacS-gacA regulatory genes during inoculant production of Pseudomonas fluorescens biocontrol strains. Appl. 
Environ. Microbiol. 66(8), 3142-3150. https://doi.org/10.1128/AEM.66.8.3142-3150 2000.

EFSA 2012. Conclusion on the peer review of the pesticide risk assessment of the active substance Pseudomonas sp. strain DSMZ 13134. EFSA J. 10(12), 1-32. https://doi .org/10.2903/j.efsa.2012.2954.

EFSA 2017. Conclusion on the peer review of the pesticide risk assessment of the active substance Pseudomonas chlororaphis strain MA. EFSA J. 15(1), e04668. https://doi .org/10.2903/j.efsa.2017.4668.

Emanuele, M. C., Scaloni, A., Lavermicocca, P., Jacobellis, N. S., Camoni, L., Di Giorgio, D., Pucci, P., Paci, M., Segre, A. and Ballio, A. 1998. Corpeptins, new bioactive lipodepsipeptides from cultures of Pseudomonas corrugata. FEBS Lett. 433(3), 317320. https://doi.org/10.1016/S0014-5793(98)00933-8.

EPA, U. 2017a. US EPA, Pesticide Product Label, Howler T\&O.

EPA, U. 2017b. US EPA, Pesticide Product Label, ZIO.

EPA, U. 2017c. Pesticide Product Label, FROSTBAN B.

EPA, U. 2006. Pesticide Product Label, Spot-less.

EU 2013. Commission implementation regulation (EU) No 829. Off. J. Eur. Union L232, 29-32.

Fang, R., Lin, J., Yao, S., Wang, Y., Wang, J., Zhou, C., Wang, H. and Xiao, M. 2013. Promotion of plant growth, biological control and induced systemic resistance in maize by Pseudomonas aurantiaca JD37. Ann. Microbiol. 63(3), 1177-1185. https:// doi.org/10.1007/s13213-012-0576-7.

Fenton, A. M., Stephens, P. M., Crowley, J., O'Callaghan, M. and O'Gara, F. 1992. Exploitation of gene(s) involved in 2,4-diacetylphloroglucinol biosynthesis to confer a new biocontrol capability to a Pseudomonas strain. Appl. Environ. Microbiol. 58(12), 3873-3878. https://doi.org/10.1128/AEM.58.12.3873-3878.1992.

Flury, P., Aellen, N., Ruffner, B., Péchy-Tarr, M., Fataar, S., Metla, Z., Dominguez-Ferreras, A., Bloemberg, G., Frey, J., Goesmann, A., Raaijmakers, J. M., Duffy, B., Höfte, M., Blom, J., Smits, T. H. M., Keel, C. and Maurhofer, M. 2016. Insect pathogenicity in plantbeneficial pseudomonads: phylogenetic distribution and comparative genomics. ISME J. 10(10), 2527-2542. https://doi.org/10.1038/ismej.2016.5.

Flury, P., Vesga, P., Dominguez-Ferreras, A., Tinguely, C., Ullrich, C. I., Kleespies, R. G., Keel, C. and Maurhofer, M. 2019. Persistence of root-colonizing Pseudomonas protegens in herbivorous insects throughout different developmental stages and dispersal to new host plants. ISME J. 13(4), 860-872. https://doi.org/10.1038/s 41396-018-0317-4.

Flury, P., Vesga, P., Péchy-Tarr, M., Aellen, N., Dennert, F., Hofer, N., Kupferschmied, K. P., Kupferschmied, P., Metla, Z., Ma, Z., Siegfried, S., de Weert, S., Bloemberg, G., Höfte, M., Keel, C. J. and Maurhofer, M. 2017. Antimicrobial and insecticidal: cyclic lipopeptides and hydrogen cyanide produced by plant-beneficial Pseudomonas strains CHA0, CMR12a, and PCL1391 contribute to insect killing. Front. Microbiol. 8, 100. https://doi.org/10.3389/fmicb.2017.00100.

Frapolli, M., Pothier, J. F., Défago, G. and Moënne-Loccoz, Y. 2012. Evolutionary history of synthesis pathway genes for phloroglucinol and cyanide antimicrobials in plantassociated fluorescent pseudomonads. Mol. Phylogenet. Evol. 63(3), 877-890. https ://doi.org/10.1016/j.ympev.2012.02.030.

Frasson, D., Opoku, M., Picozzi, T., Torossi, T., Balada, S., Smits, T. H. M. and Hilber, U. 2017. Pseudomonas wadenswilerensis sp. nov. and Pseudomonas reidholzensis sp. 
nov., two novel species within the Pseudomonas putida group isolated from forest soil. Int. J. Syst. Evol. Microbiol. 67(8), 2853-2861. https://doi.org/10.1099/ijsem.0 .002035 .

Frederiks, C. and Wesseler, J. H. 2018. A comparison of the EU and US regulatory frameworks for the active substance registration of microbial biological control agents. Pest Manag. Sci. 75(1), 87-103. https://doi.org/10.1002/ps.5133.

Fröhlich, A., Buddrus-Schiemann, K., Durner, J., Hartmann, A. and von Rad, U. 2012. Response of barley to root colonization by Pseudomonas sp. DSMZ 13134 under laboratory, greenhouse, and field conditions. J. Plant Interact. 7(1), 1-9. https://doi .org/10.1080/17429145.2011.597002.

Gao, J., Xie, G., Peng, F. and Xie, Z. 2015. Pseudomonas donghuensis sp. nov., exhibiting high-yields of siderophore. Antonie Leeuwenhoek Int. J. Gen. Mol. Microbiol. 107(1), 83-94. https://doi.org/10.1007/s10482-014-0306-1.

Gardan, L., Shafik, H., Belouin, S., Broch, R., Grimont, F. and Grimont, P. A. D. 1999. DNA relatedness among the pathovars of Pseudomonas syringae and description of Pseudomonas tremae sp. nov. and Pseudomonas cannabina sp. nov. (ex Sutic and Dowson 1959). Int. J. Syst. Bacteriol. 49(2), 469-478. https://doi.org/10.1099/0 0207713-49-2-469.

Garrido-Sanz, D., Arrebola, E., Martínez-Granero, F., García-Méndez, S., Muriel, C., BlancoRomero, E., Martín, M., Rivilla, R. and Redondo-Nieto, M. 2017. Classification of isolates from the Pseudomonas fluorescens complex into phylogenomic groups based in group-specific markers. Front. Microbiol. 8, 413. https://doi.org/10.3389 /fmicb.2017.00413.

Garrido-Sanz, D., Meier-Kolthoff, J. P., Göker, M., Martín, M., Rivilla, R. and RedondoNieto, M. 2016. Genomic and genetic diversity within the Pseudomonas fluorescens complex. PLoS ONE 11(2), e0150183. https://doi.org/10.1371/journal.pone.015 0183.

Ge, Y., Huang, X., Wang, S., Zhang, X. and Xu, Y. 2004. Phenazine-1-carboxylic acid is negatively regulated and pyoluteorin positively regulated by gacA in Pseudomonas sp. M18. FEMS Microbiol. Lett. 237, 41-47. https://doi.org/10.1016/j.femsle.2004.06 .028 .

Geels, F. P. and Schippers, B. 1983. Selection of antagonistic fluorescent Pseudomonas spp. and their root colonization and persistence following treatment of seed potatoes. J. Phytopathol. 108(3-4), 193-206. https://doi.org/10.1111/j.1439-0434 .1983.tb00579.x.

Geudens, N. and Martins, J. C. 2018. Cyclic lipodepsipeptides from Pseudomonas spp.biological Swiss-army knives. Front. Microbiol. 9, 1867. https://doi.org/10.3389/ fmicb.2018.01867.

Girard, L., Höfte, M. and De Mot, R. 2020a. Lipopeptide families at the interface between pathogenic and beneficial Pseudomonas-plant interactions. Crit. Rev. Microbiol. 46(4), 397-419. https://doi.org/10.1080/1040841X.2020.1794790.

Girard, L., Lood, C., Rokni-zadeh, H., Noort, V. Van, Lavigne, R. and De Mot, R. 2020b. Reliable identification of environmental Pseudomonas isolates using the $r p o D$ gene. Microorganisms 8(8), 1-12. https://doi.org/10.3390/microorganisms 80 81166.

Gislason, A. S. and de Kievit, T. R. 2020. Friend or foe? Exploring the fine line between Pseudomonas brassicacearum and phytopathogens. J. Med. Microbiol. 69(3), 347360. https://doi.org/10.1099/jmm.0.001145. 
Gomez-Lama Cabanas, C., Legarda, G., Ruano-Rosa, D., Pizarro-Tobias, P., ValverdeCorredor, A., Niqui, J. L., Trivino, J. C., Roca, A. and Mercado-Blanco, J. 2018. Indigenous Pseudomonas spp. strains from the olive (Olea europaea L.) rhizosphere as effective biocontrol agents against Verticillium dahliae: from the host roots to the bacterial genomes. Front. Microbiol. 9, 277. https://doi.org/10.3389/fmicb.2018.00277.

Gomila, M., Busquets, A., Mulet, M., García-Valdés, E. and Lalucat, J. 2017. Clarification of taxonomic status within the Pseudomonas syringae species group based on a phylogenomic analysis. Front. Microbiol. 8, 2422. https://doi.org/10.3389/fmicb .2017.02422.

Gomila, M., Peña, A., Mulet, M., Lalucat, J. and García-Valdés, E. 2015. Phylogenomics and systematics in Pseudomonas. Front. Microbiol. 6, 214. https://doi.org/10.3389/fmicb .2015.00214.

Götze, S. and Stallforth, P. 2020. Structure, properties, and biological functions of nonribosomal lipopeptides from pseudomonads. Nat. Prod. Rep. 37(1), 29-54. https://doi.org/10.1039/c9np00022d.

Government of India 2020. Major uses of Biopesticides (Registered under the insecticides act, 1968) [WWW Document]. Available at: http://ppqs.gov.in/divisions/cib-rc/majo r-uses-of-pesticides.

Gross, H. and Loper, J. E. 2009. Genomics of secondary metabolite production by Pseudomonas spp. Nat. Prod. Rep. 26(11), 1408-1446. https://doi.org/10.1039/ b817075b.

Gross, H., Stockwell, V. O., Henkels, M. D., Nowak-Thompson, B., Loper, J. E. and Gerwick, W. H. 2007. The genomisotopic approach: a systematic method to isolate products of orphan biosynthetic gene clusters. Chem. Biol. 14(1), 53-63. https://doi.org/10.1 016/j.chembiol.2006.11.007.

Haas, D. and Défago, G. 2005. Biological control of soil-borne pathogens by fluorescent pseudomonads. Nat. Rev. Microbiol. 3(4), 307-319. https://doi.org/10.1038/ nrmicro1129.

Haas, D. and Keel, C. 2003. Regulation of antibiotic production in root-colonizing Pseudomonas spp. and relevance for biological control of plant disease. Annu. Rev. Phytopathol. 41, 117-153. https://doi.org/10.1146/annurev. phyto.41.052002.09 5656.

Han, S. H., Lee, S. J., Moon, J. H., Park, K. H., Yang, K. Y., Cho, B. H., Kim, K. Y., Kim, Y. W., Lee, M. C., Anderson, A. J. and Kim, Y. C. 2006. GacS-dependent production of 2R, 3R-butanediol by Pseudomonas chlororaphis $\mathrm{O} 6$ is a major determinant for eliciting systemic resistance against Erwinia carotovora but not against Pseudomonas syringae pv. tabaci in tobacco. Mol. Plant Microbe Interact. 19(8), 924-930. https:// doi.org/10.1094/MPMI-19-0924.

Hardalo, C. and Edberg, S. C. 1997. Pseudomonas aeruginosa: assessment of risk from drinking water. Crit. Rev. Microbiol. 23(1), 47-75. https://doi.org/10.3109/104084 19709115130.

Hardebeck, G. A., Turco, R. F., Latin, R. and Reicher, Z. J. 2004. Application of Pseudomonas aureofaciens Tx-1 through irrigation for control of dollar spot and brown patch on fairway-height turf. HortSci. 39(7), 1750-1753. https://doi.org/10.21273/HORTSCl 39.7.1750.

Harrison, L. A., Letendre, L. E. O., Kovacevich, P., Pierson, E. and Weller, D. 1993. Purification of an antibiotic effective against Gaeumannomyces graminis var. tritici produced by a biocontrol agent, Pseudomonas aureofaciens. Soil Biol. Biochem. 25(2), 215-221. 
Hayat, R., Ali, S., Amara, U., Khalid, R. and Ahmed, I. 2010. Soil beneficial bacteria and their role in plant growth promotion: a review. Ann. Microbiol. 60(4), 579-598. https://do i.org/10.1007/s13213-010-0117-1.

Heiman, C. M., Wiese, J., Kupferschmied, P., Maurhofer, M., Keel, C. and Vacheron, J. 2020. Draft genome sequence of Pseudomonas sp. strain LD120, isolated from the marine alga Saccharina latissima. Microbiol. Resour. Announc. 9(8), e01305-19. https://doi .org/10.1128/MRA.01305-19.

Hernandez-Jerez, A. F., Adriaanse, P., Aldrich, A., Berny, P., Coja, T., Duquesne, S., Marinovich, M., Millet, M., Pelkonen, O., Pieper, S., Tiktak, A., Topping, C. J., Wolterink, G., Herman, L. and Chiusolo, A. 2020. Statement on the translocation potential by Pseudomonas chlororaphis MA342 in plants after seed treatment of cereals and peas and assessment of the risk to humans. EFSA J. 18, 6276. https://doi.org/10 $.2903 /$ j.efsa.2020.6276.

Hesse, C., Schulz, F., Bull, C. T., Shaffer, B. T., Yan, Q., Shapiro, N., Hassan, K. A., Varghese, N., Elbourne, L. D. H., Paulsen, I. T., Kyrpides, N., Woyke, T. and Loper, J. E. 2018. Genome-based evolutionary history of Pseudomonas spp. Environ. Microbiol. 20(6), 2142-2159. https://doi.org/10.1111/1462-2920.14130.

Hill, D. S., Stein, J. I., Torkewitz, N. R., Morse, A. M., Howell, C. R., Pachlatko, J. P., Becker, J. O. and Ligon, J. M. 1994. Cloning of genes involved in the synthesis of pyrrolnitrin from Pseudomonas fluorescens and role of pyrrolnitrin synthesis in biological control of plant disease. Appl. Environ. Microbiol. 60(1), 78-85. https://doi.org/10.1 128/AEM.60.1.78-85.1994.

Hökeberg, M., Gerhardson, B. and Johnsson, L. 1997. Biological control of cereal seedborne diseases by seed bacterization with greenhouse-selected bacteria. Eur. J. Plant Pathol. 103(1), 25-33. https://doi.org/10.1023/A:1008681608400.

Howell, C. R. and Stipanovic, R. D. 1980. Suppression of Pythium ultimum-induced damping-off of cotton seedlings by Pseudomonas fluorescens and its antibiotic, pyoluteorin. Phytopathology 70, 712-715.

Howell, C. R. and Stipanovic, R. D. 1979. Control of Rhizoctonia solani on cotton seedlings with Pseudomonas fluorescens and with an antibiotic produced by the bacterium. Phytopathology 69(5), 480-482.

Hu, H. B., Xu, Y.-Q., Chen, F., Zhang, X. H. and Hur, B. K. 2005. Isolation and characterization of a new fluorescent Pseudomonas strain that produces both phenazine-1-carboxylic acid and pyoluteorin. J. Microbiol. Biotechnol. 15, 86-90.

Hu, W., Gao, Q., Hamada, M. S., Dawood, D. H., Zheng, J., Chen, Y. and Ma, Z. 2014. Potential of Pseudomonas chlororaphis subsp. aurantiaca strain Pcho10 as a biocontrol agent against Fusarium graminearum. Phytopathology 104(12), 1289-1297. https://doi.org /10.1094/PHYTO-02-14-0049-R.

Huang, J., Xu, Y., Zhang, H., Li, Y., Huang, X., Ren, B. and Zhang, X. 2009. Temperaturedependent expression of phzM and its regulatory genes lasl and pts $P$ in rhizosphere isolate Pseudomonas sp. strain M18. Appl. Environ. Microbiol. 75(20), 6568-6580. https://doi.org/10.1128/AEM.01148-09.

Huang, R., Feng, Z., Chi, X., Sun, X., Lu, Y., Zhang, B., Lu, R., Luo, W., Wang, Y., Miao, J. and $\mathrm{Ge}, \mathrm{Y}$. 2018. Pyrrolnitrin is more essential than phenazines for Pseudomonas chlororaphis G05 in its suppression of Fusarium graminearum. Microbiol. Res. 215, 55-64. https://doi.org/10.1016/j.micres.2018.06.008.

Huang, X., Zhu, D., Ge, Y., Hu, H., Zhang, X. and Xu, Y. 2004. Identification and characterization of $p l t Z$, a gene involved in the repression of pyoluteorin biosynthesis 
in Pseudomonas sp. M18. FEMS Microbiol. Lett. 232(2), 197-202. https://doi.org/10 .1016/S0378-1097(04)00074-6.

Hultberg, M., Alsberg, T., Khalil, S. and Alsanius, B. 2010a. Suppression of disease in tomato infected by Pythium ultimum with a biosurfactant produced by Pseudomonas koreensis. BioControl 55(3), 435-444. https://doi.org/10.1007/s 10526-009-9261-6.

Hultberg, M., Bengtsson, T. and Liljeroth, E. 2010b. Late blight on potato is suppressed by the biosurfactant-producing strain Pseudomonas koreensis 2.74 and its biosurfactant. BioControl 55(4), 543-550. https://doi.org/10.1007/s10526-010-9289-7.

Hunziker, L., Bönisch, D., Groenhagen, U., Bailly, A., Schulz, S. and Weisskopf, L. 2015. Pseudomonas strains naturally associated with potato plants produce volatiles with high potential for inhibition of Phytophthora infestans. Appl. Environ. Microbiol. 81(3), 821-830. https://doi.org/10.1128/AEM.02999-14.

lavicoli, A., Boutet, E., Buchala, A. and Métraux, J. P. 2003. Induced systemic resistance in Arabidopsis thaliana in response to root inoculation with Pseudomonas fluorescens C H A0. Mol. Plant. Microbe Interact. 16(10), 851-858. https://doi.org/10.1094/MPMI 2003.16.10.851.

Iswandi, A., Bossier, P., Vandenabeele, J. and Verstraete, W. 1987. Relation between soil microbial activity and the effect of seed inoculation with the rhizopseudomonas strain 7NSK2 on plant growth. Biol. Fertil. Soils 3(3), 147-151.

Jahanshah, G., Yan, Q., Gerhardt, H., Pataj, Z., Lämmerhofer, M., Pianet, I., Josten, M., Sahl, H. G., Silby, M. W., Loper, J. E. and Gross, H. 2019. Discovery of the cyclic lipopeptide gacamide $A$ by genome mining and repair of the defective GacA regulator in Pseudomonas fluorescens Pf0-1. J. Nat. Prod. 82(2), 301-308. https://doi.org/10.1 021/acs.jnatprod.8b00747.

Janisiewicz, W. J. and Marchi, A. 1992. Control of storage rots on various pear cultivars with a saprophytic strain of Pseudomonas syringae. Plant Dis. 76, 555-560.

Jasim, B., Anisha, C., Rohini, S., Kurian, J. M., Jyothis, M. and Radhakrishnan, E. K. 2014. Phenazine carboxylic acid production and rhizome protective effect of endophytic Pseudomonas aeruginosa isolated from Zingiber officinale. World J. Microbiol. Biotechnol. 30(5), 1649-1654. https://doi.org/10.1007/s11274-013-1582-z.

Jeong, J. J., Moon, H. J., Pathiraja, D., Park, B., Choi, I. G. and Kim, K. D. 2018. Draft genome sequences of Bacillus megaterium KU143, Microbacterium testaceum KU313, and Pseudomonas protegens AS15, isolated from stored rice grains. Genome Announc. 6(22), e00468-18. https://doi.org/10.1128/genomeA.00468-18.

Jiang, Q., Xiao, J., Zhou, C., Mu, Y., Xu, B., He, Q. and Xiao, M. 2014. Complete genome sequence of the plant growth-promoting rhizobacterium Pseudomonas aurantiaca strain JD37. J. Biotechnol. 192(A), 85-86. https://doi.org/10.1016/j.jbiotec.2014.10 .021.

Jiang, Z., Chen, M., Yu, X. and Xie, Z. 2016. 7-Hydroxytropolone produced and utilized as an iron-scavenger by Pseudomonas donghuensis. BioMetals 29(5), 817-826. https:// doi.org/10.1007/s10534-016-9954-0.

Johnsson, L., Hökeberg, M. and Gerhardson, B. 1998. Performance of the Pseudomonas chlororaphis biocontrol agent MA 342 against cereal seed-borne diseases in field experiments. Eur. J. Plant Pathol. 104(7), 701-711. https://doi.org/10.1023/A :1008632102747.

Jousset, A., Schuldes, J., Keel, C., Maurhofer, M., Daniel, R., Scheu, S. and Thuermer, A. 2014. Full-genome sequence of the plant growth-promoting bacterium 
pseudomonas protegens CHA0. Genome Announc. 2(2), e00322-14. https://doi.org /10.1128/genomeA.00322-14.

Jussila, M. M., Jurgens, G., Lindström, K. and Suominen, L., 2006. Genetic diversity of culturable bacteria in oil-contaminated rhizosphere of Galega orientalis. Environ. Pollut. 139, 244-257. https://doi.org/10.1016/j.envpol.2005.05.013.

Kabaluk, J. T., Svircev, A. M., Goettel, M. S. and Woo, S. G. 2010. The Use and Regulation of Microbial Pesticides in Representative Jurisdictions Worldwide. IOBC Global 99. Available at: www.IOBC-Global.org

Kaduskar, R. D., Scala, G. D., Al Jabri, Z. J. H., Arioli, S., Musso, L., Oggioni, M. R., Dallavalle, S. and Mora, D. 2017. Promysalin is a salicylate-containing antimicrobial with a cellmembrane-disrupting mechanism of action on Gram-positive bacteria. Sci. Rep. 7(1), 8861. https://doi.org/10.1038/s41598-017-07567-0.

Kamilova, F., Validov, S., Azarova, T., Mulders, I. and Lugtenberg, B. 2005. Enrichment for enhanced competitive plant root tip colonizers selects for a new class of biocontrol bacteria. Environ. Microbiol. 7(11), 1809-1817. https://doi.org/10.1111/j.1462-2920 .2005.00889.x.

Kang, B. R., Anderson, A. J. and Kim, Y. C. 2019. Hydrogen cyanide produced by Pseudomonas chlororaphis $\mathrm{O} 6$ is an aphicidal metabolite. Can. J. Microbiol. 65(3), 185-190. https://doi.org/10.1139/cjm-2018-0372.

Kang, B. R., Anderson, A. J. and Kim, Y. C. 2018. Hydrogen cyanide produced by Pseudomonas chlororaphis $\mathrm{O} 6$ exhibits nematicidal activity against Meloidogyne hapla. Plant Pathol. J. 34(1), 35-43. https://doi.org/10.5423/PPJ.OA.06.2017.0115.

Kavino, M., Harish, S., Kumar, N., Saravanakumar, D. and Samiyappan, R. 2008. Induction of systemic resistance in banana (Musa spp.) against Banana bunchy top virus (BBTV) by combining chitin with root-colonizing Pseudomonas fluorescens strain CHA0. Eur. J. Plant Pathol. 120(4), 353-362. https://doi.org/10.1007/s10658 -007-9223-8.

Keel, C., Schnider, U., Maurhofer, M., Voisard, C., Laville, J., Burger, U., Wirthner, P., Haas, D. and Défago, G. 1992. Suppression of root diseases by Pseudomonas fluorescens $\mathrm{CHA0}$ : importance of the bacterial secondary metabolite 2,4-diacetylphloroglucinol. Mol. Plant Microbe Interact. 5(1), 4-13.

Kidarsa, T. A., Goebel, N. C., Zabriskie, T. M. and Loper, J. E. 2011. Phloroglucinol mediates cross-talk between the pyoluteorin and 2,4-diacetylphloroglucinol biosynthetic pathways in Pseudomonas fluorescens Pf-5. Mol. Microbiol. 81(2), 395-414. https:// doi.org/10.1111/j.1365-2958.2011.07697.x.

Kilani, J. and Fillinger, S. 2016. Phenylpyrroles: 30 years, two molecules and (nearly) no resistance. Front. Microbiol. 7, 2014. https://doi.org/10.3389/fmicb.2016.02014.

Kim, M. S., Kim, Y. C. and Cho, B. H. 2004. Gene expression analysis in cucumber leaves primed by root colonization with Pseudomonas chlororaphis $\mathrm{O} 6$ upon challengeinoculation with Corynespora cassiicola. Plant Biol. (Stuttg) 6(2), 105-108. https://doi .org/10.1055/s-2004-817803.

Kirner, S., Hammer, P. E., Hill, D. S., Altmann, A., Fischer, I., Weislo, L. J., Lanahan, M., van Pée, K. H. and Ligon, J. M. 1998. Functions encoded by pyrrolnitrin biosynthetic genes from Pseudomonas fluorescens. J. Bacteriol. 180(7), 1939-1943.

Kivisaar, M. 2020. Narrative of a versatile and adept species Pseudomonas putida. J. Med. Microbiol. 69, 324-338. https://doi.org/10.1099/JMM.0.001137.

Kosina, M., Bartak, M., Maslanova, I., Vavrova Pascutti, A., Sedo, O., Lexa, M. and Sedlacek, I. 2013. Pseudomonas prosekii sp. nov., a novel psychrotrophic bacterium 
from Antarctica. Curr. Microbiol. 67, 637-646. https://doi.org/10.1007/s00284 -013-0406-6.

Krzyzanowska, D. M., Ossowicki, A. and Jafra, S. 2014. Genome sequence of Pseudomonas sp. strain P482, a tomato rhizosphere isolate with broad-spectrum antimicrobial activity. Genome Announc. 2(3), e00394-14. https://doi.org/10.1128/genomeA .00394-14.

Krzyzanowska, D. M., Ossowicki, A., Rajewska, M., Maciag, T., Jablonska, M., Obuchowski, M., Heeb, S. and Jafra, S. 2016. When genome-based approach meets the "Old but Good": revealing genes involved in the antibacterial activity of Pseudomonas sp. P482 against soft rot pathogens. Front. Microbiol. 7, 782. https://doi.org/10.3389/ fmicb.2016.00782.

Krzyzanowska, D. M., Potrykus, M., Golanowska, M., Polonis, K., Gwizdek-Wisniewska, A., Lojkowska, E. and Jafra, S. 2012. Rhizosphere bacteria as potential biocontrol agents against soft rot caused by various Pectobacterium and Dickeya spp. strains. J. Plant Pathol. 94, 367-378. https://doi.org/10.4454/JPP.FA.2012.042.

Kuiper, I., Lagendijk, E. L., Pickford, R., Derrick, J. P., Lamers, G. E. M., Thomas-Oates, J. E., Lugtenberg, B. J. J. and Bloemberg, G. V. 2003. Characterization of two Pseudomonas putida lipopeptide biosurfactants, putisolvin I and II, which inhibit biofilm formation and break down existing biofilms. Mol. Microbiol. 51(1), 97-113. https://doi.org/10 .1046/j.1365-2958.2003.03751.x.

Kumar, A., Munder, A., Aravind, R., Eapen, S. J., Tümmler, B. and Raaijmakers, J. M. 2013. Friend or foe: genetic and functional characterization of plant endophytic Pseudomonas aeruginosa. Environ. Microbiol. 15(3), 764-779. https://doi.org/10 $.1111 / 1462-2920.12031$.

Kumar, T., Wahla, V., Pandey, P., Dubey, R. C. and Maheshwari, D. K. 2009. Rhizosphere competent Pseudomonas aeruginosa in the management of Heterodera cajani on sesame. World J. Microbiol. Biotechnol. 25(2), 277-285. https://doi.org/10.1007/s 11274-008-9890-4.

Kuzmanović, N., Eltlbany, N., Ding, G., Baklawa, M., Min, L., Wei, L. and Smalla, K. 2018. Analysis of the genome sequence of plant beneficial strain Pseudomonas sp. RU47. J. Biotechnol. 281, 183-192. https://doi.org/10.1016/j.jbiotec.2018.07.023.

Kwon, S. W., Kim, J. S., Park, I. C., Yoon, S. H., Park, D. H., Lim, C. K. and Go, S. J. 2003. Pseudomonas koreensis sp. nov., Pseudomonas umsongensis sp. nov. and Pseudomonas jinjuensis sp. nov., novel species from farm soils in Korea. Int. J. Syst. Evol. Microbiol. 53(1), 21-27. https://doi.org/10.1099/ijs.0.02326-0.

Lalucat, J., Mulet, M., Gomila, M. and García-Valdés, E. 2020. Genomics in bacterial taxonomy: impact on the genus Pseudomonas. Genes (Basel) 11(2). https://doi.org /10.3390/genes11020139.

Lamers, J. G., Schippers, B. and Geels, F. P. 1988. Soil-borne diseases of wheat in the Netherlands and results of seed bacterization with pseudomonads against Gaeumannomyces graminis var. tritici, associated with disease resistance. In: Jorna, M. L. and Slootmaker, L. A. J. (Eds), Cereal Breeding Related to Integrated Cereal Production. Proceedings of the Conference of the Cereal Section of EUCARPIA. Wageningen, pp. 134-139.

Lanteigne, C., Gadkar, V. J., Wallon, T., Novinscak, A. and Filion, M. 2012. Production of DAPG and HCN by Pseudomonas sp. LBUM300 contributes to the biological control of bacterial canker of tomato. Phytopathology 102(10), 967-973. https://doi.org/10 .1094/PHYTO-11-11-0312. 
Laville, J., Blumer, C., Von Schroetter, C., De Gaia, V., Défago, G., Keel, C. and Haas, D. 1998 Characterization of the hcnABC gene cluster encoding hydrogen cyanide synthase and anaerobic regulation by ANR in the strictly aerobic biocontrol agent Pseudomonas fluorescens CHA0. J. Bacteriol. 180(12), 3187-3196. https://doi.org /10.1128/JB.180.12.3187-3196.1998.

Le, C. N., Kruijt, M. and Raaijmakers, J. M. 2012. Involvement of phenazines and lipopeptides in interactions between Pseudomonas species and Sclerotium rolfsii, causal agent of stem rot disease on groundnut. J. Appl. Microbiol. 112(2), 390-403. https://doi.org/10.1111/j.1365-2672.2011.05205.x.

Lee, J. H., Ma, K. C., Ko, S. J., Kang, B. R., Kim, I. S. and Kim, Y. C. 2011. Nematicidal activity of a nonpathogenic biocontrol bacterium, Pseudomonas chlororaphis O6. Curr. Microbiol. 62(3), 746-751. https://doi.org/10.1007/s00284-010-9779-y.

Lemanceau, P., Expert, D., Gaymard, F., Bakker, P. A. H. M. and Briat, J. -F. 2009. Role of iron in plant-microbe interactions. Adv. Bot. Res. 51, 491-549. https://doi.org/10.1016/S 0065-2296(09)51012-9.

Levy, E., Gough, F. J., Berlin, K. D., Guiana, P. W. and Smith, J. T. 1992 Inhibition of Septoria tritici and other phytopathogenic fungi and bacteria by Pseudomonas fluorescens and its antibiotics. Plant Pathol. 41(3), 335-341. https://doi.org/10.1111/j.1365-3059 .1992.tb02355.x.

Li, W., De Vleeschouwer, M., Ghequire, M. G. K., Sinnaeve, D., Rokni-Zadeh, H., Madder, A., Rozenski, J., Martins, J. and De Mot, R. 2013a. Xantholysin and promysalin, novel antimicrobial secondary metabolites from Pseudomonas putida rhizosphere isolates. In: Pseudomonas, 14th International Conference, Abstracts. Federation of European Microbiological Societies (FEMS).

Li, W., Estrada de los Santos, P., Matthijs, S., Xie, G. L., Busson, R., Cornelis, P., Rozenski, J. and De Mot, R. 2011. Promysalin, a salicylate-containing Pseudomonas putida antibiotic, promotes surface colonization and selectively targets other Pseudomonas. Chem. Biol. 18(10), 1320-1330. https://doi.org/10.1016/j.chembiol. 2011.08.006.

Li, W., Rokni-Zadeh, H., De Vleeschouwer, M., Ghequire, M. G. K. K., Sinnaeve, D., Xie, G.-L. L., Rozenski, J., Madder, A., Martins, J. C. and De Mot, R. 2013b. The antimicrobial compound xantholysin defines a new group of Pseudomonas cyclic lipopeptides. PLOS ONE 8(5), e62946. https://doi.org/10.1371/journal.pone.0062946.

Li, X., Kot, W., Wang, D., Zheng, S., Wang, G. and Hansen, L. H. 2015. Draft genome sequence of Se (IV )-reducing bacterium Pseudomonas migulae ES3-33. Genome Announc. 3, e00406-15. https://doi.org/10.1128/genomeA.00406-15.Copyright.

$\mathrm{Li}, \mathrm{Y}$, Jiang, H., Xu, Y. and Zhang, X. 2008. Optimization of nutrient components for enhanced phenazine-1-carboxylic acid production by gacA-inactivated Pseudomonas sp. M18G using response surface method. Appl. Microbiol. Biotechnol. 77(6), 12071217. https://doi.org/10.1007/s00253-007-1213-4.

Liatukas, Ž., Supronienè, S., Ruzgas, V. and Leistrumaitè, A. 2019. Effects of organic seed treatment methods on spring barley seed quality, crop, productivity and disease incidence. Zemdirbyste Agric. 106(3), 241-248. https://doi.org/10.13080/z-a.2019 .106.031.

Ligon, J. M., Hill, D. S., Hammer, P. E., Torkewitz, N. R., Hofmann, D., Kempf, H. J. and Van Pée, K. H. 2000. Natural products with antifungal activity from Pseudomonas biocontrol bacteria. Pest Manag. Sci. 56, 688-695. https://doi.org/10.1002/1526-4 998(200008)56:8. 
Lim, D. J., Yang, S. Y., Noh, M. Y., Lee, C. W., Kim, J. C. and Kim, I. S. 2017. Identification of lipopeptide xantholysins from Pseudomonas sp. DJ15 and their insecticidal activity against Myzus persicae. Entomol. Res. 47(6), 337-343. https://doi.org/10.1111/1748 $-5967.12241$.

Lindow, S. E., McGourty, G. and Elkins, R. 1996. Interactions of antibiotics with Pseudomonas fluorescens strain A506 in the control of fire blight and frost injury to pear. Phytopathology 86(8), 841-848.

Lindow, S. E. and Suslow, T. V. 2003. Temporal dynamics of the biocontrol agent Pseudomonas fluorescens strain A506 in flowers in inoculated pear trees. Phytopathology 93(6), 727-737.

Loewen, P. C., Switala, J., Fernando, W. G. D. and de Kievit, T. 2014. Genome sequence of Pseudomonas brassicacearum DF41. Genome Announc. 2(3), e00390-14. https:// doi.org/10.1128/genomeA.00390-14.

Loper, J. E., Hassan, K. A., Mavrodi, D. V., Davis, E. W., Lim, C. K., Shaffer, B. T., Elbourne, L. D. H., Stockwell, V. O., Hartney, S. L., Breakwell, K., Henkels, M. D., Tetu, S. G., Rangel, L. I., Kidarsa, T. A., Wilson, N. L., van de Mortel, J. E., Song, C., Blumhagen, R., Radune, D., Hostetler, J. B., Brinkac, L. M., Durkin, A. S., Kluepfel, D. A., Wechter, W. P., Anderson, A. J., Kim, Y. C., Pierson, L. S., Pierson, E. A., Lindow, S. E., Kobayashi, D. Y., Raaijmakers, J. M., Weller, D. M., Thomashow, L. S., Allen, A. E. and Paulsen, I. T. 2012. Comparative genomics of plant-associated pseudomonas spp.: insights into diversity and inheritance of traits involved in multitrophic interactions. PLoS Genet. 8(7), e1002784. https://doi.org/10.1371/journal.pgen.1002784.

Loper, J. E., Henkels, M. D., Shaffer, B. T., Valeriote, F. A. and Gross, H. 2008. Isolation and identification of rhizoxin analogs from Pseudomonas fluorescens Pf- 5 by using a genomic mining strategy. Appl. Environ. Microbiol. 74(10), 3085-3093. https://doi .org/10.1128/AEM.02848-07.

Loper, J. E., Kobayashi, D. Y. and Paulsen, I. T. 2007. The genomic sequence of Pseudomonas fluorescens Pf-5: insights into biological control. Phytopathology 97(2), 233-238. https://doi.org/10.1094/PHYTO-97-2-0233.

Lopes, L. D., Davis, E. W., Pereira E Silva, M. C., Weisberg, A. J., Bresciani, L., Chang, J. H., Loper, J. E. and Andreote, F. D. 2018. Tropical soils are a reservoir for fluorescent Pseudomonas spp. biodiversity. Environ. Microbiol. 20(1), 62-74. https://doi.org/10 .1111/1462-2920.13957.

Lötjönen, T. and Torniainen, M. 2005. Does Cedomon work? Forskningsnytt 1, 26-27.

Lugtenberg, B. and Kamilova, F. 2009. Plant-growth-promoting rhizobacteria. Annu. Rev. Microbiol. 63, 541-556. https://doi.org/10.1146/annurev.micro.62.081307.162918.

Ma, Y., Rajkumar, M., Zhang, C. and Freitas, H. 2016. Beneficial role of bacterial endophytes in heavy metal phytoremediation. J. Environ. Manage. 174, 14-25. https://doi.org/10 .1016/j.jenvman.2016.02.047.

Ma, Z., Geudens, N., Kieu, N. P., Sinnaeve, D., Ongena, M., Martins, J. C. and Höfte, M. 2016a. Biosynthesis, chemical structure, and structure-activity relationship of orfamide lipopeptides produced by Pseudomonas protegens and related species. Front. Microbiol. 7, 382. https://doi.org/10.3389/fmicb.2016.00382.

Ma, Z., Hua, G. K. H., Ongena, M. and Höfte, M. 2016b. Role of phenazines and cyclic lipopeptides produced by Pseudomonas sp. CMR12a in induced systemic resistance on rice and bean. Environ. Microbiol. Rep. 8(5), 896-904. https://doi.org/10.1111 /1758-2229.12454. 
Ma, Z., Ongena, M. and Höfte, M. 2017. The cyclic lipopeptide orfamide induces systemic resistance in rice to Cochliobolus miyabeanus but not to Magnaporthe oryzae. Plant Cell Rep. 36(11), 1731-1746. https://doi.org/10.1007/s00299-017-2187-z.

Mahajan-Miklos, S., Rahme, L. G. and Ausubel, F. M. 2000. Elucidating the molecular mechanisms of bacterial virulence using non-mammalian hosts. Mol. Microbiol. 37(5), 981-988. https://doi.org/10.1046/j.1365-2958.2000.02056.x.

Maksimov, I. V., Abizgil, R. R. and Pusenkova, L. I. 2011. Plant growth promoting rhizobacteria as alternative to chemical crop protectors from pathogens (review). Appl. Biochem. Microbiol. 47, 373-385. https://doi.org/10.1134/S0003683811 040090.

Maldonado-González, M. M., Schilirò, E., Prieto, P. and Mercado-Blanco, J. 2015. Endophytic colonization and biocontrol performance of Pseudomonas fluorescens PICF7 in olive (Olea europaea L.) are determined neither by pyoverdine production nor swimming motility. Environ. Microbiol. 17, 3139-3153. https://doi.org/10.1111 /1462-2920.12725.

Mark, G. L., Morrissey, J. P., Higgins, P. and O'Gara, F. 2006. Molecular-based strategies to exploit Pseudomonas biocontrol strains for environmental biotechnology applications. FEMS Microbiol. Ecol. 56(2), 167-177. https://doi.org/10.1111/j.1574 $-6941.2006 .00056 . x$.

Matilla, M. A., Ramos, J. L., Bakker, P. A. H. M., Doornbos, R., Badri, D. V., Vivanco, J. M. and Ramos-González, M. I. 2010. Pseudomonas putida KT2440 causes induced systemic resistance and changes in Arabidopsis root exudation. Environ. Microbiol. Rep. 2(3), 381-388. https://doi.org/10.1111/j.1758-2229.2009.00091.x.

Matthijs, S., Tehrani, K. A., Laus, G., Jackson, R. W., Cooper, R. M. and Cornelis, P. 2007. Thioquinolobactin, a Pseudomonas siderophore with antifungal and anti-Pythium activity. Environ. Microbiol. 9(2), 425-434. https://doi.org/10.1111/j.1462-2920 .2006.01154.x.

Maurhofer, M., Hase, C., Meuwly, P., Metraux, J. P. and Defago, G. 1994a. Induction of systemic resistance of tobacco to tobacco necrosis virus by the root-colonizing Pseudomonas fluorescens strain CHAO: influence of the gacA gene and of pyoverdine production. Phytopathology 84(2). https://doi.org/10.1094/Phyto-84 $-139$.

Maurhofer, M., Keel, C., Haas, D. and Défago, G. 1994b. Pyoluteorin production by Pseudomonas fluorescens strain CHAO is involved in the suppression of Pythium damping-off of cress but not of cucumber. Eur. J. Plant Pathol. 100(3-4), 221-232. https://doi.org/10.1007/BF01876237.

Mavrodi, D. V., Blankenfeldt, W. and Thomashow, L. S. 2006. Phenazine compounds in fluorescent Pseudomonas spp. biosynthesis and regulation. Annu. Rev. Phytopathol. 44, 417-445. https://doi.org/10.1146/annurev.phyto.44.013106.145710.

Mavrodi, D. V., Mavrodi, O. V., Parejko, J. A., Bonsall, R. F., Kwak, Y. S., Paulitz, T. C., Thomashow, L. S. and Weller, D. M. 2012a. Accumulation of the antibiotic phenazine1 -carboxylic acid in the rhizosphere of dryland cereals. Appl. Environ. Microbiol. 78(3), 804-812. https://doi.org/10.1128/AEM.06784-11.

Mavrodi, O. V., Mavrodi, D. V., Parejko, J. A., Thomashow, L. S. and Weller, D. M. 2012 b. Irrigation differentially impacts populations of indigenous antibiotic-producing pseudomonas spp. In the rhizosphere of wheat. Appl. Environ. Microbiol. 78(9), 3214-3220. https://doi.org/10.1128/AEM.07968-11. 
Mavrodi, D. V., Parejko, J. A., Mavrodi, O. V., Kwak, Y. S., Weller, D. M., Blankenfeldt, W. and Thomashow, L. S. 2013. Recent insights into the diversity, frequency and ecological roles of phenazines in fluorescent Pseudomonas spp. Environ. Microbiol. 15(3), 675686. https://doi.org/10.1111/j.1462-2920.2012.02846.x.

May, R., Völksch, B. and Kampmann, G. (1997). Antagonistic activities of epiphythic bacteria from soybean leaves against Pseudomonas syringae pv. glycinea in vitro and in planta. Microb Ecol 43:118-124.

Mehnaz, S., Baig, D. N., Jamil, F., Weselowski, B. and Lazarovits, G. 2009. Characterization of a phenazine and hexanoyl homoserine lactone producing Pseudomonas aurantiaca strain PB-St2, isolated from sugarcane stem. J. Microbiol. Biotechnol. 19(12), 1688-1694. https://doi.org/10.4014/jmb.0904.04022.

Mehnaz, S., Bauer, J. S. and Gross, H. 2014. Complete genome sequence of the sugar cane endophyte Pseudomonas aurantiaca PB-St2, a disease-suppressive bacterium with antifungal activity toward the plant pathogen Colletotrichum falcatum. Genome Announc. 2(1), e01108-13. https://doi.org/10.1128/genomeA.01108-13.

Mehnaz, S., Saleem, R. S. Z., Yameen, B., Pianet, I., Schnakenburg, G., Pietraszkiewicz, H., Valeriote, F., Josten, M., Sahl, H. G., Franzblau, S. G. and Gross, H. 2013. Lahorenoic acids A-C, Ortho-dialkyl-substituted aromatic acids from the biocontrol strain Pseudomonas aurantiaca PB-St2. J. Nat. Prod. 76(2), 135-141. https://doi.org/10 $.1021 / \mathrm{np} 3005166$.

Melnyk, R. A., Hossain, S. S. and Haney, C. H. 2019. Convergent gain and loss of genomic islands drive lifestyle changes in plant-associated pseudomonas. ISME J. 13(6), 1575-1588. https://doi.org/10.1038/s41396-019-0372-5.

Mendes, L. W., de Chaves, M. G., Fonseca, M. C., Mendes, R., Raaijmakers, J. M. and Tsai, S. M. 2019. Resistance breeding of common bean shapes the physiology of the rhizosphere microbiome. Front. Microbiol. 10, 2252. https://doi.org/10.3389/fmicb .2019 .02252 .

Mendes, L. W. and Mendes, R. 2018. Breeding for soil-borne pathogen resistance impacts active rhizosphere microbiome of common bean. ISME J. 12(12), 3038-3042. https:/ /doi.org/10.1038/s41396-018-0234-6.

Mendes, L. W., Raaijmakers, J. M., Hollander, M. De, Mendes, R. and Tsai, S. M. 2017. Influence of resistance breeding in common bean on rhizosphere microbiome composition and function. ISME J. 12(1), 212-224. https://doi.org/10.1038/ismej .2017.158.

Mendes, R., Kruijt, M., De Bruijn, I., Dekkers, E., Van Der Voort, M., Schneider, J. H. M., Piceno, Y. M., DeSantis, T. Z., Andersen, G. L., Bakker, P. A. H. M. and Raaijmakers, J. M. 2011. Deciphering the rhizosphere microbiome for disease-suppressive bacteria. Science 332(6033), 1097-1100. https://doi.org/10.1126/science.1203980.

Mercado-Blanco, J. 2015. Pseudomonas strains that exert biocontrol of plant pathogens. In: Ramos, J.-L., Goldberg, J. B. and Filloux, A. (Eds), Pseudomonas: New Aspects of Pseudomonas Biology (vol. 7). Springer, Dordrecht, pp. 121-172. https://doi.org/10 .1007/978-94-017-9555-5.

Meyer, J. M. 2000. Pyoverdines: pigments, siderophores and potential taxonomic markers of fluorescent Pseudomonas species. Arch. Microbiol. 174(3), 135-142. https://doi .org/10.1007/s002030000188.

Meziane, H., Van Der Sluis, I., van Loon, L. C., Höfte, M. and Bakker, P. A. H. M. 2005. Determinants of Pseudomonas putida WCS358 involved in inducing systemic 
resistance in plants. Mol. Plant Pathol. 6(2), 177-185. https://doi.org/10.1111/j.1364 $-3703.2005 .00276 . x$.

Michavila, G., Adler, C., De Gregorio, P. R., Lami, M. J., Caram Di Santo, M. C., Zenoff, A. M., de Cristobal, R. E. and Vincent, P. A. 2017. Pseudomonas protegens CS1 from the lemon phyllosphere as a candidate for citrus canker biocontrol agent. Plant Biol. (Stuttg) 19(4), 608-617. https://doi.org/10.1111/plb.12556.

Michelsen, C. F., Jensen, H., Venditto, V. J., Hennessy, R. C. and Stougaard, P. 2015a. Bioactivities by a crude extract from the Greenlandic Pseudomonas sp. In 5 involves the nonribosomal peptides, nunamycin and nunapeptin. PeerJ 3, e1476. https://doi .org/10.7717/peerj.1476.

Michelsen, C. F., Watrous, J., Glaring, M. A., Kersten, R., Koyama, N. and Dorrestein, P. C. 2015b. Nonribosomal peptides, key biocontrol components for Pseudomonas fluorescens In5, isolated from a Greenlandic suppressive soil. mBio 6, e00079-15. https://doi.org/10.1128/mBio.00079-15.Editor.

Michelsen, C. F. and Stougaard, P. 2011. A novel antifungal Pseudomonas fluorescens isolated from potato soils in Greenland. Curr. Microbiol. 62(4), 1185-1192. https:// doi.org/10.1007/s00284-010-9846-4.

Mishra, J. and Arora, N. K. 2018. Secondary metabolites of fluorescent pseudomonads in biocontrol of phytopathogens for sustainable agriculture. Appl. Soil Ecol. 125, 35-45. https://doi.org/10.1016/j.apsoil.2017.12.004.

Molina, L. Á., Ramos, C., Duque, E., Ronchel, M. C., García, J. M., Wyke, L. and Ramos, J. L. 2000. Survival of Pseudomonas putida KT2440 in soil and in the rhizosphere of plants under greenhouse and environmental conditions. Soil Biol. Biochem. 32(3), 315-321. https://doi.org/10.1016/S0038-0717(99)00156-X.

Molloy, D. P., Mayer, D. A., Giamberini, L. and Gaylo, M. J. 2013. Mode of action of Pseudomonas fluorescens strain CL145A, a lethal control agent of dreissenid mussels (Bivalvia: Dreissenidae). J. Invertebr. Pathol. 113(1), 115-121. https://doi.org /10.1016/j.jip.2012.12.013.

Moradali, M. F., Ghods, S. and Rehm, B. H. A. 2017. Pseudomonas aeruginosa lifestyle: a paradigm for adaptation, survival, and persistence. Front. Cell. Infect. Microbiol. 7, 39. https://doi.org/10.3389/fcimb.2017.00039.

Morris, C. E., Monteil, C. L. and Berge, O. 2013. The life history of Pseudomonas syringae: linking agriculture to earth system processes. Annu. Rev. Phytopathol. 51, 85-104. https://doi.org/10.1146/annurev-phyto-082712-102402.

Moruzzi, S., Firrao, G., Polano, C., Borselli, S., Loschi, A., Ermacora, P., Loi, N. and Martini, M. 2017. Genomic-assisted characterisation of Pseudomonas sp. strain Pf4, a potential biocontrol agent in hydroponics. Biocontrol Sci. Technol. 27(8), 969-991. https://doi .org/10.1080/09583157.2017.1368454.

Mossialos, D., Meyer, J. M., Budzikiewicz, H., Wolff, U., Koedam, N., Baysse, C., Anjaiah, V. and Cornelis, P. 2000. Quinolobactin, a new siderophore of Pseudomonas fluorescens ATCC 17400, the production of which is repressed by the cognate pyoverdine. Appl. Environ. Microbiol. 66(2), 487-492. https://doi.org/10.1128/AEM .66.2.487-492.2000.

Moszczynska, E., Pytlarz-Kozicka, M. and Grzeszczuk, J. 2015. The impact of applying biological treatment on the infection of potato tubers by the fungus Rhizoctonia solani and the bacterium Streptomyces scabiei. J. Res. Appl. Agric. Eng. 60(4), 46-50. 
Mulet, M., Lalucat, J. and García-Valdés, E. 2010. DNA sequence-based analysis of the Pseudomonas species. Environ. Microbiol. 12(6), 1513-1530. https://doi.org/10.1 111/j.1462-2920.2010.02181.x.

Müller, T. and Behrendt, U. 2021. Exploiting the biocontrol potential of plant-associated pseudomonads - a step towards pesticide-free agriculture? Biol. Control 155, 104538. https://doi.org/10.1016/j.biocontrol.2021.104538.

Muzio, F. M., Agaras, B. C., Masi, M., Tuzi, A., Evidente, A. and Valverde, C. 2020. 7-hydroxytropolone is the main metabolite responsible for the fungal antagonism of Pseudomonas donghuensis strain SVBP6. Environ. Microbiol. 22(7), 2550-2563. https://doi.org/10.1111/1462-2920.14925.

Naseby, D. C., Way, J. A., Bainton, N. J. and Lynch, J. M. 2001. Biocontrol of Pythium in the pea rhizosphere by antifungal metabolite producing and non-producing Pseudomonas strains. J. Appl. Microbiol. 90, 421-429.

Nazir, R., Mazurier, S., Yang, P., Lemanceau, P. and van Elsas, J. D. 2017. The ecological role of type three secretion systems in the interaction of bacteria with fungi in soil and related habitats is diverse and context-dependent. Front. Microbiol. 8, 38. https:// doi.org/10.3389/fmicb.2017.00038.

Nelson, K. E., Weinel, C., Paulsen, I. T., Dodson, R. J., Hilbert, H., Martins Dos Santos, V. A. P., Fouts, D. E., Gill, S. R., Pop, M., Holmes, M., Brinkac, L., Beanan, M., DeBoy, R. T., Daugherty, S., Kolonay, J., Madupu, R., Nelson, W., White, O., Peterson, J., Khouri, H., Hance, I., Lee, P. C., Holtzapple, E., Scanlan, D., Tran, K., Moazzez, A., Utterback, T., Rizzo, M., Lee, K., Kosack, D., Moestl, D., Wedler, H., Lauber, J., Stjepandic, D., Hoheisel, J., Straetz, M., Heim, S., Kiewitz, C., Eisen, J. A., Timmis, K. N., Düsterhöft, A., Tümmler, B. and Fraser, C. M. 2002. Complete genome sequence and comparative analysis of the metabolically versatile Pseudomonas putida KT2440. Environ. Microbiol. 4(12), 799-808.

Nesemann, K., Braus-stromeyer, S. A., Thuermer, A., Daniel, R., Mavrodi, D. V. Thomashow, L. S., Weller, D. M. and Braus, H. 2015. Draft genome sequence of the phenazineproducing Pseudomonas fluorescens strain 2-79. Genome Announc. 3, 5-6. https:// doi.org/10.1128/genomeA.00130-15.Copyright.

Ngumbi, E. and Kloepper, J. 2016. Bacterial-mediated drought tolerance : current and future prospects. Appl. Soil Ecol. 105, 109-125. https://doi.org/10.1016/j.apsoil.20 16.04.009.

Nguyen, D. D., Melnik, A. V., Koyama, N., Lu, X., Schorn, M., Fang, J., Aguinaldo, K., Lincecum, T. L., Ghequire, M. G. K., Carrion, V. J., Cheng, T. L., Duggan, B. M., Malone, J. G., Mauchline, T. H., Sanchez, L. M., Kilpatrick, A. M., Raaijmakers, J. M., De Mot, R., Moore, B. S., Medema, M. H. and Dorrestein, P. C. 2016. Indexing the pseudomonas specialized metabolome enabled the discovery of poaeamide $B$ and the bananamides. Nat. Microbiol. 2, 16197. https://doi.org/10.1038/nmicrobiol.2 016.197.

Northover, J. and Zhou, T. 2002. Control of rhizopus rot of peaches with postharvest treatments of tebuconazole, fludioxonil, and Pseudomonas syringae. Can. J. Plant Pathol. 24(2), 144-153. https://doi.org/10.1080/07060660309506989.

Nowak-Thompson, B., Hammer, P. E., Hill, D. S., Stafford, J., Torkewitz, N., Gaffney, T. D., Lam, S. T. and Ligon, J. M. 2003. 2, 5-Dialkylresorcinol biosynthesis in Pseudomonas aurantiaca : novel head-to-head condensation of two fatty acid-derived precursors. J. Bacteriol. 185, 860-869. https://doi.org/10.1128/JB.185.3.860. 
Nyfeler, R. and Ackermann, P. 1992. Phenylpyrroles, a new class of agricultural fungicides related to the natural antibiotic pyrrolnitrin III. ACS Symposium Series. American Chemical Society, 395-404. https://doi.org/10.1021/bk-1992-0504.ch036.

Ogura, K., Shimada, K. and Miyoshi-Akiyama, T. 2019. A multilocus sequence typing scheme of Pseudomonas putida for clinical and environmental isolates. Sci. Rep. 9(1), 13980. https://doi.org/10.1038/s41598-019-50299-6.

Olorunleke, F. E., Hua, G. K. H., Kieu, N. P., Ma, Z. and Höfte, M. 2015a. Interplay between orfamides, sessilins and phenazines in the control of Rhizoctonia diseases by Pseudomonas sp. CMR12a. Environ. Microbiol. Rep. 7(5), 774-781. https://doi.org /10.1111/1758-2229.12310.

Olorunleke, F. E., Kieu, N. P., Höfte, M., Kieu Phuong, N. and Höfte, M. 2015b. Recent advances in Pseudomonas biocontrol. In: Murillo, J., Vinatzer, B. A., Jackson, R. W. and Arnold, D. L. (Eds), Bacteria-Plant Interactions: Advanced Research and Future Trends. Caister Academic Press, UK, pp. 167-198. https://doi.org/10.21775/97819 08230584.07.

Omoboye, O. O. 2019. Cyclic lipopeptide diversity and biocontrol versatility of Pseudomonas species associated with the cocoyam rhizospere. PhD thesis. Ghent University, Belgium.

Omoboye, O. O., Geudens, N., Duban, M., Chevalier, M., Flahaut, C., Martins, J. C., Leclère, V., Oni, F. E. and Höfte, M. 2019a. Pseudomonas sp. COW3 produces new bananamide-type cyclic lipopeptides with antimicrobial activity against Pythium myriotylum and Pyricularia oryzae. Molecules 24(22), 4170. https://doi.org/10.3390 /molecules24224170.

Omoboye, O. O., Oni, F. E., Batool, H., Yimer, H. Z., De Mot, R. and Höfte, M. 2019b. Pseudomonas cyclic lipopeptides suppress the rice blast fungus Magnaporthe oryzae by induced resistance and direct antagonism. Front. Plant Sci. 10, 901. https:// doi.org/10.3389/fpls.2019.00901.

Oni, F. E., Geudens, N., Adiobo, A., Omoboye, O. O., Enow, E. A., Onyeka, J. T., Salami, A. E., De Mot, R., Martins, J. C. and Höfte, M. 2020a. Biosynthesis and antimicrobial activity of pseudodesmin and viscosinamide cyclic lipopeptides produced by pseudomonads associated with the cocoyam rhizosphere. Microorganisms 8(7), 1-26. https://doi.org/10.3390/microorganisms8071079.

Oni, F. E., Geudens, N., Onyeka, J. T., Olorunleke, O. F., Salami, A. E., Omoboye, O. O., Arias, A. A., Adiobo, A., De Neve, S., Ongena, M., Martins, J. C. and Höfte, M. 2020 b. Cyclic lipopeptide-producing Pseudomonas koreensis group strains dominate the cocoyam rhizosphere of a Pythium root rot suppressive soil contrasting with $P$. putida prominence in conducive soils. Environ. Microbiol. 22(12), 5137-5155. https://doi .org/10.1111/1462-2920.15127.

Oni, F. E., Geudens, N., Omoboye, O. O., Bertier, L., Hua, H. G. K., Adiobo, A., Sinnaeve, D., Martins, J. C. and Höfte, M. 2019a. Fluorescent Pseudomonas and cyclic lipopeptide diversity in the rhizosphere of cocoyam (Xanthosoma sagittifolium). Environ. Microbiol. 21(3), 1019-1034. https://doi.org/10.1111/1462-2920.14520.

Oni, F. E., Olorunleke, O. F. and Höfte, M. 2019b. Phenazines and cyclic lipopeptides produced by Pseudomonas sp. CMR12a are involved in the biological control of Pythium myriotylum on cocoyam (Xanthosoma sagittifolium). Biol. Control 129, 109114. https://doi.org/10.1016/j.biocontrol.2018.10.005.

Parejko, J. A., Mavrodi, D. V., Mavrodi, O. V., Weller, D. M. and Thomashow, L. S. 2013. Taxonomy and distribution of phenazine-producing Pseudomonas spp. in the 
dryland agroecosystem of the Inland Pacific Northwest, United States. Appl. Environ. Microbiol. 79(12), 3887-3891. https://doi.org/10.1128/AEM.03945-12.

Park, J. Y., Yang, S. Y., Kim, Y. C., Kim, J. C., Dang, Q. L. Le, Kim, J. J. and Kim, I. S. 2012. Antiviral peptide from Pseudomonas chlororaphis $\mathrm{O} 6$ against tobacco mosaic virus (TMV). J. Korean Soc. Appl. Biol. Chem. 55(1), 89-94. https://doi.org/10.1007/s 13765-012-0015-2.

Partida-Martinez, L. P. and Hertweck, C. 2007. A gene cluster encoding rhizoxin biosynthesis in Burkholderia rhizoxina, the bacterial endosymbiont of the fungus Rhizopus microsporus. ChemBioChem. Chembiochem 8(1), 41-45. https://doi.org /10.1002/cbic.200600393.

Paterson, J., Jahanshah, G., Li, Y., Wang, Q., Mehnaz, S. and Gross, H. 2017. The contribution of genome mining strategies to the understanding of active principles of PGPR strains. FEMS Microbiol. Ecol. 93(3), 1-12. https://doi.org/10.1093/femsec/fiw249.

Paul, N. C., Ji, S. H., Deng, J. X. and Yu, S. H. 2013. Assemblages of endophytic bacteria in chili pepper (Capsicum annuum L.) and their antifungal activity against phytopathogens in vitro. Plant Omi. J. 41, 441-448.

Paulin, M. M., Novinscak, A., Lanteigne, C., Gadkar, V. J. and Filion, M. 2017. Interaction between 2,4-diacetylphloroglucinol- and hydrogen cyanide-producing Pseudomonas brassicacearum LBUM300 and Clavibacter michiganensis subsp. michiganensis in the tomato rhizosphere. Appl. Environ. Microbiol. 83(13), 1-13. https://doi.org/10.1128/ AEM.00073-17.

Paulsen, I. T., Press, C. M., Ravel, J., Kobayashi, D. Y., Myers, G. S. A., Mavrodi, D. V., DeBoy, R. T., Seshadri, R., Ren, Q., Madupu, R., Dodson, R. J., Durkin, A. S., Brinkac, L. M., Daugherty, S. C., Sullivan, S. A., Rosovitz, M. J., Gwinn, M. L., Zhou, L., Schneider, D. J., Cartinhour, S. W., Nelson, W. C., Weidman, J., Watkins, K., Tran, K., Khouri, H., Pierson, E. A., Pierson, L. S., Thomashow, L. S. and Loper, J. E. 2005. Complete genome sequence of the plant commensal Pseudomonas fluorescens Pf-5. Nat. Biotechnol. 23(7), 873-878. https://doi.org/10.1038/nbt1110.

Péchy-Tarr, M., Bruck, D. J., Maurhofer, M., Fischer, E., Vogne, C., Henkels, M. D., Donahue, K. M., Grunder, J., Loper, J. E. and Keel, C. 2008. Molecular analysis of a novel gene cluster encoding an insect toxin in plant-associated strains of Pseudomonas fluorescens. Environ. Microbiol. 10(9), 2368-2386. https://doi.org/10.1111/j.1462 -2920.2008.01662.x.

Peix, A., Ramírez-Bahena, M. H. and Velázquez, E. 2018. The current status on the taxonomy ofPseudomonas revisited: an update. Infect. Genet. Evol. 57, 106-116. https://doi .org/10.1016/j.meegid.2017.10.026.

Peix, A., Ramírez-Bahena, M. H. and Velázquez, E. 2009. Historical evolution and current status of the taxonomy of genus Pseudomonas. Infect. Genet. Evol. 9(6), 1132-1147. https://doi.org/10.1016/j.meegid.2009.08.001.

Peix, A., Valverde, A., Rivas, R., Igual, J. M., Ramírez-Bahena, M. H., Mateos, P. F., SantaRegina, I., Rodríguez-Barrueco, C., Martínez-Molina, E. and Velázquez, E. 2007. Reclassification of Pseudomonas aurantiaca as a synonym of Pseudomonas chlororaphis and proposal of three subspecies, P. chlororaphis subsp. chlororaphis subsp. nov. P. chlororaphis subsp. aureofaciens subsp. nov. Int. J. Syst. Evol. Microbiol. 57(6), 1286-1290. https://doi.org/10.1099/ijs.0.64621-0.

Pérez-Jaramillo, J. E., Mendes, R. and Raaijmakers, J. M. 2016. Impact of plant domestication on rhizosphere microbiome assembly and functions. Plant Mol. Biol. 90(6), 635-644. https://doi.org/10.1007/s11103-015-0337-7. 
Perneel, M., D'Hondt, L., De Maeyer, K., Adiobo, A., Rabaey, K. and Höfte, M. 2008. Phenazines and biosurfactants interact in the biological control of soil-borne diseases caused by Pythium spp. Environ. Microbiol. 10(3), 778-788. https://doi.org /10.1111/j.1462-2920.2007.01501.x.

Perneel, M., Heyrman, J., Adiobo, A., De Maeyer, K., Raaijmakers, J. M., De Vos, P. and Höfte, M. 2007. Characterization of CMR5c and CMR12a, novel fluorescent Pseudomonas strains from the cocoyam rhizosphere with biocontrol activity. J. Appl. Microbiol. 103(4), 1007-1020. https://doi.org/10.1111/j.1365-2672.2007.03345.x.

Pfender, W. F., Kraus, J. and Loper, J. E. 1993. A genomic region from Pseudomonas fluorescens $\mathrm{Pf}-5$ required for pyrrolnitrin production and inhibition of Pyrenophora tritici-repentis in wheat straw. Phytopathology 83(11). https://doi.org/10.1094/Phyto -83-1223.

Phillips, D. A., Fox, T. C., King, M. D., Bhuvaneswari, T. V. and Teuber, L. R. 2004. Microbial products trigger amino acid exudation from plant roots. Plant Physiol. 136(1), 28872894. https://doi.org/10.1104/pp.104.044222.

Philmus, B., Shaffer, B. T., Kidarsa, T. A., Yan, Q., Raaijmakers, J. M., Begley, T. P. and Loper, J. E. 2015. Investigations into the biosynthesis, regulation, and self-resistance of toxoflavin in Pseudomonas protegens Pf-5. Chembiochem 16(12), 1782-1790. https://doi.org/10.1002/cbic.201500247.

Pierson, L. S. and Thomashow, L. S. 1992. Cloning and heterologous expression of the phenazine biosynthetic locus from Pseudomonas aureofaciens 30-84. Mol. Plant Microbe Interact. 5(4), 330-339 https://doi.org/10.1094/mpmi-5-330.

Pieterse, C. M. J., Zamioudis, C., Berendsen, R. L., Weller, D. M., Van Wees, S. C. M. and Bakker, P. A. H. M. 2014. Induced systemic resistance by beneficial microbes. Annu. Rev. Phytopathol. 52, 347-375. https://doi.org/10.1146/annurev-phyto-082712102340.

Polano, C., Martini, M., Savian, F., Moruzzi, S., Ermacora, P. and Firrao, G. 2019. Genome sequence and antifungal activity of two niche-sharing pseudomonas protegens related strains isolated from hydroponics. Microb. Ecol. 77(4), 1025-1035. https://do i.org/10.1007/s00248-018-1238-5.

Powell, J. F., Vargas, J. M., Nair, M. G., Detweiler, A. R. and Chandra, A. 2000. Management of dollar spot on creeping bentgrass with metabolites of Pseudomonas aureofaciens (TX-1). Plant Dis. 84(1), 19-24. https://doi.org/10.1094/PDIS.2000.8 4.1.19.

Preston, G., Spiers, A., Jackson, R., Gal, M., Gehrig, S., Malone, J., Moon, C., Godfrey, S., Bertrand, N., Field, D. and Rainey, P. 2003. Pseudomonas in the underworld: the secret life of Pseudomonas fluorescens SBW25. In: lacobellis, N. S., Collmer, A., Hutcheson, S., Mansfield, J., Morris, C. E., Murillo, J., Schaad, N., Stead, D., Surico, G. and Ulrich, M. (Eds), Pseudomonas Syringae and Related Pathogens. Biology and Genetics. Kluwer Academic Publishers, pp. 347-353. Amsterdam, the Netherlands.

Preston, G. M., Bertrand, N. and Rainey, P. B. 2001. Type III secretion in plant growthpromoting pseudomonas fluorescens SBW25. Mol. Microbiol. 41(5), 999-1014. https ://doi.org/10.1046/j.1365-2958.2001.02560.x.

Price-Whelan, A., Dietrich, L. E. P. and Newman, D. K. 2006. Rethinking "secondary" metabolism: physiological roles for phenazine antibiotics. Nat. Chem. Biol. 2(2), 71-78. https://doi.org/10.1038/nchembio764.

Pukatzki, S., Kessin, R. H. and Mekalanos, J. J. 2002. The human pathogen Pseudomonas aeruginosa utilizes conserved virulence pathways to infect the social amoeba 
Dictyostelium discoideum. Proc. Natl. Acad. Sci. U. S. A. 99(5), 3159-3164. https://doi .org/10.1073/pnas.052704399.

Raaijmakers, J. M., de Bruijn, I., Nybroe, O. and Ongena, M. 2010. Natural functions of lipopeptides from Bacillus and Pseudomonas: more than surfactants and antibiotics. FEMS Microbiol. Rev. 34(6), 1037-1062. https://doi.org/10.1111/j.1574-6976.2010 $.00221 . x$.

Raaijmakers, J. M. and Mazzola, M. 2012. Diversity and natural functions of antibiotics produced by beneficial and plant pathogenic bacteria. Annu. Rev. Phytopathol. 50, 403-424. https://doi.org/10.1146/annurev-phyto-081211-172908.

Raaijmakers, J. M., Vlami, M. and de Souza, J. T. 2002. Antibiotic production by bacterial biocontrol agents. Antonie Leeuwenhoek Int. J. Gen. Mol. Microbiol. 81(1-4), 537547. https://doi.org/10.1023/A:1020501420831.

Rajkumar, M., Bruno, L. B., Banu, J. R., Bruno, L. B. and Banu, J. R. 2017. Alleviation of environmental stress in plants: the role of beneficial Pseudomonas spp. Crit. Rev. Environ. Sci. Technol. 47, 372-407. https://doi.org/10.1080/10643389.2017.13 18619.

Ramette, A., Frapolli, M., Saux, M. F. Le, Gruffaz, C., Meyer, J. M., Défago, G., Sutra, L. and Moënne-Loccoz, Y. 2011. Pseudomonas protegens sp. nov., widespread plantprotecting bacteria producing the biocontrol compounds 2,4-diacetylphloroglucinol and pyoluteorin. Syst. Appl. Microbiol. 34(3), 180-188. https://doi.org/10.1016/j .syapm.2010.10.005.

Rangel, L. I., Henkels, M. D., Shaffer, B. T., Walker, F. L., Davis, E. W., Stockwell, V. O., Bruck, D., Taylor, B. J. and Loper, J. E. 2016. Characterization of toxin complex gene clusters and insect toxicity of bacteria representing four subgroups of Pseudomonas fluorescens. PLoS ONE 11(8), e0161120. https://doi.org/10.1371/journal.pone.016 1120.

Reddy, G. S. N., Matsumoto, G. I., Schumann, P., Stackerbrandt, E. and Shivaji, S. 2004. Psychrophilic pseudomonads from Antarctica: Pseudomonas antartica sp. nov., Pseudomonas meridiana sp. nov. and Pseudomonas proteolytica sp. nov. Int. J. Syst. Evol. Microbiol. 54(3), 713-719. https://doi.org/10.1099/ijs.0.02827-0.

Redondo-Nieto, M., Barret, M., Morrisey, J. P., Germaine, K., Martínez-Granero, F., Barahona, E., Navazo, A., Sánchez-Contreras, M., Moynihan, J. A., Giddens, S. R., Coppoolse, E. R., Muriel, C., Stiekema, W. J., Rainey, P. B., Dowling, D., O'Gara, F., Martín, M. and Rivilla, R. 2012. Genome sequence of the biocontrol strain Pseudomonas fluorescens F113. J. Bacteriol. 194(5), 1273-1274. https://doi.org/10.1128/JB.06601-11.

Redondo-Nieto, M., Barret, M., Morrissey, J., Germaine, K., Martínez-Granero, F., Barahona, E., Navazo, A., Sánchez-Contreras, M., Moynihan, J. A., Muriel, C., Dowling, D., O'Gara, F., Martín, M. and Rivilla, R. 2013. Genome sequence reveals that Pseudomonas fluorescens F113 possesses a large and diverse array of systems for rhizosphere function and host interaction. BMC Genomics 14, 54. https://doi.org /10.1186/1471-2164-14-54.

Rezzonico, F., Binder, C., Défago, G. and Moënne-loccoz, Y. 2005. The Type III secretion system of biocontrol Pseudomonas fluorescens KD targets the phytopathogenic Chromista Pythium ultimum and promotes cucumber protection. Mol. Plant Microbe Interact. 18(9), 991-1001. https://doi.org/10.1094/MPMI-18-0991 -, pp. 18-0991.

Rodriguez, F. and Pfender, W. F. 1997. Antibiosis and antagonism of Sclerotinia homoeocarpa and Drechslera poae by Pseudomonas fluorescens Pf-5 in vitro and 
in planta. Phytopathology 87(6), 614-621. https://doi.org/10.1094/PHYTO.1997.87 .6 .614 .

Rokni-Zadeh, H., Li, W., Yilma, E., Sanchez-Rodriguez, A. and De Mot, R. 2013. Distinct lipopeptide production systems for WLIP (white line-inducing principle) in Pseudomonas fluorescens and Pseudomonas putida. Environ. Microbiol. Rep. 5(1), 160-169. https://doi.org/10.1111/1758-2229.12015.

Ruffner, B., Péchy-Tarr, M., Höfte, M., Bloemberg, G., Grunder, J., Keel, C. and Maurhofer, M. 2015. Evolutionary patchwork of an insecticidal toxin shared between plant-associated pseudomonads and the insect pathogens Photorhabdus and Xenorhabdus. BMC Genomics 16, 609. https://doi.org/10.1186/s12864-015-1763-2.

Ruffner, B., Péchy-Tarr, M., Ryffel, F., Hoegger, P., Obrist, C., Rindlisbacher, A., Keel, C. and Maurhofer, M. 2012. Oral insecticidal activity of plant-associated pseudomonads. Environ. Microbiol. 15(3), 751-763. https://doi.org/10.1111/j.1462-2920.2012.0288 4.x.

Savchuk, S. and Fernando, W. G. D. 2004. Effect of timing of application and population dynamics on the degree of biological control of Sclerotinia sclerotiorum by bacterial antagonists. FEMS Microbiol. Ecol. 49(3), 379-388. https://doi.org/10.1016/j.femsec .2004.04.014.

Sazinas, P., Hansen, M. L., Aune, M. I., Fischer, M. H. and Jelsbak, L. 2019. A rare thioquinolobactin siderophore present in a bioactive Pseudomonas sp. DTU12.1. Genome Biol. Evol. 11(12), 3529-3533. https://doi.org/10.1093/gbe/evz267.

Schalk, I. J., Rigouin, C. and Godet, J. 2020. An overview of siderophore biosynthesis among fluorescent pseudomonads and new insights into their complex cellular organization. Environ. Microbiol. 22(4), 1447-1466. https://doi.org/10.1111/1462-2920.14937.

Scheepmaker, J. W. A., Busschers, M., Sundh, I., Eilenberg, J. and Butt, T. M. 2019. Sense and nonsense of the secondary metabolites data requirements in the EU for beneficial microbial control agents. Biol. Control 136. https://doi.org/10.1016/j.bioc ontrol.2019.104005, 104005.

Schreiter, S., Babin, D., Smalla, K. and Grosch, R. 2018. Rhizosphere competence and biocontrol effect of Pseudomonas sp. RU47 independent from plant species and soil type at the field scale. Front. Microbiol. 9, 97. https://doi.org/10.3389/fmicb.2018 .00097.

Seaton, S. C., Silby, M. W. and Levy, S. B. 2013. Pleiotropic effects of GacA on Pseudomonas fluorescens Pf0-1 in vitro and in soil. Appl. Environ. Microbiol. 79(17), 5405-5410. https://doi.org/10.1128/AEM.00819-13.

Shanahan, P., O'Sullivan, D. J., Simpson, P., Glennon, J. D. and O'Gara, F. 1992. Isolation of 2,4-diacetylphloroglucinol from a fluorescent pseudomonad and investigation of physiological parameters influencing its production. Appl. Environ. Microbiol. 58(1), 353-358. https://doi.org/10.1128/AEM.58.1.353-358.1992.

Sharifi-Tehrani, A., Zala, M., Natsch, A., Moënne-Loccoz, Y. and Défago, G. 1998. Biocontrol of soil-borne fungal plant diseases by 2,4-diacetylphloroglucinol-producing fluorescent pseudomonads with different restriction profiles of amplified $16 \mathrm{~S}$ rDNA. Eur. J. Plant Pathol. 104(7), 631-643. https://doi.org/10.1023/A:1008672104562.

Siddiqui, I. A. and Shaukat, S. S. 2003. Suppression of root-knot disease by Pseudomonas fluorescens CHAO in tomato: importance of bacterial secondary metabolite, 2,4-diacetylpholoroglucinol. Soil Biol. Biochem. 35(12), 1615-1623. https://doi.org /10.1016/j.soilbio.2003.08.006. 
Siddiqui, I. A., Shaukat, S. S., Sheikh, I. H. and Khan, A. 2006. Role of cyanide production by Pseudomonas fluorescens $\mathrm{CHAO}$ in the suppression of root-knot nematode, Meloidogyne javanica in tomato. World J. Microbiol. Biotechnol. 22(6), 641-650. https://doi.org/10.1007/s11274-005-9084-2.

Sigler, W. V., Nakatsu, C. H., Reicher, Z. J. and Turco, R. F. 2001. Fate of the biological control agent Pseudomonas aureofaciens TX-1 after application to turfgrass. Appl. Environ. Microbiol. 67(8), 3542-3548. https://doi.org/10.1128/AEM.67.8.3542-3548 2001.

Sikorski, J., Stackebrandt, E. and Wackernagel, W. 2001. Pseudomonas kilonensis sp. nov., a bacterium isolated from agricultural soil. Int. J. Syst. Evol. Microbiol. 51(4), 15491555. https://doi.org/10.1099/00207713-51-4-1549.

Smilanick, J. L., Gouin-Behe, C. C., Margosan, E. A., Bull, C. T. and Mackey, B. E. 1996. Virulence on citrus of Pseudomonas syringae strains that control postharvest green mould of citrus fruit. Plant Dis. 80(10), 1123-1128.

Smits, T. H. M., Rezzonico, F., Frasson, D., Vesga, P., Vacheron, J., Blom, J., Pothier, J. F., Keel, C., Maurhofer, M. and Sievers, M. 2019. Updated genome sequence and annotation for the full genome of Pseudomonas protegens CHA0. Microbiol. Resour. Announc. 8(39), e01002-19. https://doi.org/10.1128/MRA.01002-19.

Snopková, K., Čejková, D., Dufková, K., Sedláček, I. and Šmajs, D. 2020. Genome sequences of two Antarctic strains of Pseudomonas prosekii: insights into adaptation to extreme conditions. Arch. Microbiol. 202, 447-454. https://doi.org/10.1007/s 00203-019-01755-4.

Sonnleitner, E., Abdou, L. and Haas, D. 2009. Small RNA as global regulator of carbon catabolite repression in Pseudomonas aeruginosa. Proc. Natl. Acad. Sci. U. S. A. 106(51), 21866-21871. https://doi.org/10.1073/pnas.pnas.0910308106.

Sonnleitner, E. and Haas, D. 2011. Small RNAs as regulators of primary and secondary metabolism in Pseudomonas species. Appl. Microbiol. Biotechnol. 91(1), 63-79. https://doi.org/10.1007/s00253-011-3332-1.

South, K. A., Peduto Hand, F. and Jones, M. L. 2020. Beneficial bacteria identified for the control of Botrytis cinerea in Petunia greenhouse production. Plant Dis. 104(6), 1801-1810. https://doi.org/10.1094/PDIS-10-19-2276-RE.

Stanier, R. Y., Palleroni, N. J. and Doudoroff, M. 1966. The aerobic pseudomonads: a taxonomic study. J. Gen. Microbiol. 43(2), 159-271. https://doi.org/10.1099/002212 87-43-2-159.

Stockwell, V. O., Johnson, K. B., Sugar, D. and Loper, J. E. 2010. Control of fire blight by Pseudomonas fluorescens A506 and Pantoea vagans C9-1 applied as single strains and mixed inocula. Phytopathology 100(12), 1330-1339. https://doi.org/10.1094/ PHYTO-03-10-0097.

Stockwell, V. O. and Stack, J. P. 2007. Using Pseudomonas spp. for integrated biological control. Phytopathology 97(2), 244-249. https://doi.org/10.1094/PHYTO-97-2-0244.

Strano, C. P., Bella, P., Licciardello, G., Caruso, A. and Catara, V. 2017. Role of secondary metabolites in the biocontrol activity of Pseudomonas corrugata and Pseudomonas mediterranea. Eur. J. Plant Pathol. 149(1), 103-115. https://doi.org/10.1007/s10658 -017-1169-x.

Strano, C. P., Bella, P., Licciardello, G., Fiore, A., Lo Piero, A. R., Fogliano, V., Venturi, V. and Catara, V. 2015. Pseudomonas corrugata crpCDE is part of the cyclic lipopeptide corpeptin biosynthetic gene cluster and is involved in bacterial virulence in tomato 
and in hypersensitive response in Nicotiana benthamiana. Mol. Plant Pathol. 16(5), 495-506. https://doi.org/10.1111/mpp.12207.

Stringlis, I. A., Zamioudis, C., Berendsen, R. L., Bakker, P. A. H. M. and Pieterse, C. M. J. 2019. Type III secretion system of beneficial rhizobacteria Pseudomonas simiae WCS417 and Pseudomonas defensor WCS374. Front. Microbiol. 10, 1631. https:// doi.org/10.3389/fmicb.2019.01631.

Stringlis, I. A., Zhang, H., Pieterse, C. M. J., Bolton, M. D. and De Jonge, R. 2018. Microbial small molecules-weapons of plant subversion. Nat. Prod. Rep. 35(5), 410-433. https://doi.org/10.1039/c7np00062f.

Stutz, E. W., Défago, G. and Kern, H. 1986. Naturally occurring fluorescent pseudomonads involved in suppression of black root rot of tobacco. Phytopathology 76(2). https:// doi.org/10.1094/Phyto-76-181.

Tabassum, B., Khan, A., Tariq, M., Ramzan, M., Iqbal Khan, M. S., Shahid, N. and Aaliya, K. 2017. Bottlenecks in commercialisation and future prospects of PGPR. Appl. Soil Ecol. 121, 102-117. https://doi.org/10.1016/j.apsoil.2017.09.030.

Takeuchi, K., Kiefer, P., Reimmann, C., Keel, C., Dubuis, C., Rolli, J., Vorholt, J. A. and Haas, D. 2009. Small RNA-dependent expression of secondary metabolism is controlled by Krebs cycle function in Pseudomonas fluorescens. J. Biol. Chem. 284(50), 3497634985. https://doi.org/10.1074/jbc.M109.052571.

Takeuchi, K., Noda, N., Katayose, Y., Mukai, Y., Numa, H., Yamada, K. and Someya, N. 2015. Rhizoxin analogs contribute to the biocontrol activity of a newly isolated Pseudomonas strain. Mol. Plant Microbe Interact. 28(3), 333-342. https://doi.org/10 .1094/MPMI-09-14-0294-FI.

Takeuchi, K., Noda, N. and Someya, N. 2014. Complete genome sequence of the biocontrol strain Pseudomonas protegens Cab57 discovered in Japan reveals strainspecific diversity of this species. PLoS ONE 9(4), e93683. https://doi.org/10.1371/j ournal.pone.0093683.

Takeuchi, K. and Someya, N. 2019. An overview of recent genomic research on biocontrol pseudomonad strains isolated from the field in Japan. Jpn. Agric. Res. Q. 53(2), 8791. https://doi.org/10.6090/jarq.53.87.

Thomashow, L. S. 2013. Phenazines in the environment: microbes, habitats, and ecological relevance. In: Chincholkar, S. and Thomashow, L. (Eds), Microbial Phenazines. Springer, Berlin, Heidelberg, pp. 199-216. https://doi.org/10.1007/978-3-642-4 0573-0_10.

Thomashow, L. S. and Weller, D. M. 1996. Current concepts in the use of introduced bacteria for biological disease control: mechanisms and antifungal metabolites. In: Stacey, G. and Keen, N. T. (Eds), Plant-Microbe Interactions (vol. 1). Chapman \& Hall, New York, pp. 187-236.

Thrane, C., Harder Nielsen, T., Neiendam Nielsen, M., Sørensen, J. and Olsson, S. 2000. Viscosinamide-producing Pseudomonas fluorescens DR54 exerts a biocontrol effect on Pythium ultimum in sugar beet rhizosphere. FEMS Microbiol. Ecol. 33(2), 139146. https://doi.org/10.1111/j.1574-6941.2000.tb00736.x.

Timmis, K. N. 2002. Pseudomonas putida: a cosmopolitan. Environ. Microbiol. 4(12), 779-781.

Tran, H., Ficke, A., Asiimwe, T., Höfte, M. and Raaijmakers, J. M. 2007. Role of the cyclic lipopeptide massetolide a in biological control of Phytophthora infestans and in colonization of tomato plants by Pseudomonas fluorescens. New Phytol. 175(4), 731-742. https://doi.org/10.1111/j.1469-8137.2007.02138.x. 
Tran, P. N., Savka, M. A. and Gan, H. M. 2017. In-silico taxonomic classification of 373 genomes reveals species misidentification and new genospecies within the genus Pseudomonas. Front. Microbiol. 8, 1296. https://doi.org/10.3389/fmicb.2017 .01296 .

Trippe, K., McPhail, K., Armstrong, D., Azevedo, M. and Banowetz, G. 2013. Pseudomonas fluorescens SBW25 produces furanomycin, a non-proteinogenic amino acid with selective antimicrobial properties. BMC Microbiol. 13, 111. https://doi.org/10.1186 /1471-2180-13-111.

Tziros, G. T., Lagopodi, A. L. and Tzavella-Klonari, K. 2007. Reduction of Fusarium wilt in watermelon by Pseudomonas chlororaphis PCL1391 and P. fluorescens WCS365. Phytopathol. Mediterr. 46, 320-323. https://doi.org/10.14601/Phytopathol_Medite rr-2245.

Vacheron, J., Moënne-Loccoz, Y., Dubost, A., Gonçalves-Martins, M., Muller, D. and Prigent-Combaret, C. 2016. Fluorescent Pseudomonas strains with only few plantbeneficial properties are favored in the maize rhizosphere. Front. Plant Sci. 7, 1212. https://doi.org/10.3389/fpls.2016.01212.

Vacheron, J., Péchy-Tarr, M., Brochet, S., Heiman, C. M., Stojiljkovic, M., Maurhofer, M. and Keel, C. 2019. T6SS contributes to gut microbiome invasion and killing of an herbivorous pest insect by plant-beneficial Pseudomonas protegens. ISME J. 13(5), 1318-1329. https://doi.org/10.1038/s41396-019-0353-8.

Vallet-Gely, I., Novikov, A., Augusto, L., Liehl, P., Bolbach, G., Péchy-Tarr, M., Cosson, P., Keel, C., Caroff, M. and Lemaitre, B. 2010. Association of hemolytic activity of Pseudomonas entomophila, a versatile soil bacterium, with cyclic lipopeptide production. Appl. Environ. Microbiol. 76(3), 910-921. https://doi.org/10.1128/AEM.02112-09.

Van Der Voort, M., Meijer, H. J. G., Schmidt, Y., Watrous, J., Dekkers, E., Mendes, R., Dorrestein, P. C., Gross, H. and Raaijmakers, J. M. 2015. Genome mining and metabolic profiling of the rhizosphere bacterium Pseudomonas sp. SH-C52 for antimicrobial compounds. Front. Microbiol. 6, 693. https://doi.org/10.3389/fmicb .2015 .00693 .

Van Wees, S. C. M., Pieterse, C. M. J., Trijssenaar, A., Van't Westende, Y. A. M., Hartog, F. and Van Loon, L. C. 1997. Differential induction of systemic resistance in Arabidopsis by biocontrol bacteria. Mol. Plant Microbe Interact. 10(6), 716-724. https://doi.org /10.1094/MPMI.1997.10.6.716.

Verhille, S., Baida, N., Dabboussi, F., Izard, D. and Leclerc, H. 1999. Taxonomic study of bacteria isolated from natural mineral waters: proposal of Pseudomonas jessenii sp. nov. and Pseudomonas mandelii sp. nov. Syst. Appl. Microbiol. 22(1), 45-58. https:// doi.org/10.1016/S0723-2020(99)80027-7.

Vincent, M. N., Harrison, L. A., Brackin, J. M., Kovacevich, P. A., Mukerji, P., Weller, D. M. and Pierson, E. A. 1991. Genetic analysis of the antifungal activity of a soilborne Pseudomonas aureofaciens strain. Appl. Environ. Microbiol. 57, 2928-2934.

Voisard, C., Bull, C. T., Keel, C., Laville, J., Maurhofer, M., Schnider, U., Défago, G. and Haas, D. 1994. Biocontrol of root diseases by Pseudomonas fluorescens CHAO: current concepts and eperimental approaches. In: O'Gara, F., Dowling, D. N. and Boesten, B. (Eds), Molecular Ecology of Rhizosphere Microorganisms: Biotechnology and the Release of GMOs, pp. 67-89. https://doi.org/10.1002/9783527615810.ch6.

Voisard, C., Keel, C., Haas, D. and Dèfago, G. 1989. Cyanide production by Pseudomonas fluorescens helps suppress black root rot of tobacco under gnotobiotic conditions. EMBO J. 8(2), 351-358. https://doi.org/10.1002/j.1460-2075.1989.tb03384.x. 
Volke, D. C., Calero, P. and Nikel, P. I. 2020. Pseudomonas putida. Trends Microbiol. 28, 512-513. https://doi.org/10.1016/j.tim.2020.02.015.

Völksch, B. and May, R. 2001. Biological control of Pseudomonas syringae pv. glycinea by epiphytic bacteria under field conditions. Microb. Ecol. 41(2), 132-139. https://doi .org/10.1007/s002480000078.

Völksch, B., Nüske, J. and May, R. 1996. Characterization of two epiphytic bacteria from soybean leaves with antagonistic activities against Pseudomonas syringae pv. glycinea. J. Basic Microbiol. 36(6), 453-462. https://doi.org/10.1002/jobm .3620360611 .

Wagner, A., Norris, S., Chatterjee, P., Morris, P. F. and Wildschutte, H. 2018. Aquatic pseudomonads inhibit oomycete plant pathogens of Glycine max. Front. Microbiol. 9, 1007. https://doi.org/10.3389/fmicb.2018.01007.

Wang, M. Q., Wang, Z., Yu, L. N., Zhang, C. S., Bi, J. and Sun, J. 2019. Pseudomonas qingdaonensis sp. nov., an aflatoxin-degrading bacterium, isolated from peanut rhizospheric soil. Arch. Microbiol. 201(5), 673-678. https://doi.org/10.1007/s00203 -019-01636-w.

Weller, D. M. 2007. Pseudomonas biocontrol agents of soilborne pathogens: looking back over 30 years. Phytopathology 97(2), 250-256. https://doi.org/10.1094/PHYTO -97-2-0250.

Weller, D. M., Landa, B. B., Mavrodi, O. V., Schroeder, K. L., De La Fuente, L., Blouin Bankhead, S., Allende Molar, R., Bonsall, R. F., Mavrodi, D. V. and Thomashow, L. S. 2007. Role of 2,4-diacetylphloroglucinol-producing fluorescent Pseudomonas spp. in the defense of plant roots. Plant Biol. (Stuttg) 9(1), 4-20. https://doi.org/10.1055 /s-2006-924473.

Weller, D. M., Mavrodi, D. V., van Pelt, J. A., Pieterse, C. M. J., van Loon, L. C. and Bakker, P. A. H. M. 2012. Induced systemic resistance in Arabidopsis thaliana against Pseudomonas syringae pv. tomato by 2,4-diacetylphloroglucinol-producing Pseudomonas fluorescens. Phytopathology 102(4), 403-412. https://doi.org/10 .1094/PHYTO-08-11-0222.

Wensing, A., Braun, S. D., Buettner, P., Expert, D., Voelksch, B., Ullrich, M. S. and Weingart, H. 2010. Impact of siderophore production by Pseudomonas syringae pv. syringae 22d/93 on epiphytic fitness and biocontrol activity against Pseudomonas syringae pv. glycinea 1a/96. Appl. Environ. Microbiol. 76(9), 2704-2711. https://doi.org/10 .1128/AEM.02979-09.

Wu, D. Q., Ye, J., Ou, H. Y., Wei, X., Huang, X., He, Y. W. and Xu, Y. 2011. Genomic analysis and temperature-dependent transcriptome profiles of the rhizosphere originating strain Pseudomonas aeruginosa M18. BMC Genom. 12, 1-17. https://doi.org/10 .1186/1471-2164-12-438.

Xu, G.-W. and Gross, D. C. 1986. Selection of fluorescent pseudomonads antagonistic to Erwinia carotovora and suppressive of potato seed piece decay. Phytopathology 76(4), 414-422. https://doi.org/10.1094/Phyto-76-414.

$\mathrm{Xu}, \mathrm{Y}$. and Liu, H. 2013. The expression and regulation of two $\mathrm{pHz}$ gene clusters in PGPR strain of Pseudomonas aeruginosa. In: 3rd Asian Conference on Plant GrowthPromoting Rhizobacteria (PGPR) and Other Microbials. Manila, Philippines (vol. M18), pp. 54-55.

Yan, Q., Lopes, L. D., Shaffer, B. T., Kidarsa, T. A., Vining, O., Philmus, B., Song, C., Stockwell, V. O., Raaijmakers, J. M., McPhail, K. L., Andreote, F. D., Chang, J. H. and Loper, J. E. 2018. Secondary metabolism and interspecific competition affect accumulation 
of spontaneous mutants in the GacS-GacA regulatory system in Pseudomonas protegens. mBio 9(1), e01845-17. https://doi.org/10.1128/mBio.01845-17.

Yan, Q., Philmus, B., Chang, J. H. and Loper, J. E. 2017. Novel mechanism of metabolic co-regulation coordinates the biosynthesis of secondary metabolites in Pseudomonas protegens. eLife 6, e22835. https://doi.org/10.7554/eLife.22835.

Yang, X. and Hong, C. 2020. Biological control of Phytophthora blight by Pseudomonas protegens strain 14D5. Eur. J. Plant Pathol. 156(2), 591-601. https://doi.org/10.1007 /s10658-019-01909-6.

Yasmin, S., Hafeez, F. Y., Mirza, M. S., Rasul, M., Arshad, H. M. I., Zubair, M. and Iqbal, M. 2017. Biocontrol of bacterial leaf blight of rice and profiling of secondary metabolites produced by rhizospheric Pseudomonas aeruginosa BRp3. Front. Microbiol. 8, 1895. https://doi.org/10.3389/fmicb.2017.01895.

Yasmin, S., Hafeez, F. Y. and Rasul, G. 2014. Evaluation of Pseudomonas aeruginosa Z5 for biocontrol of cotton seedling disease caused by Fusarium oxysporum. Biocontrol Sci. Technol. 24(11), 1227-1242. https://doi.org/10.1080/09583157.2014.932754.

Yonezuka, K., Shimodaira, J., Tabata, M., Ohji, S., Hosoyama, A., Kasai, D., Yamazoe, A., Fujita, N., Ezaki, T. and Fukuda, M. 2017. Phylogenetic analysis reveals the taxonomically diverse distribution of the Pseudomonas putida group. J. Gen. Appl. Microbiol. 63(1), 1-10. https://doi.org/10.2323/jgam.2016.06.003.

Youard, Z. A., Mislin, G. L. A., Majcherczyk, P. A., Schalk, I. J. and Reimmann, C. 2007. Pseudomonas fluorescens CHAO produces enantio-pyochelin, the optical antipode of the Pseudomonas aeruginosa siderophore pyochelin. J. Biol. Chem. 282(49), 35546-35553. https://doi.org/10.1074/jbc.M707039200.

Yu, K., Pieterse, C. M. J., Bakker, P. A. H. M. and Berendsen, R. L. 2019. Beneficial microbes going underground of root immunity. Plant Cell Environ. 42(10), 2860-2870. https:// doi.org/10.1111/pce.13632.

Zachow, C., Jahanshah, G., De Bruijn, I., Song, C., lanni, F., Pataj, Z., Gerhardt, H., Pianet, I., Lämmerhofer, M., Berg, G., Gross, H. and Raaijmakers, J. M. 2015. The novel lipopeptide poaeamide of the endophyte Pseudomonas poae RE*1-1-14 is involved in pathogen suppression and root colonization. Mol. Plant Microbe Interact. 28(7), 800-810. https://doi.org/10.1094/MPMI-12-14-0406-R.

Zhang, M., Yang, L., Hao, R., Bai, X., Wang, Y. and Yu, X. 2020a. Drought-tolerant plant growth-promoting rhizobacteria isolated from jujube (Ziziphus jujuba) and their potential to enhance drought tolerance. Plant Soil 452(1-2), 423-440. https://doi .org/10.1007/s11104-020-04582-5.

Zhang, Q. X., Kong, X. W., Li, S. Y., Chen, X. J. and Chen, X. J. 2020b. Antibiotics of Pseudomonas protegens FD6 are essential for biocontrol activity. Australas. Plant Pathol. 49, 307-317. https://doi.org/10.1007/s13313-020-00696-7.

Zhou, T., Northover, J. and Schneider, K. E. 1999. Biological control of postharvest diseases of peach with phyllosphere isolates of Pseudomonas syringae. Can. J. Plant Pathol. 21(4), 375-381. https://doi.org/10.1080/07060669909501174. 